\title{
SUPPLEMENTUM PRAEFATIONIS
}

V Aticanus 209 [Brandis Abhandl. d. k. pr. Akad. d. W. z. Berl. 1831 Y

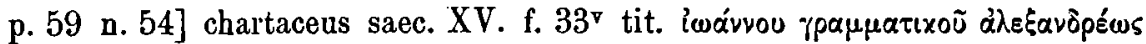

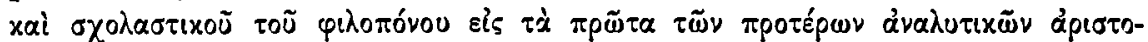

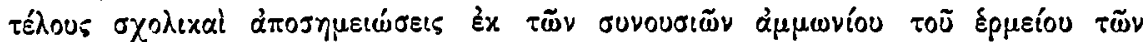

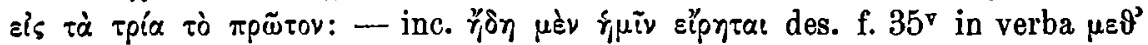

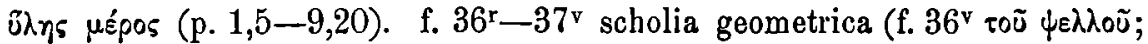

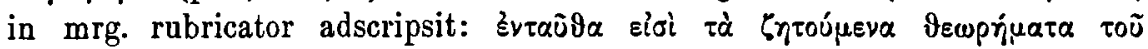

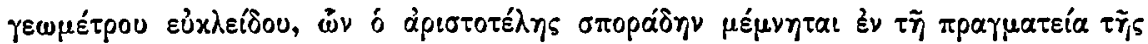

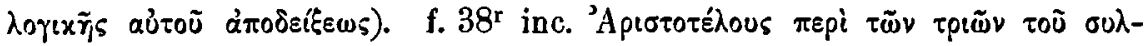

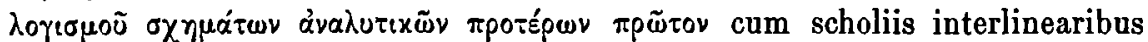
et marginalibus. scholia marginalia, quae numerantur, usque ad f. $47^{\mathrm{r}}$ (post f. 42 duo folia videntur excidisse) Philoponi sunt omnia. f. $47^{\mathrm{v}}-64^{\mathrm{r}}$ Aristotelis verba duplici commentario, Philoponi et Magenteni, ita instructa sunt, ut hoc angustum marginem exteriorem, in f. r. dextrum, in f. v. sinistrum, illud reliquas marginis partes obtineat. f. $65^{\nabla}-67 \mathrm{r}$ Philoponi iterum solius sunt. f. $67^{\circ}$ iuxta huius commentarium in mrg. exteriore Ammonii scholion

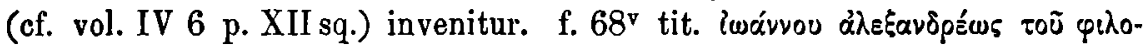

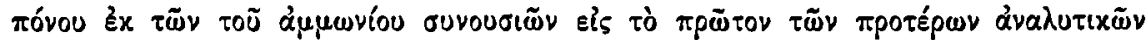

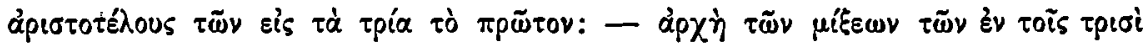

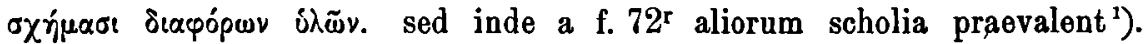

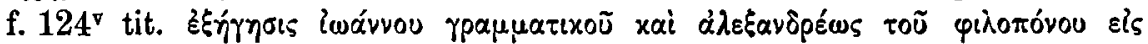

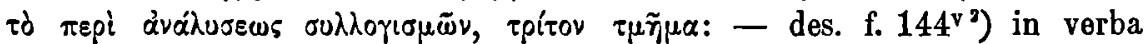

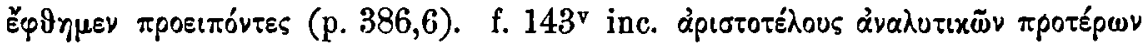

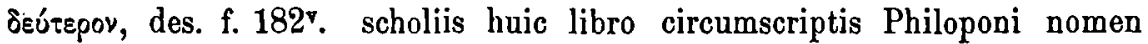
additum est f. $157^{\circ}, 160^{\mathrm{r}}, 170^{\mathrm{r}}, 171^{\mathrm{r}}, 173^{\mathrm{r} \cdot \mathrm{v}}, 182^{\mathrm{r}}$, quorum nullum cum

1) Magenteni f. 72 r. $\nabla 75 \mathrm{v} 78 \mathrm{v} 79 \mathrm{v} 80 \mathrm{r} . \mathrm{v} 81 \mathrm{r} . \mathrm{v} 82 \mathrm{r} 83 \mathrm{v} 85 \mathrm{r} 86 \mathrm{v} \quad 87 \mathrm{r} 88 \mathrm{r} 90 \mathrm{v} 93 \mathrm{v}$ 94r.v 97r 99r 105r. Neophyti 80r 112r.v 113r 114r. Ammonii f. 86r. Alexandri 104v 106 107 r.v 108r 109r 110r 111r.v 113r.v 114r.v 115r 116r 117r 118r.v 119v 120r.v $121 \mathrm{r} 122 \mathrm{r} . \mathrm{v} 123 \mathrm{r}$. v 124r.v. Pselli f. 108r 109r.v 110r 111v 113r 114r 115r $118 \mathrm{r} 119 \mathrm{r} 120 \mathrm{v}$ 122r. $\mathrm{r} 123 \mathrm{v}$.

2) Philoponi commentario in mrg. ext. f. $128 \mathrm{r} 133 \mathrm{v} 143 \mathrm{v}$ Neopbyti, f. $129 \mathrm{r} 134 \mathrm{r}$ 139r Magenteni scholia adiuncta sunt. 
nostro Philopono consentit, quocum unum scholion anonymum f. $174^{\mathrm{r}}$ congruit ${ }^{\prime}$ ). descripsit codicem Guil. Crönert. f. $124^{\mathrm{v}}-144^{\mathrm{v}}$ (p. 315,1 $-386,6$ ) contulit A. Gercke. denuo codicem a me rogatus inspexit scholiaque alterius tmematis et libri secundi cum nostro Philopono congruentia aut nomine eius signata contulit atque exscripsit A. G. Roos. cf. Z.

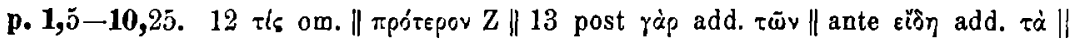

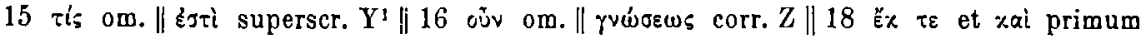

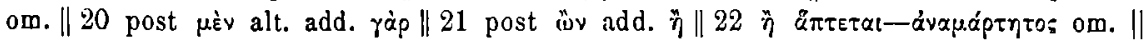

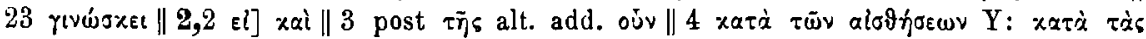

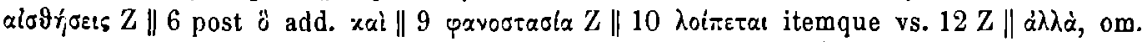

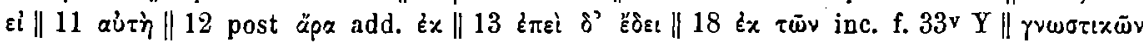

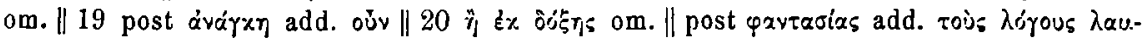

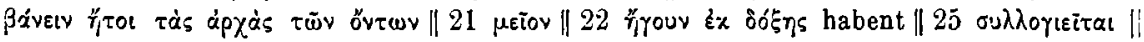

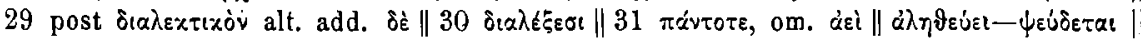

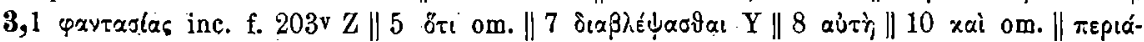

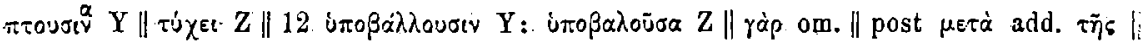

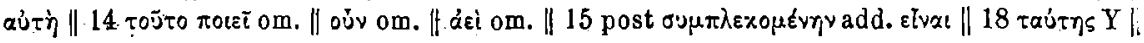

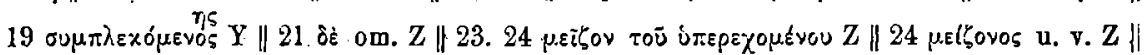

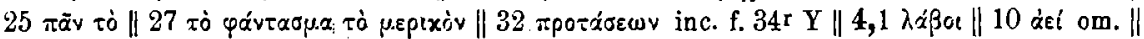

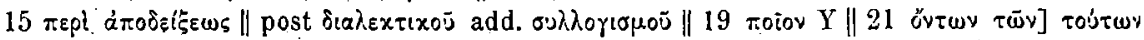

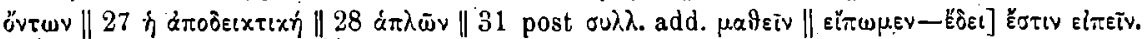

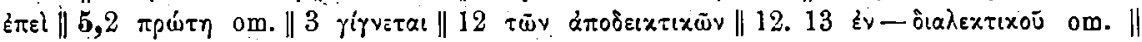

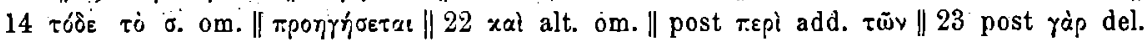

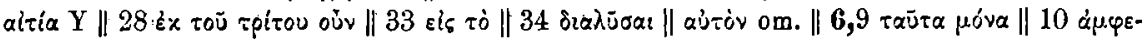

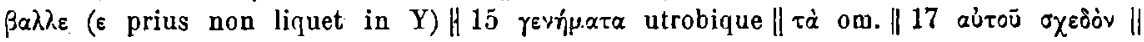

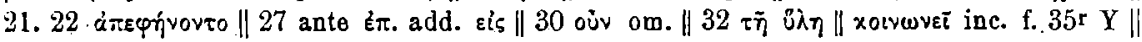

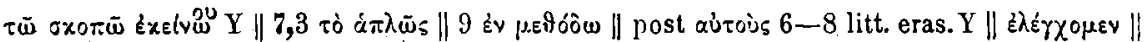

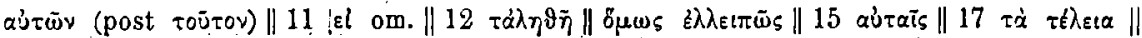

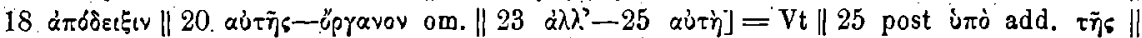

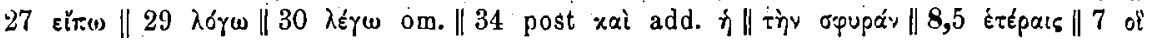

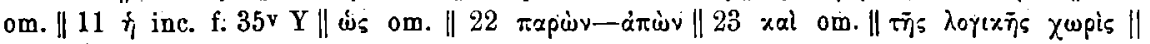

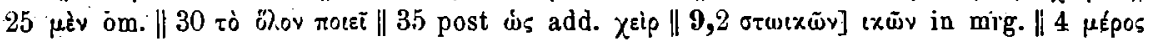

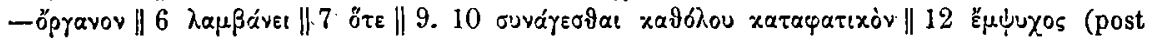

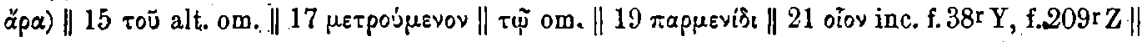

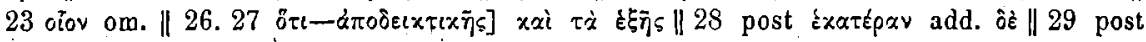

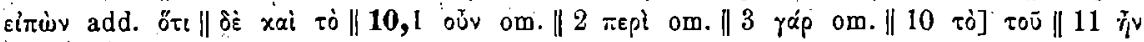

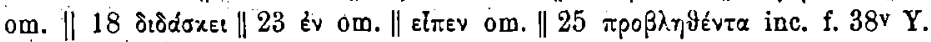

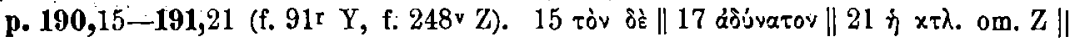

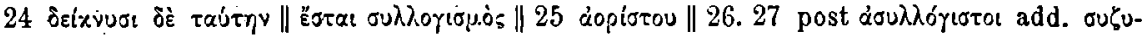

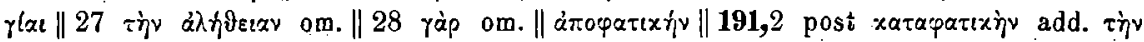

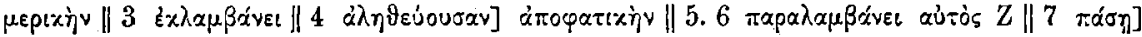

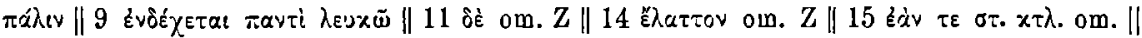

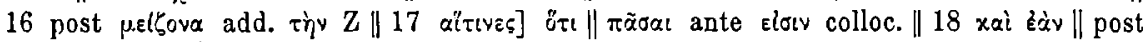

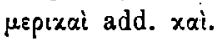

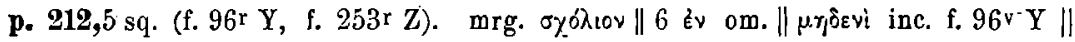

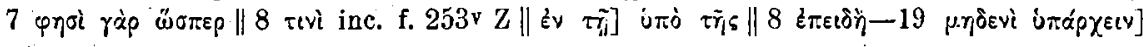

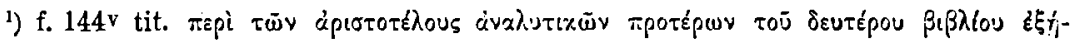

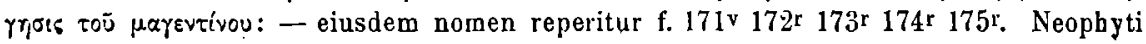
scholia exstant f. $176 \mathrm{v} 177 \mathrm{v} 178 \mathrm{r}$. 


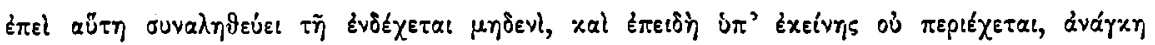

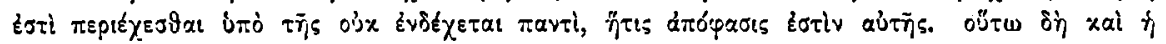

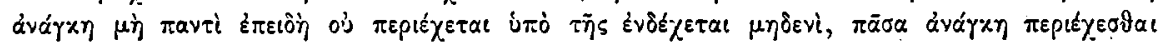

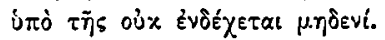

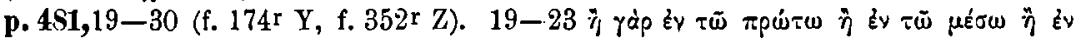

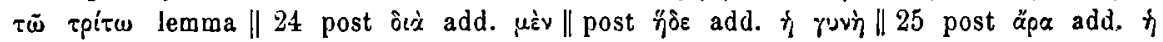

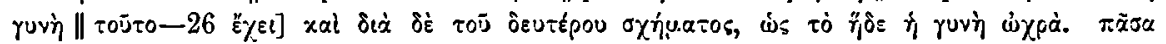

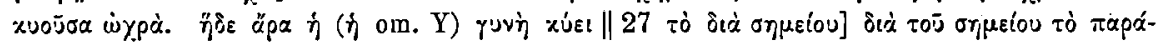

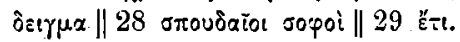

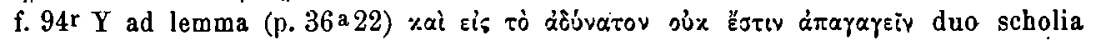

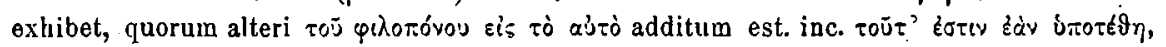

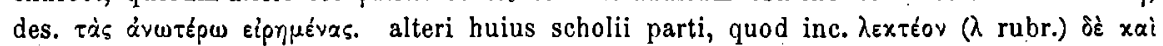

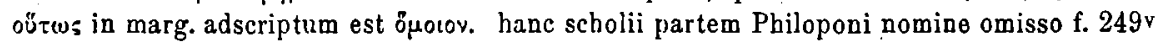
habet $Z$.

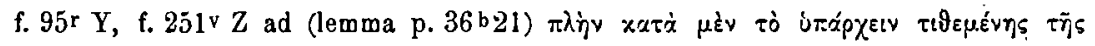

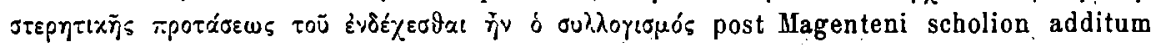

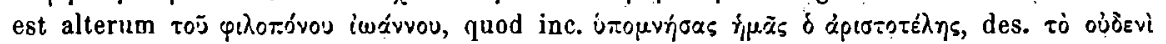

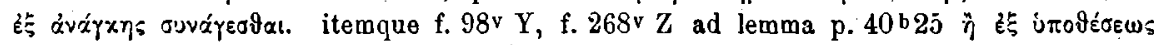

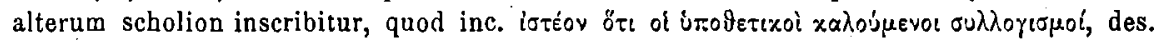

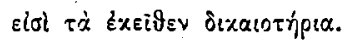

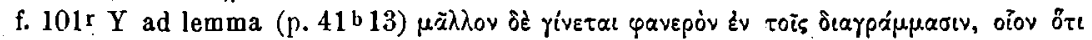

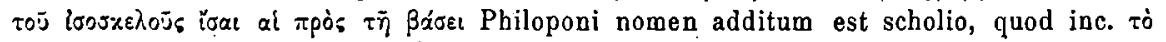

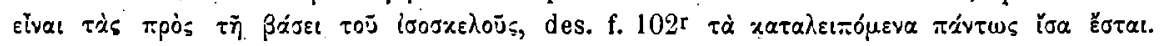

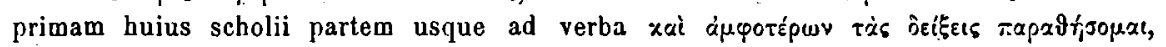

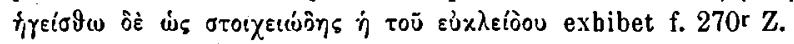

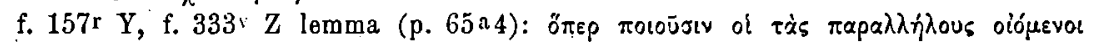

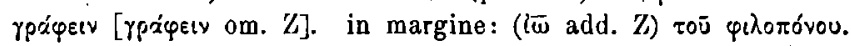

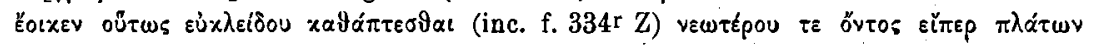

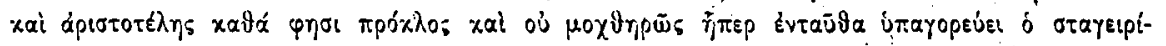

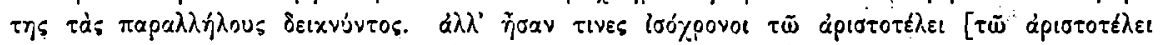

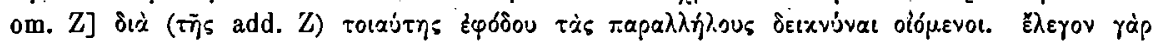

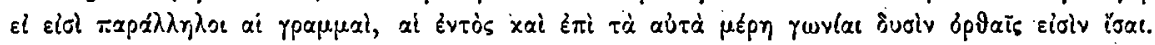

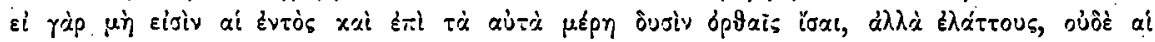

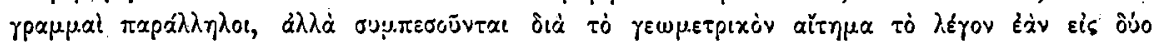

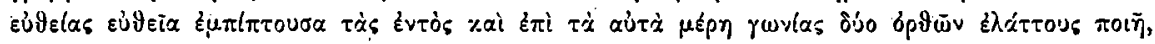

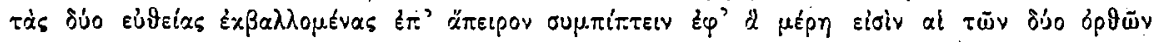

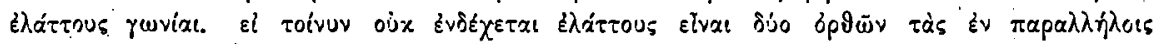

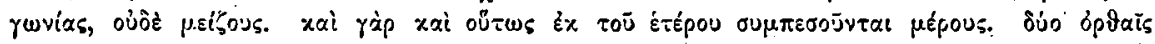

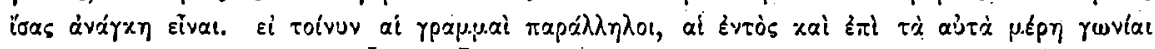

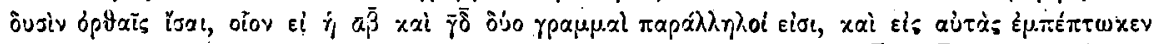

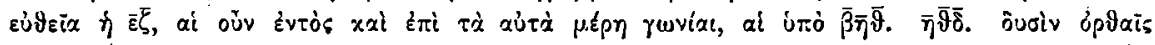

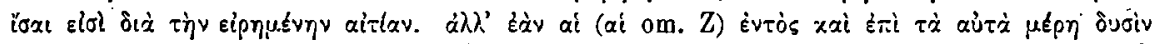

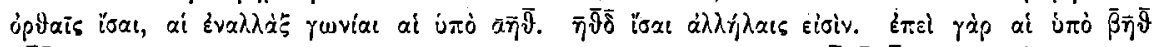

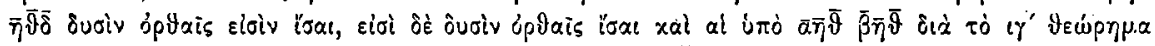

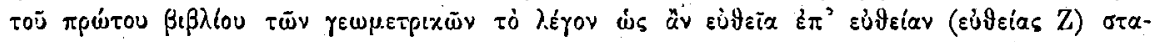

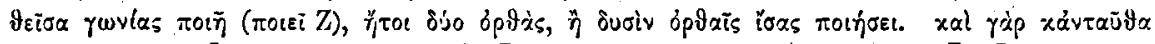

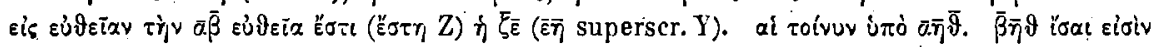

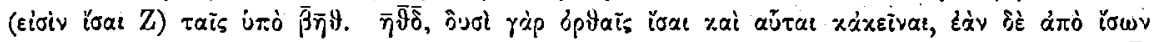

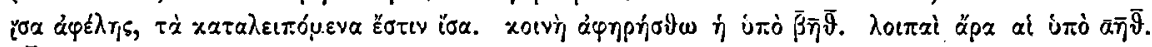

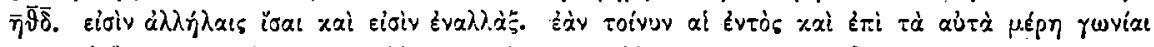

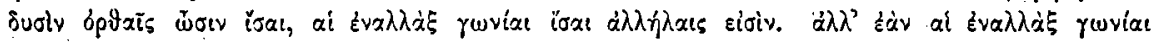




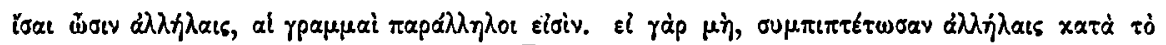

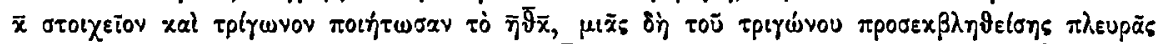

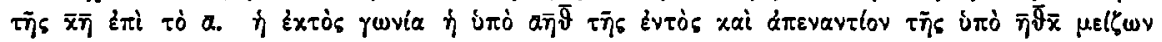

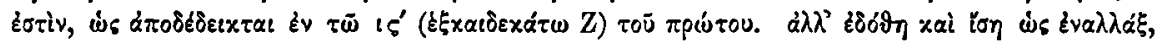

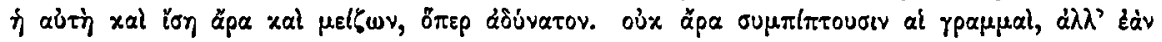

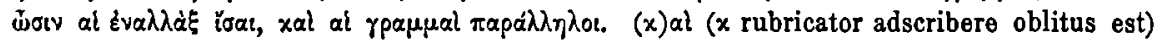

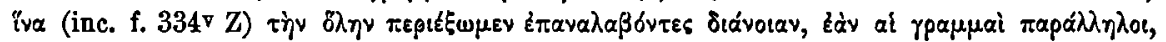

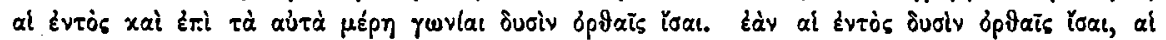

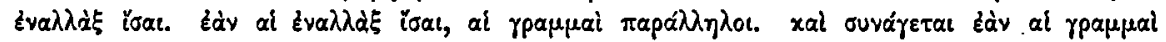

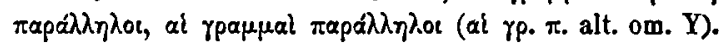

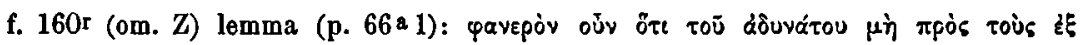

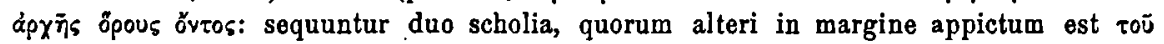

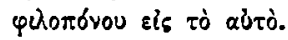

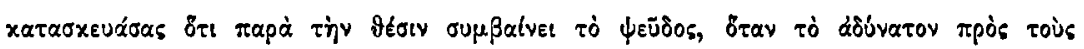

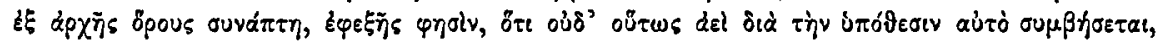

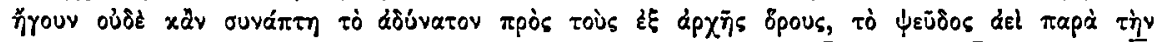

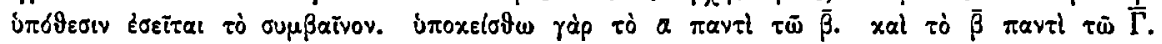

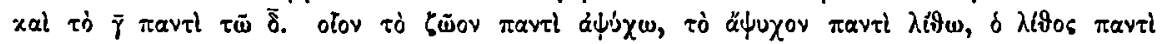

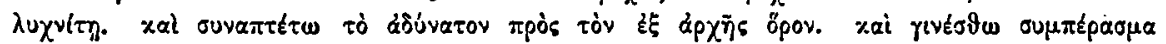

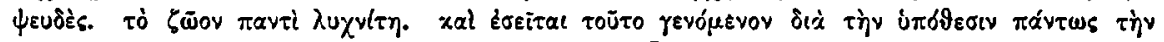

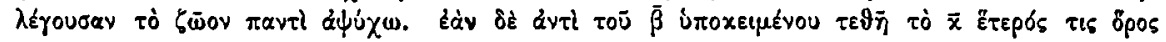

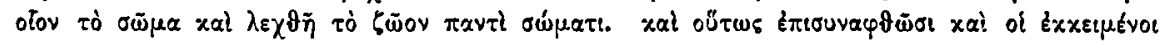

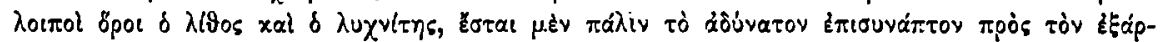

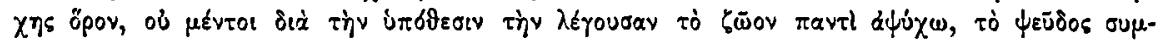

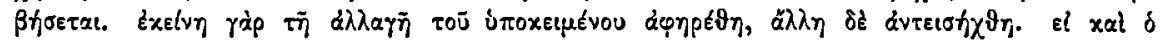

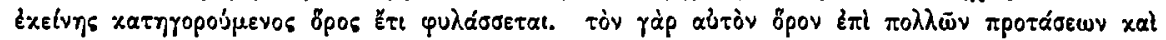

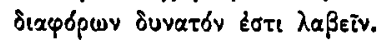

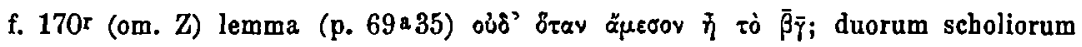

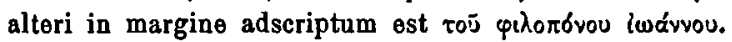

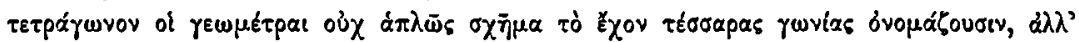

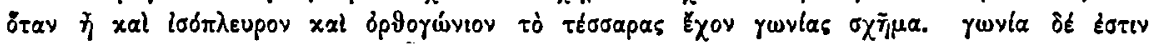

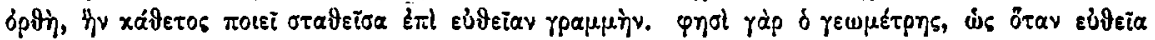

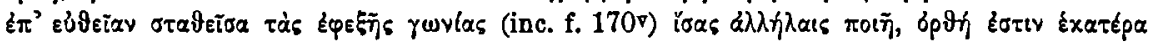

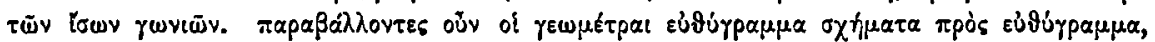

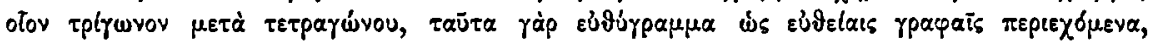

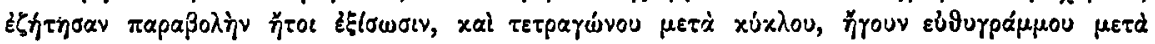

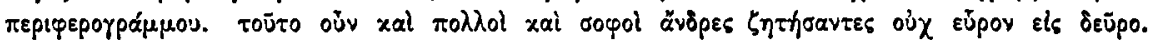

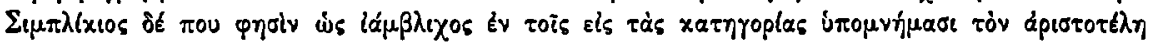

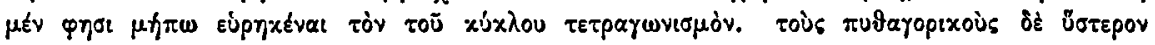

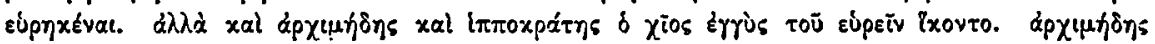

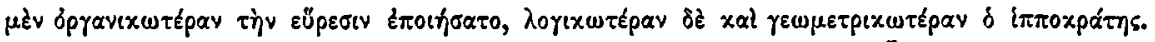

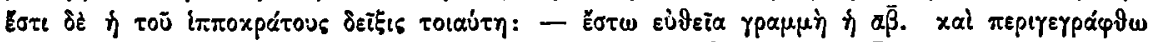

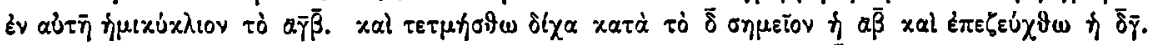

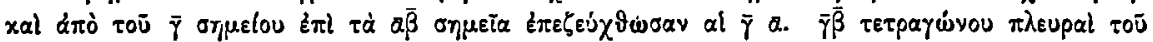

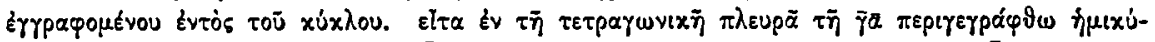

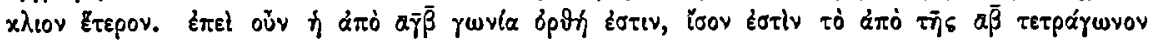

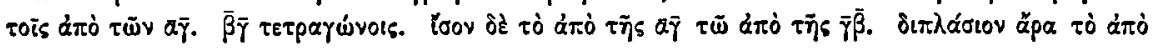

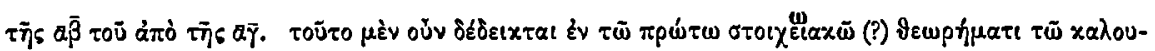

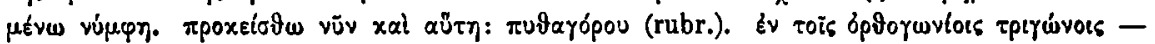

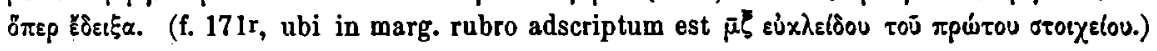




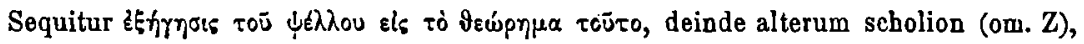

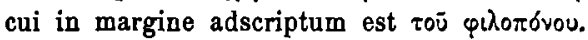

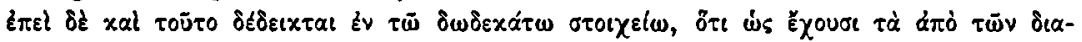

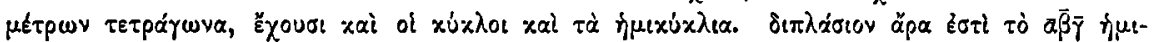

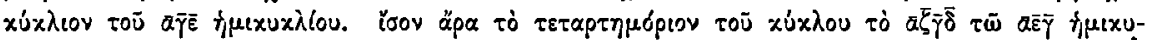

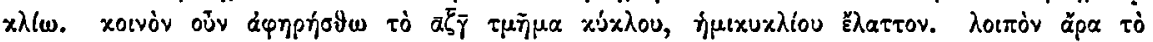

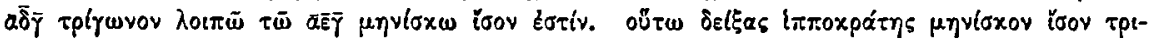

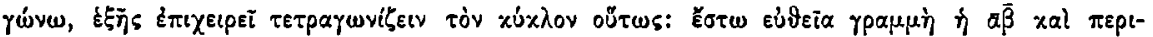

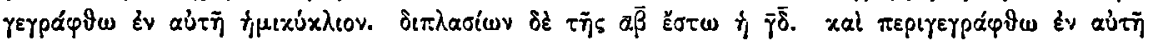

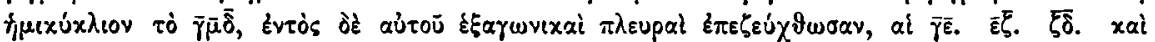

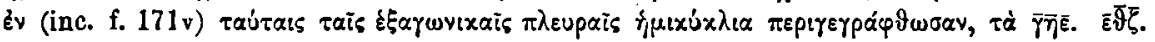

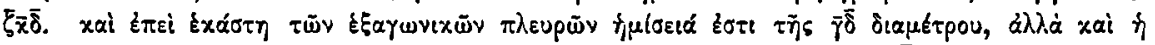

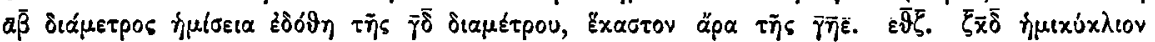

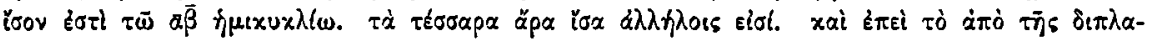

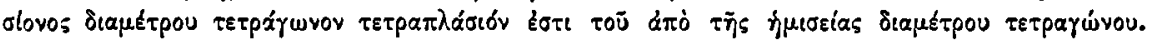

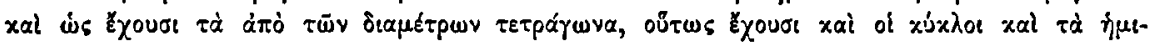

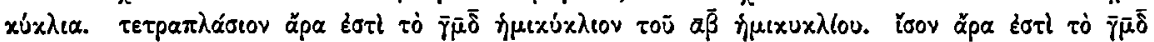

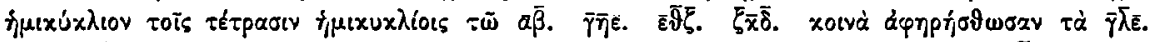

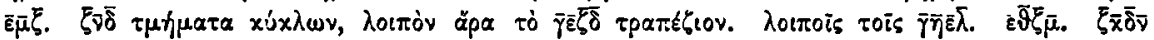

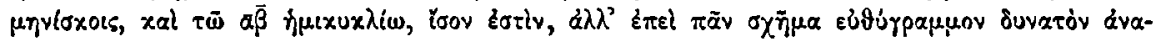

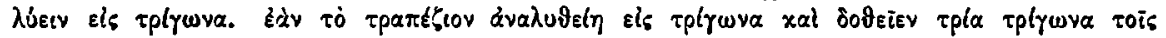

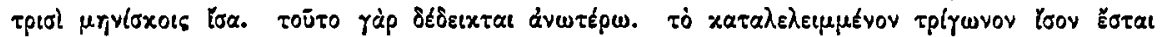

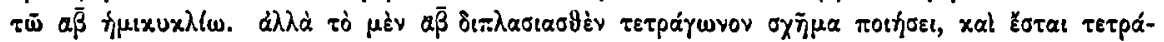

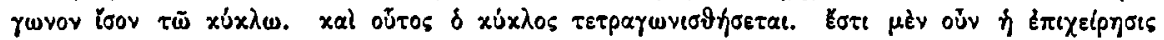

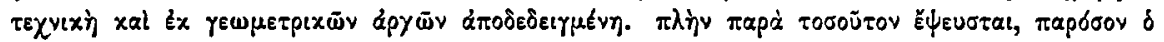

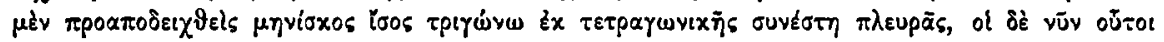

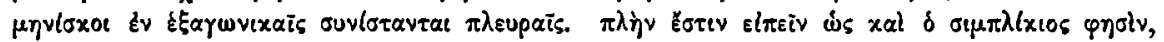

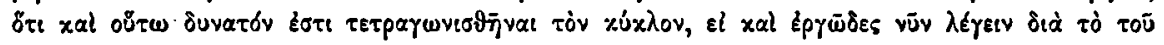

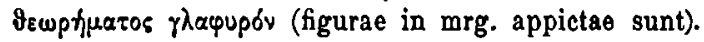

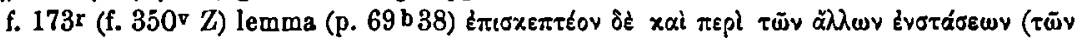

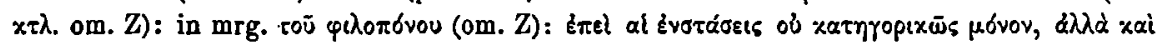

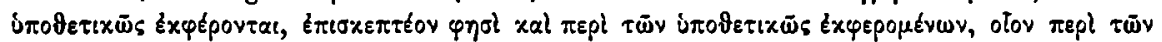

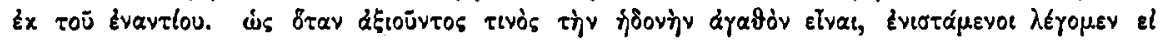

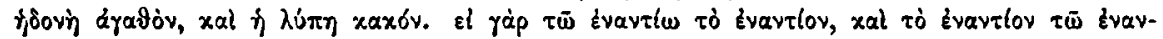

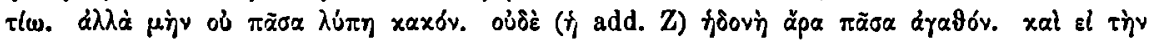

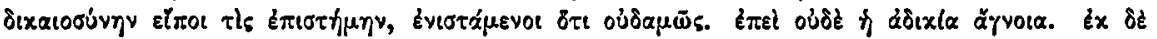

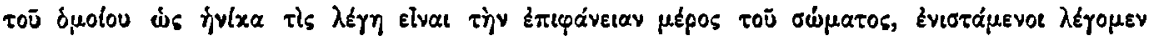

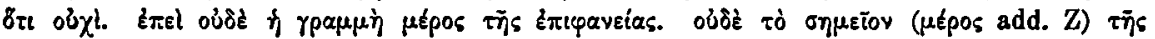

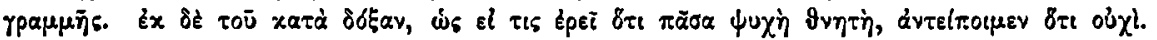

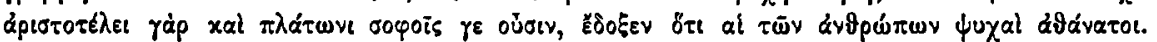

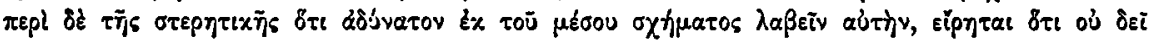

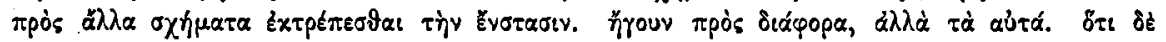

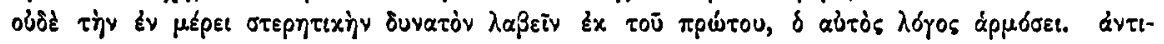

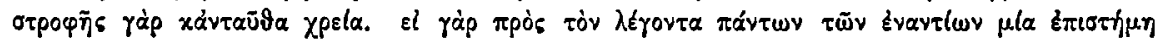

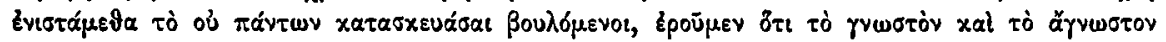

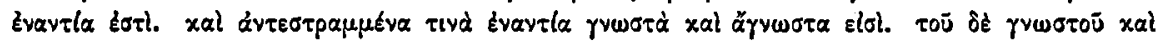

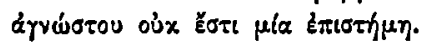

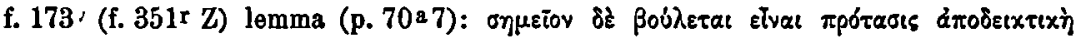

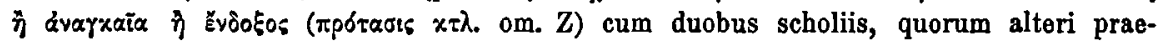

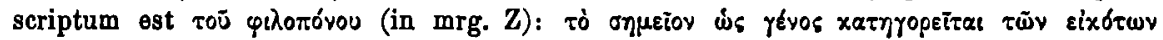

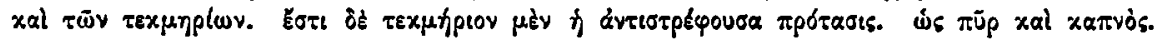




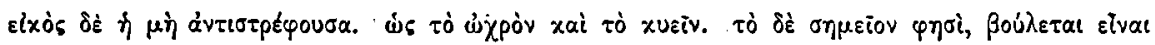

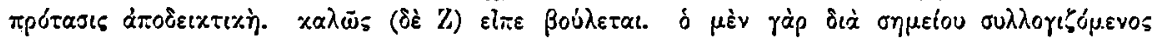

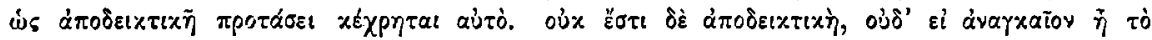

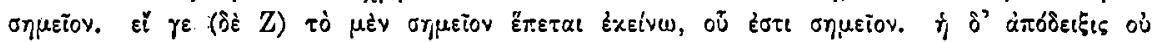

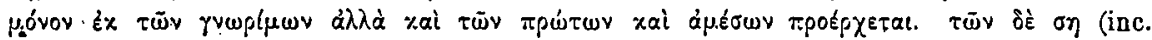

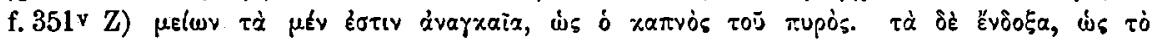

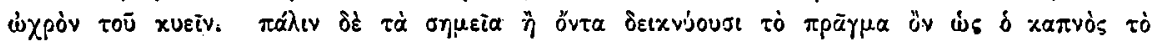

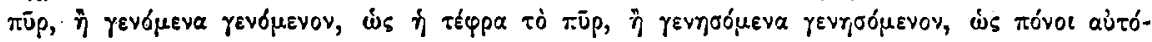

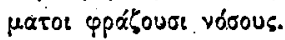

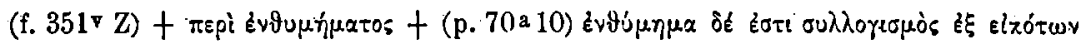

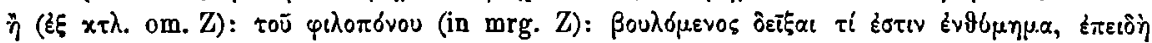

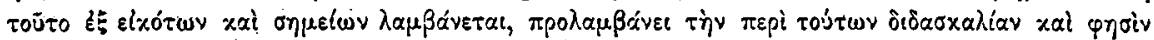

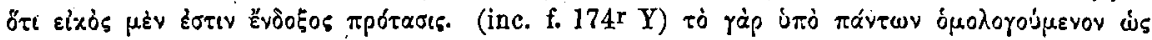

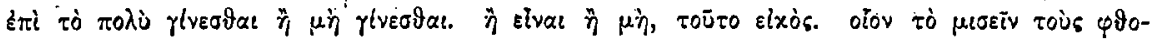

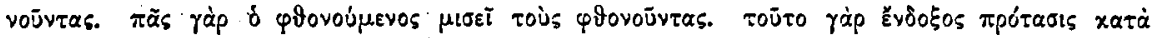

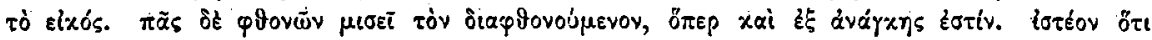

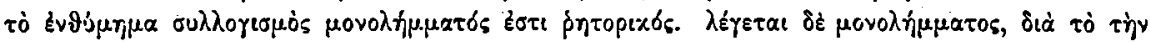

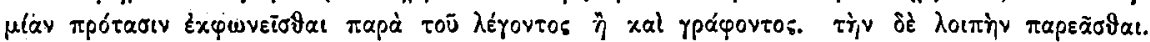

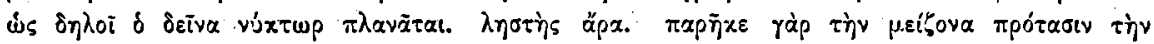

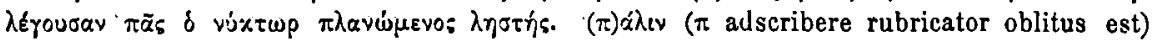

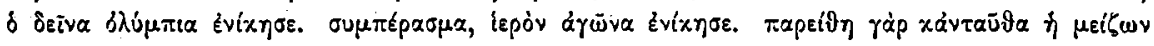

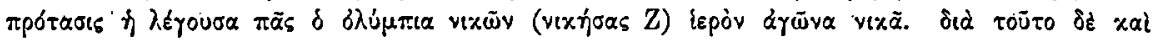

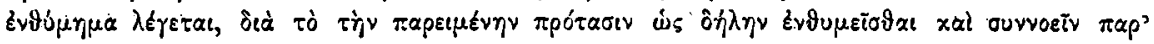

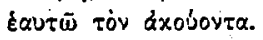

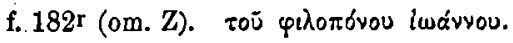

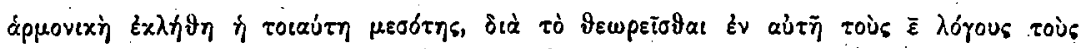

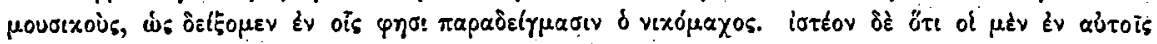

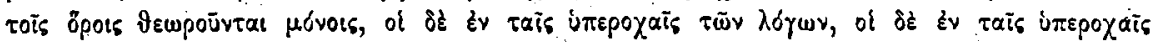

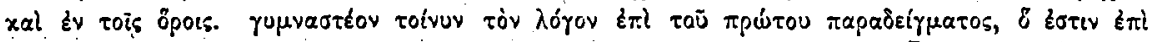

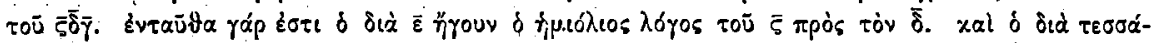

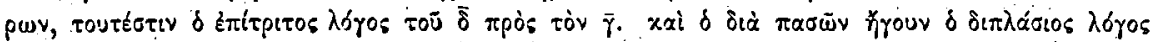

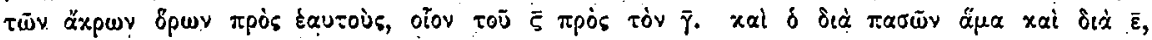

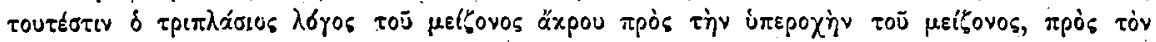

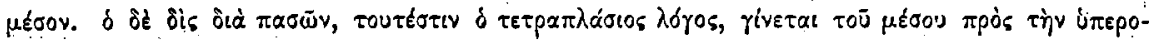

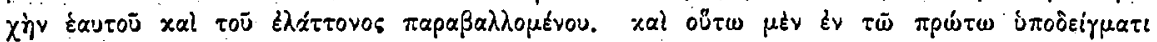

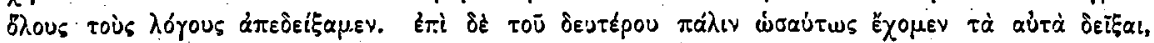

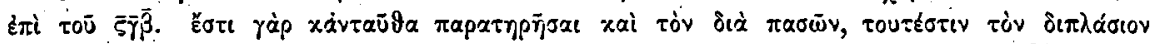

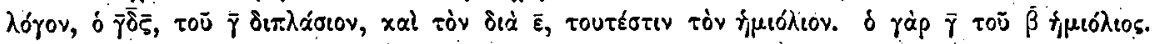

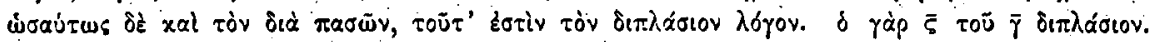

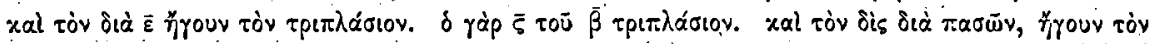

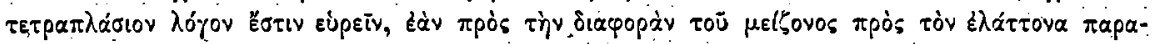

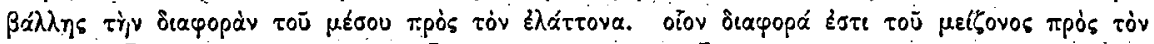

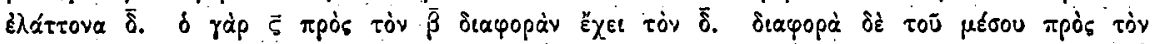

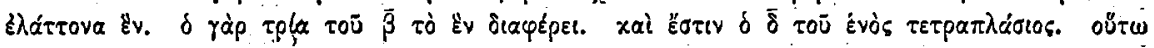

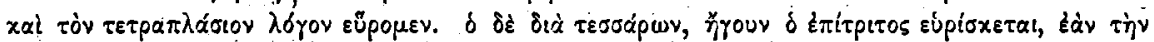

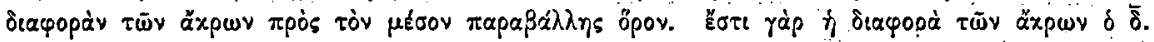

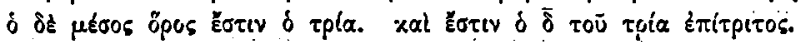

V Vaticanus 247 [Brandis 1. c. p. 53 n. 13] chartaceus saec. XV post Ammonii in librum De interpretatione commentarium [cf. vol. IV 5 p. XII] f. $202^{\mathrm{v}}-246^{\mathrm{r}}$ hunc commentarium usque ad p. 191,31 exaratum 


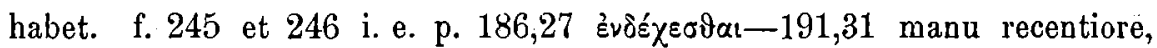
eadem, ut videtur, quae antea manum primam passim correxit, saeculo XVI, propter miserum videlicet extremi codicis habitum, suppleta sunt. collatus est a Guil. Crönert.

VAticanus 1018 [Brandis l. c. p. 52 n. 6] chartaceus saec. XV-XVI, qui Z f. $203^{\mathrm{v}}-354^{\mathrm{r}}$ Analytica priora cum Philoponi aliorumque scholiis continet, eosdem titulos fert atque $\mathrm{Y}$, cui omnino codicem simillimum esse ex iis, quae Guil. Crönert, A. Gercke, A. G. Roos notaverunt, satis apparet. sed scholiorum numerus paulo minor est. of. Y.

Vatrcanus 1021 [Brandis 1. c. p. 54 n. 17] bombycinus forma quadrata $Q$ saec. XIV-XV foliorum 411, nunc in duo volumina divisus, post Ammonii in l. De interpret. commentarium [cf. vol. IV 5 p. IX] f. $361^{\mathrm{v}}$ $-411^{\mathrm{v}}$ huius commentarii p. 1-85,33 continet. collatus est ab E. Pfuhl.

REGINENSTS 116 [Stevenson codd. mss. graec. Regin. $81 \mathrm{sq.} \mathrm{Brandis} \mathrm{1.} \mathrm{c.}$ p. 51 n. 5] chartaceus saec. XIV foliorum 393. f. 82r titulum fert íá́vvov

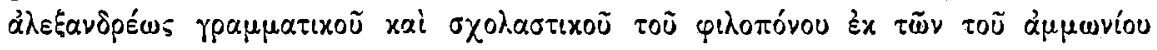

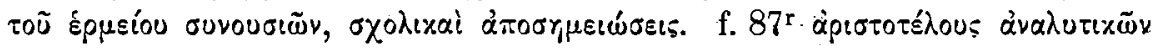

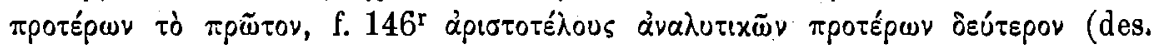
f. $171^{r}$ ) cum multis scholiis plerumque anonymis. interdum Isaaci nomen

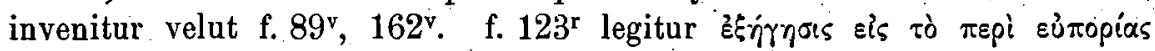

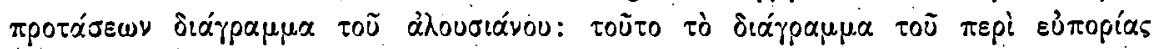

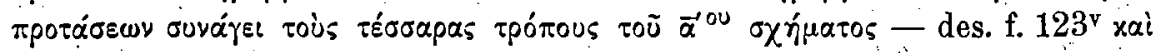

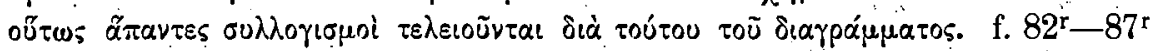
contulit et descripsit E. Pfuhl:

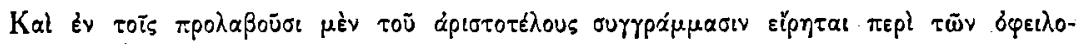

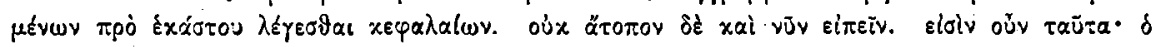

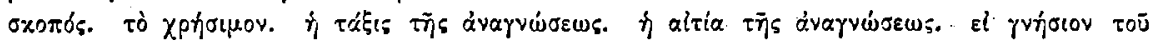

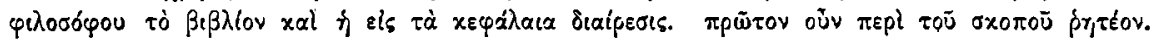

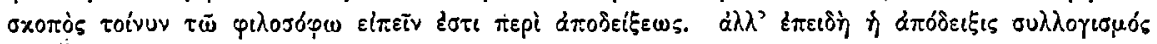

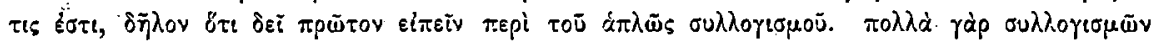

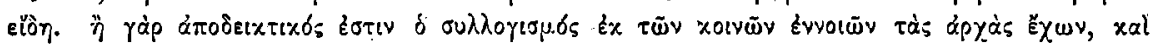

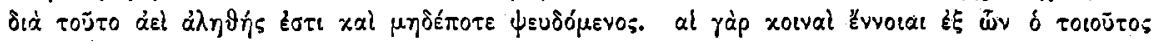

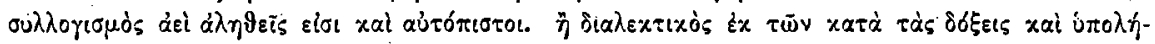

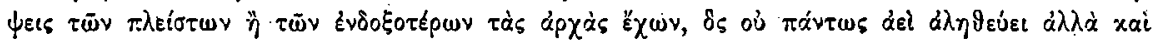

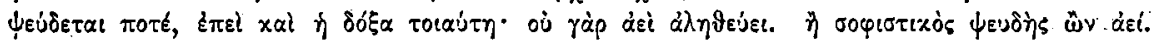

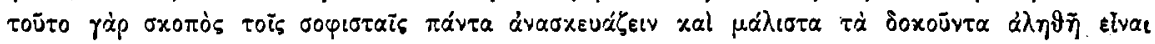

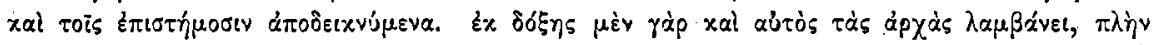

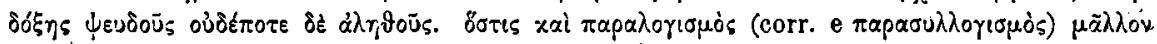

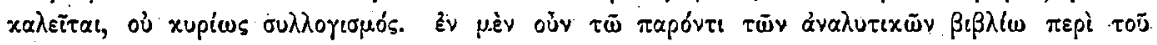

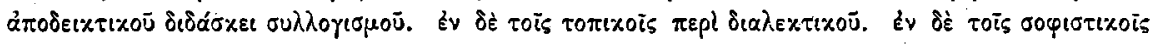

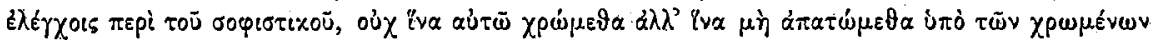

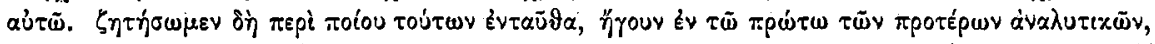

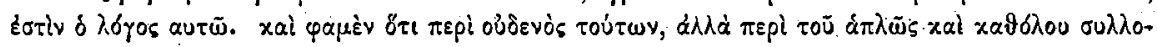

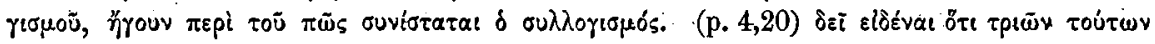

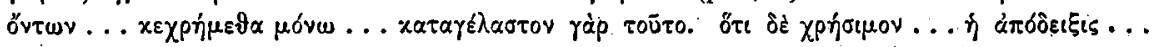

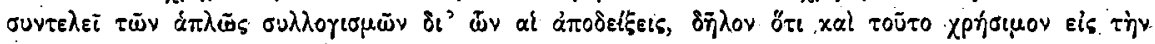

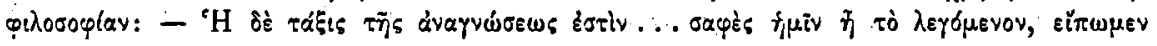




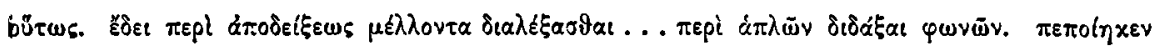

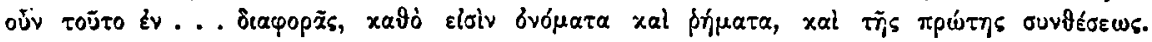

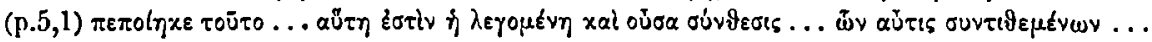

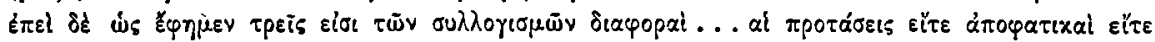

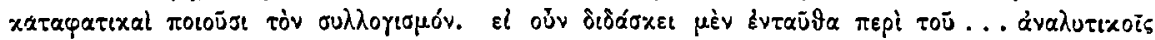

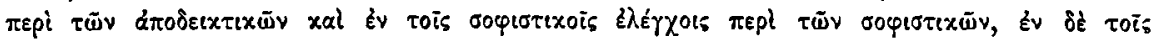

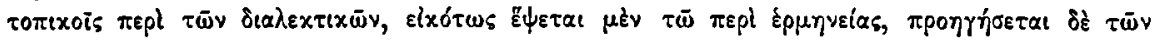

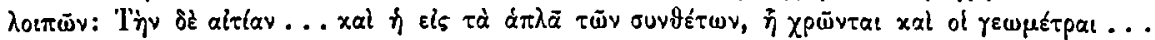

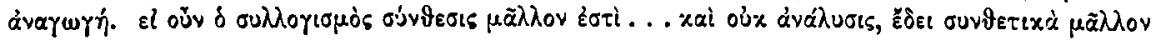

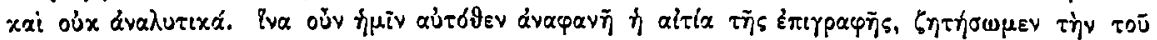

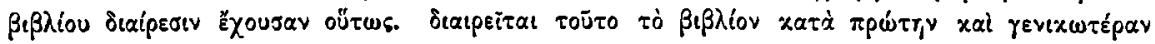

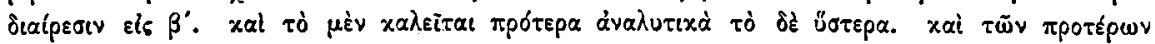

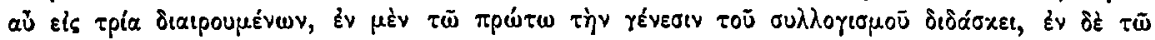

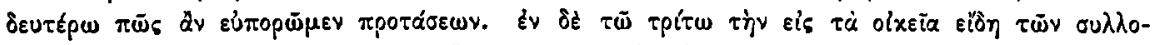

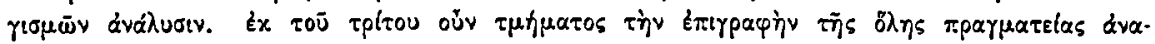

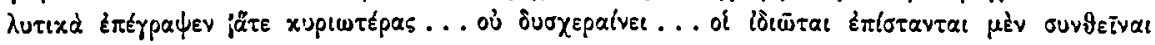

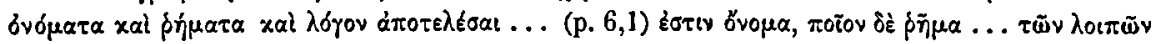

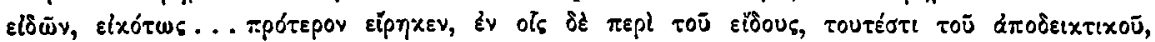

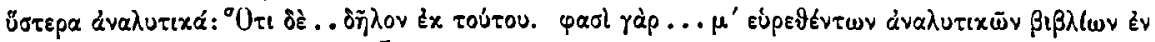

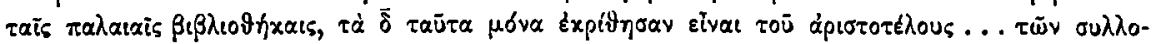

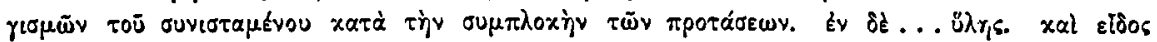

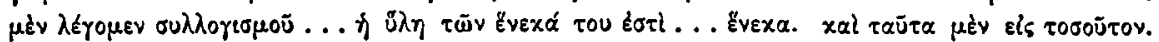

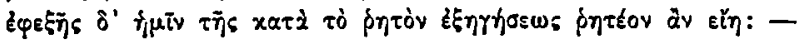

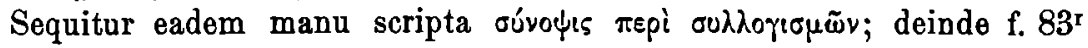
$-86^{\text {r }}$ vers. 8 alia manu exarata $\pi \varepsilon p i$ $\sigma u \lambda \lambda \circ \gamma\left\llcorner\sigma \mu \circ \tilde{\text {; }}\right.$ tum usque ad f. $86^{\mathrm{v}}$ vers. 2

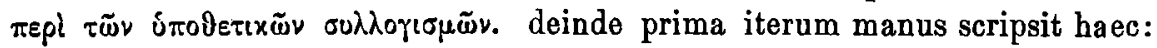

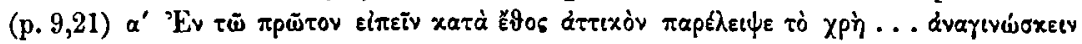

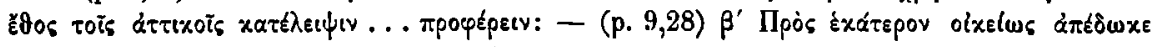

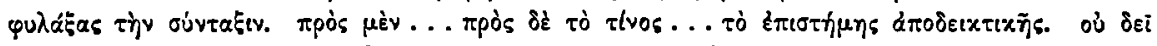

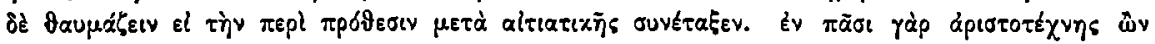

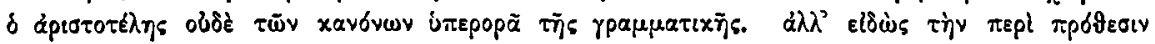

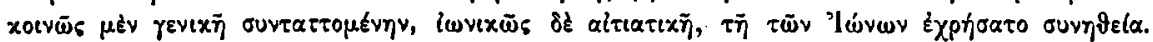

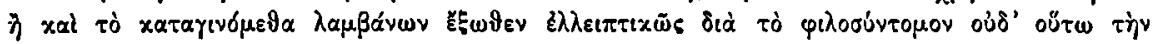

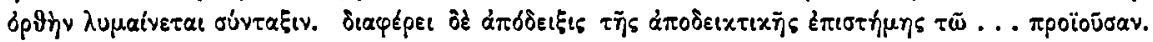

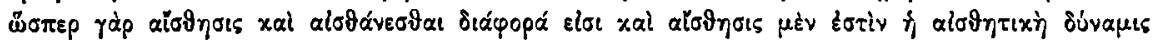

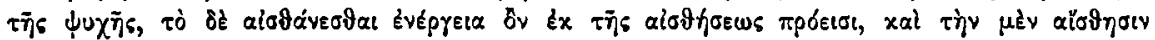

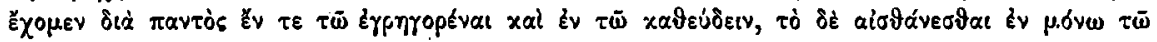
Eү

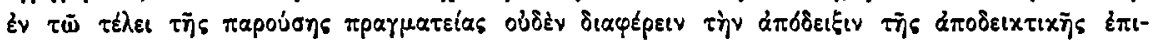

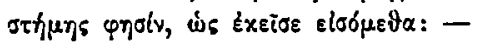

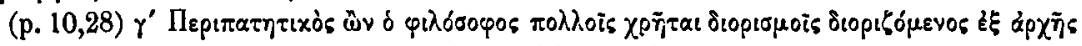

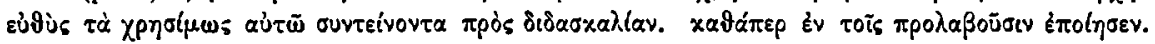

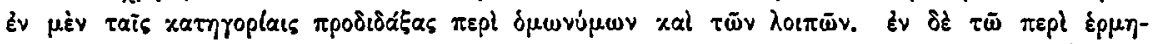

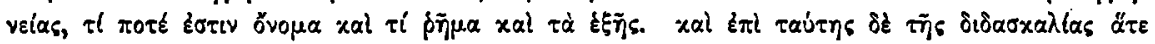

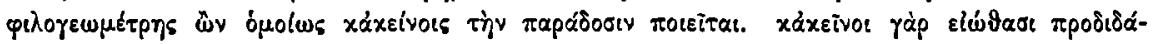

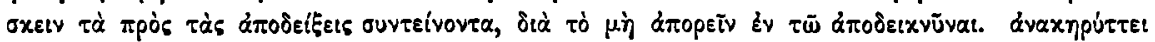

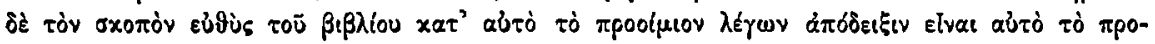

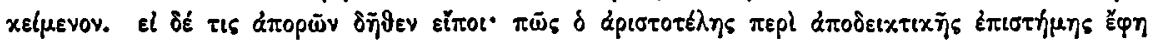

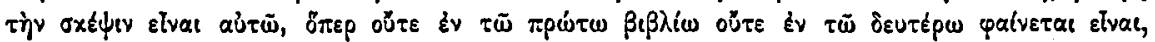

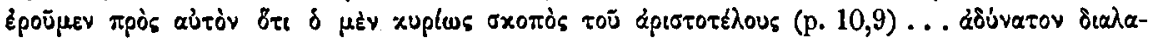

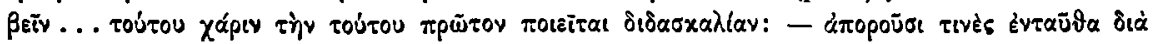




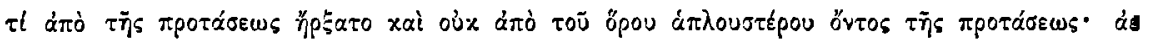

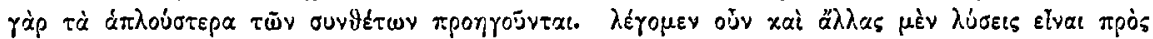

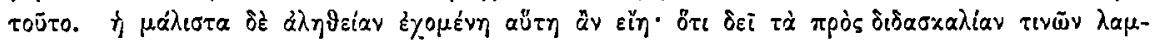

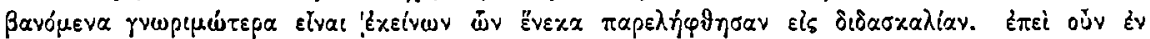

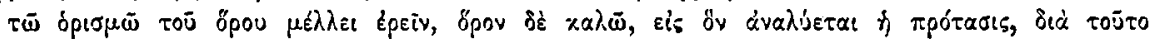

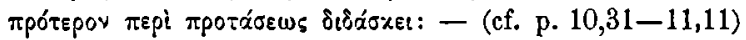

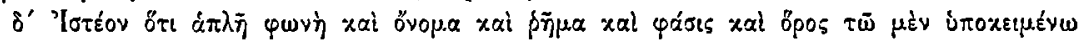

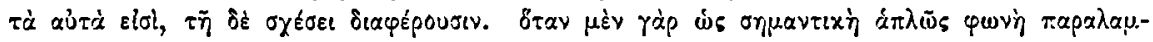

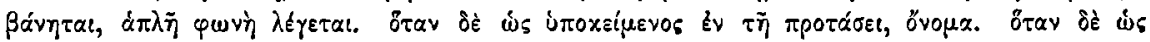

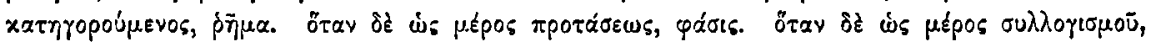
öpos: - (cf. p. 11,19-24)

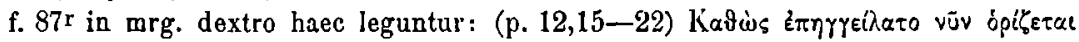

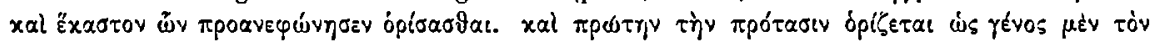

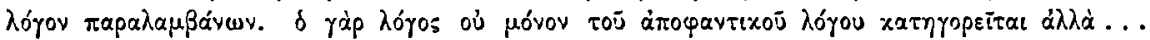

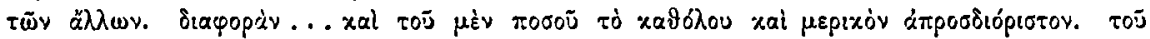

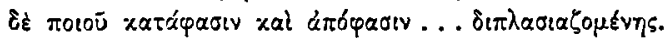

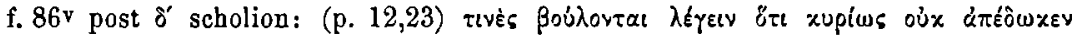

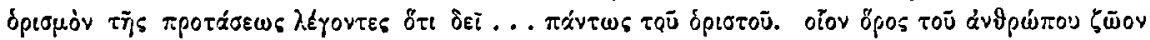

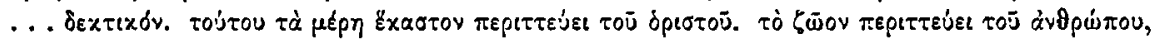

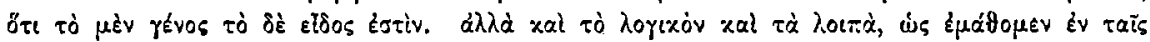

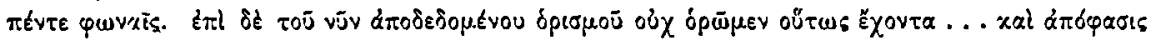

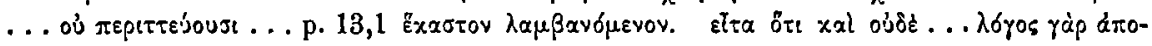

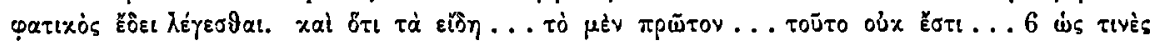

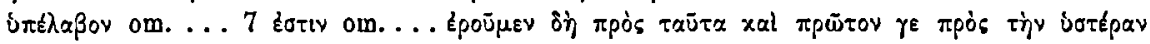

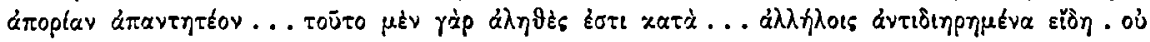

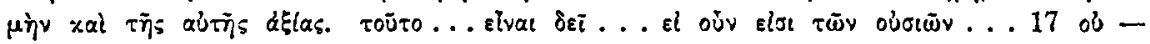

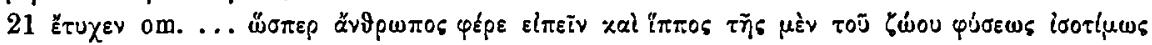

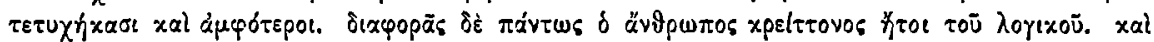

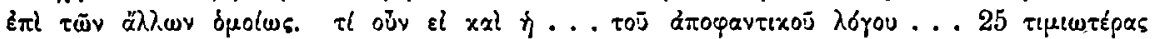

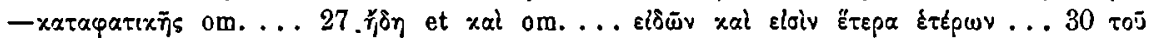

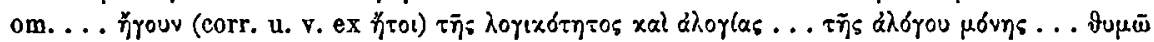

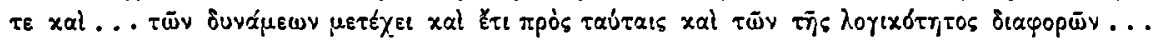

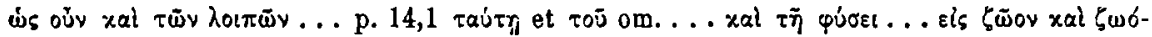

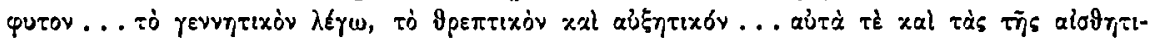

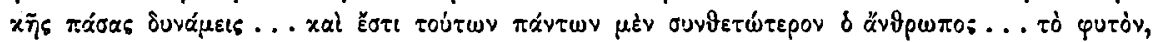

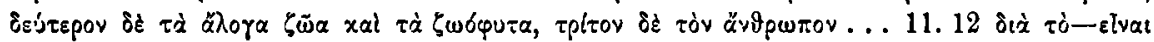

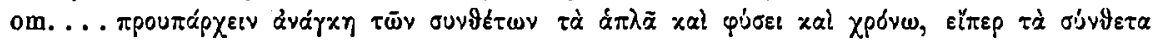

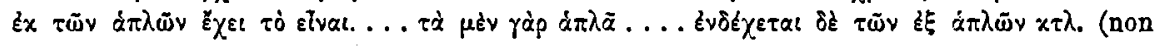
ita dissimilia p. 14,16-17,14).

Otrobonianus graec. 169 (catal. p. 95) bombycinus saec. XV, madore

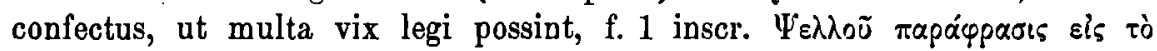

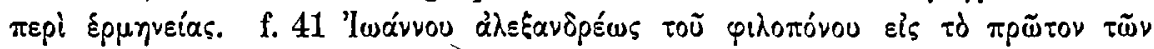

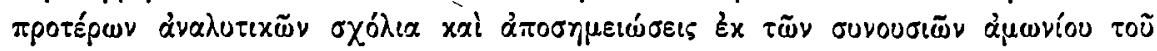

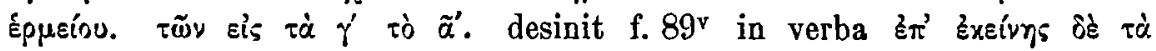
(p. 82,35). foliorum ordinem bibliopegae culpa turbatum Guil. Crönert, qui codicem examinavit, ita restituendum esse vidit, ut f. $1-32$ et $57-58$ (f. $58^{\mathrm{r}}$ et 59 vacant) Psello tribuantur, Philopono f. $41-42,53-56,43-52$, $33-40,60-89$.

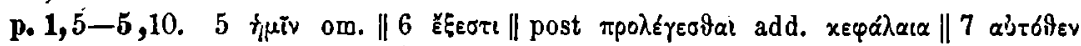

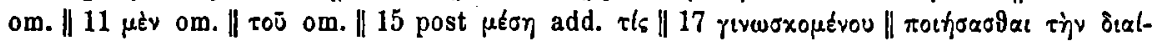




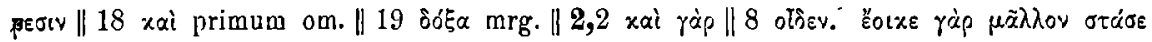

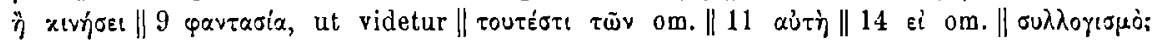

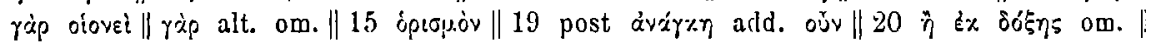

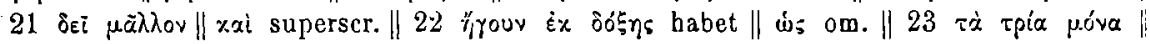

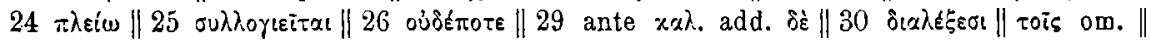

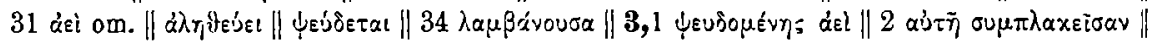

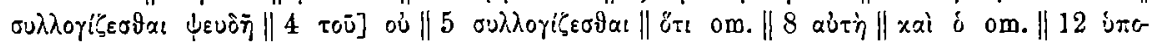

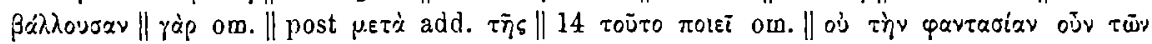

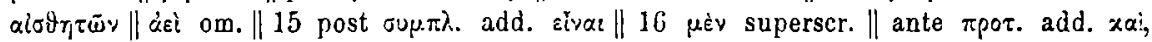

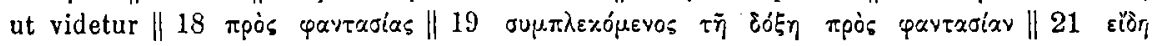

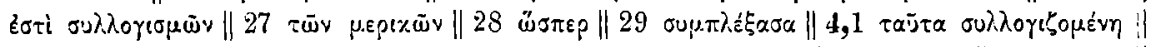

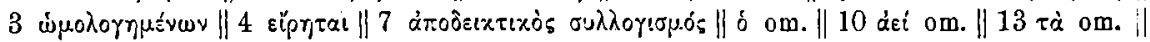

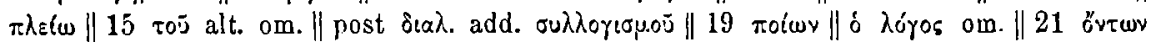

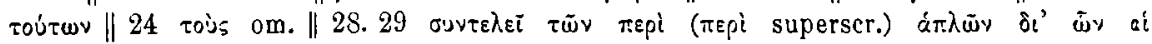

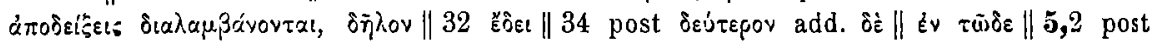

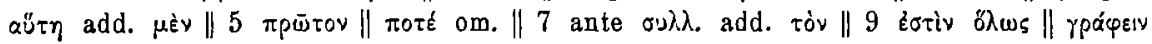
sidévat.

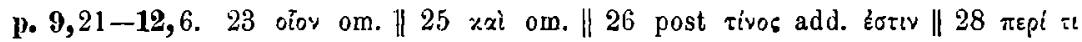

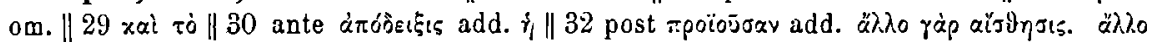

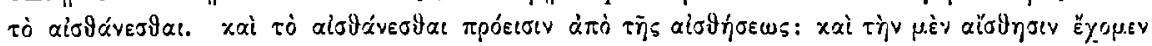

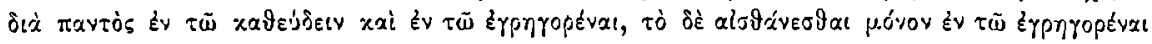

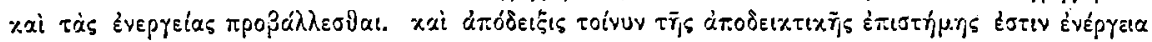

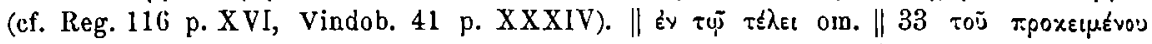

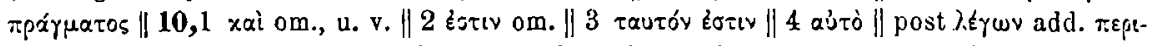

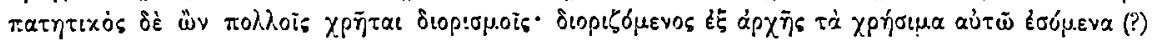

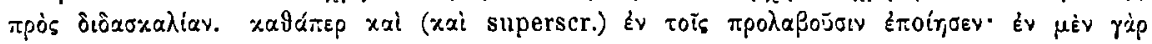

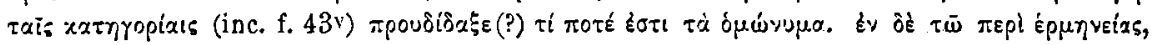

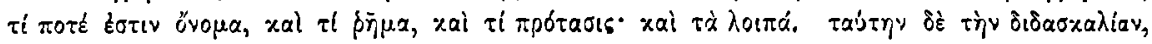

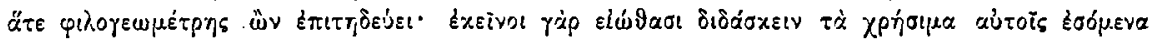

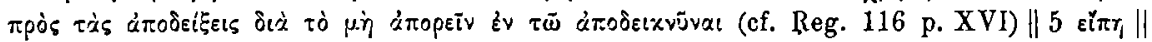

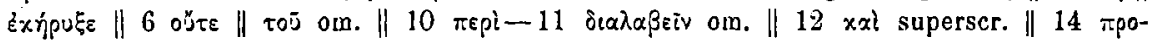

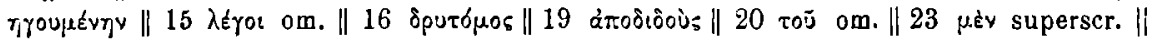

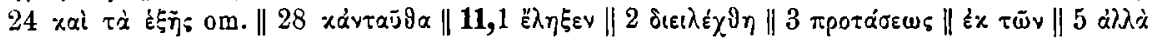

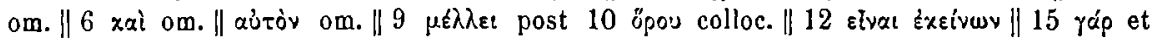

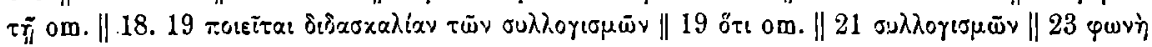

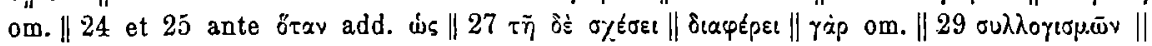

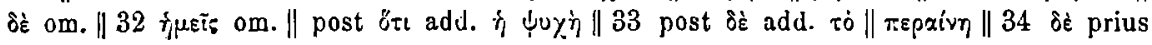

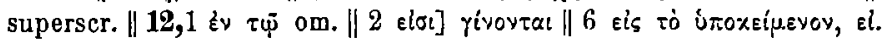

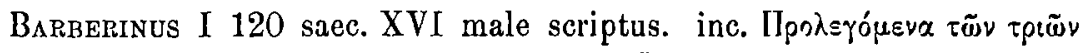

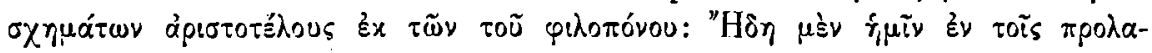

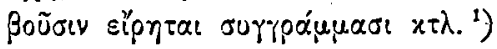

1) Barber. I 87 saec. X f. $52_{\mathrm{r}}-168^{\mathrm{v}}$ Analytica Priora et Posteriora continet cum glossis interlinearibus (saec. $X$ ) et scholiis marginalibus (saec. XIV), inter quae etiam

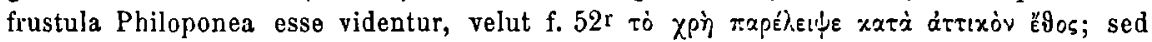
baec colligere vix operae pretium sit. - Barber. I 164 saec. XIV f. $39 \mathrm{r}-121^{v}$ Analytica Priora scholiis (initium libri I etiam paraphrasi) ornata habet plerumque anonymis, interdum Magenteni et Pselli nomen ferentibus; f. $64 \mathrm{v}$ Philoponi nomen huic scholio appositum

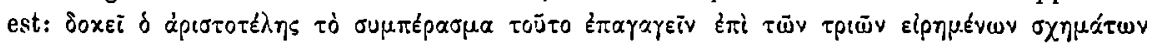
- El $\delta$ 'ávajxaiov, d́varxaiav i. e. p. 145,16 sq. - Etiam in cod. Urb. 35 saec. XIV scholia

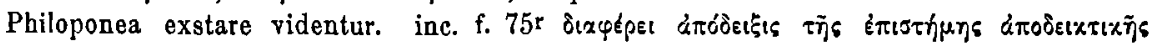


Laurentianus LXXII 1 [Bandini III 26. 27] bombycinus saec. XIII G foliorum 280, quorum f. 183-232 úto

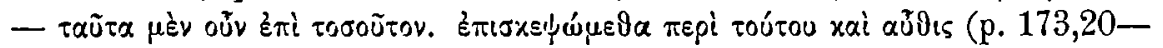
$331,15)$ saeculo XV suppleta sunt. ipse compluribus locis codicem contuli et p. $433,8-452,31$ varietatem subnotavi.

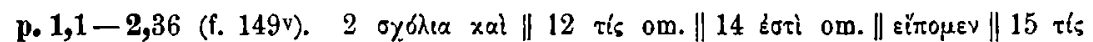

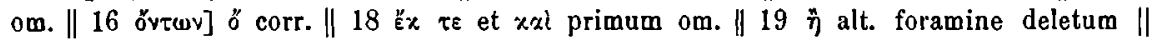

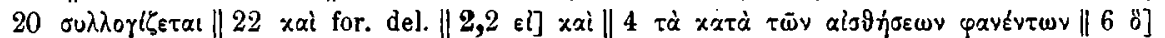

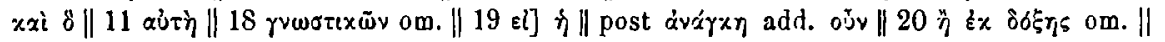

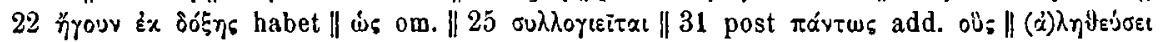

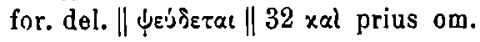

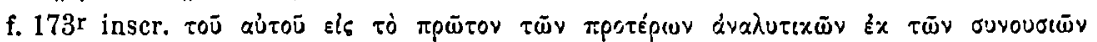

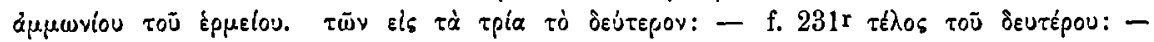

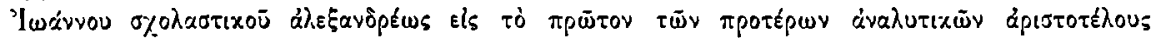

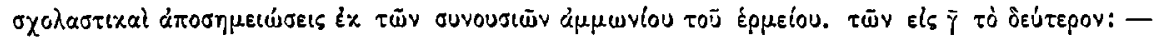

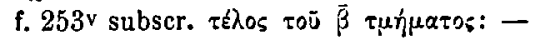

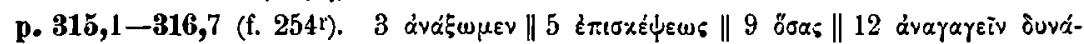

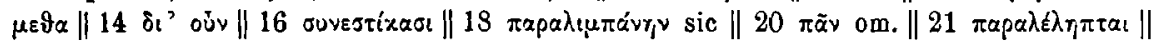

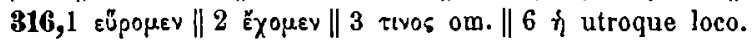

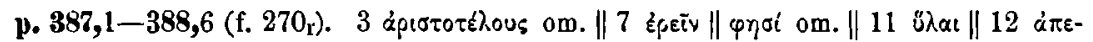

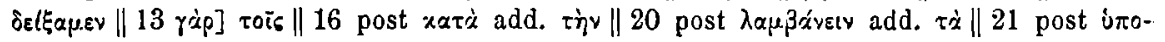

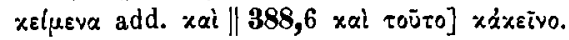

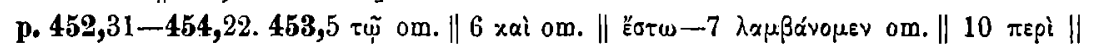

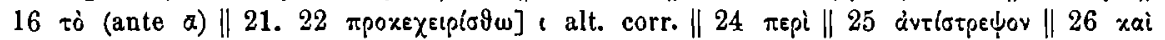

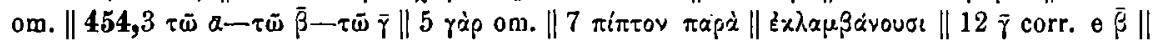

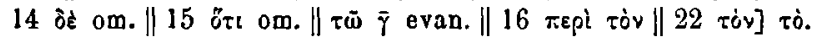

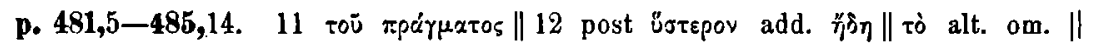

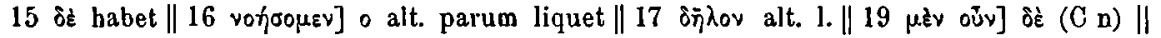

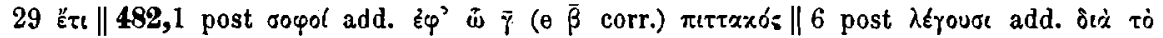

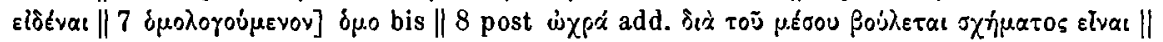

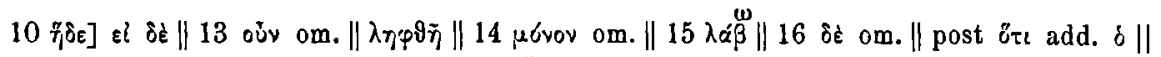

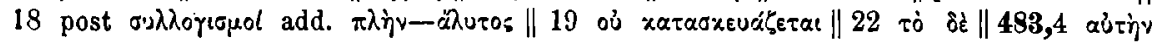

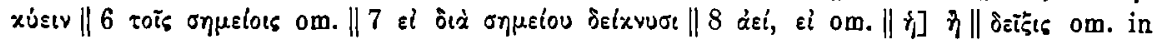

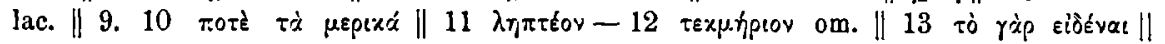

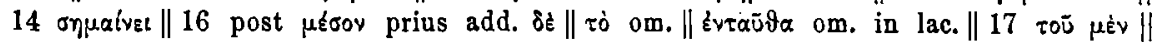

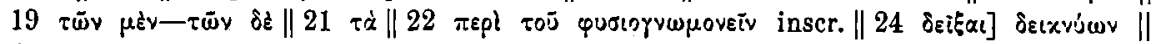

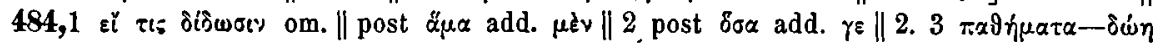

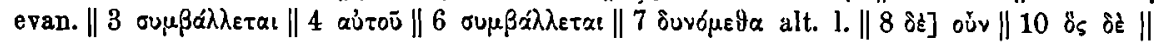

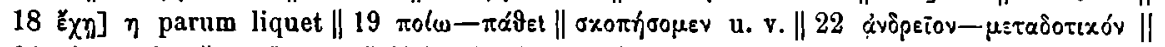

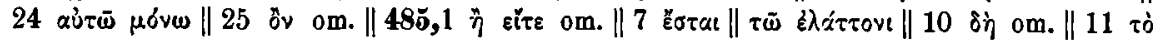
tert. om.

LaUdentianus LXXII 5 [Bandini III 30] membraneus saec. XI Analytica Priora continet cum scholiis e Philoponi commentario excerptis. contulit et exscripsit quae hic propono $\mathrm{H}$. Vitelli:

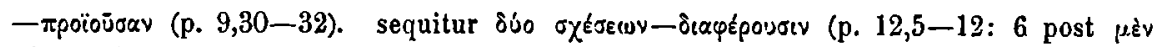

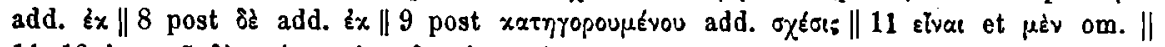

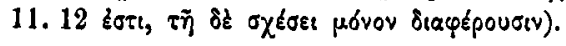


f. 67จ. p. 12,5-11. 8 post $\delta \dot{\varepsilon}$ add. éx \| 11 Elvat om.

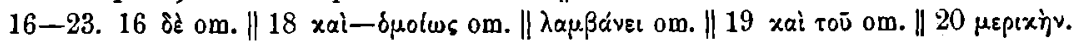

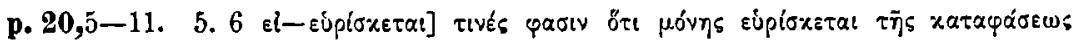

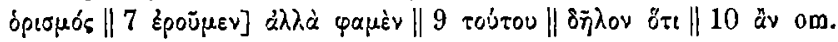

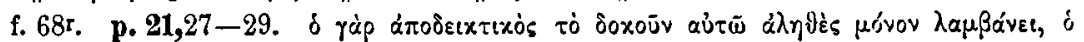

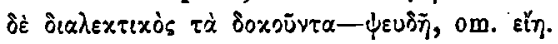

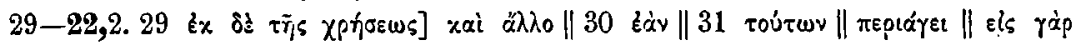

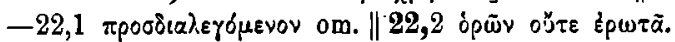

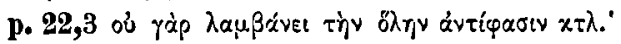

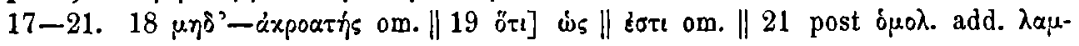

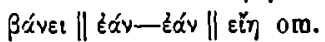

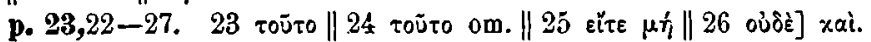

31-24,2. 31 xoiv̄̄s $\lambda \alpha \beta \varepsilon i v \mid 24,2$ ti om. \| тò $\ddot{j}$ om.

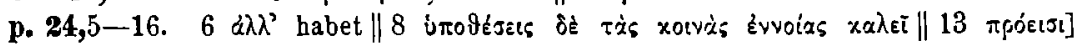

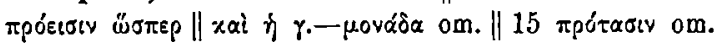

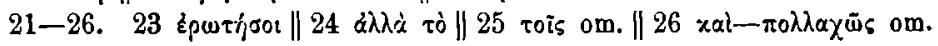

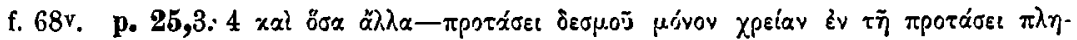
poüolv.

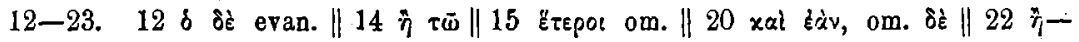

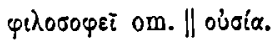

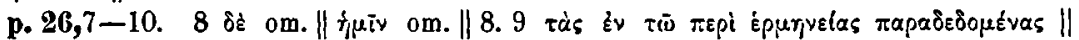

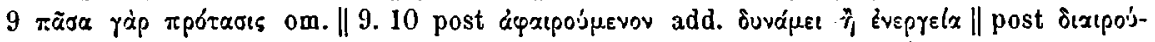

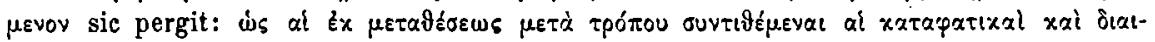

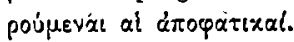

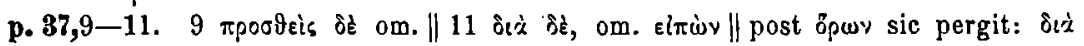

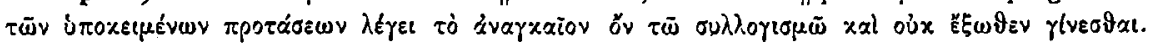

14 aेvil-16. $14 \pi \varepsilon p i \lambda \eta \varphi 9 \varepsilon l s$.

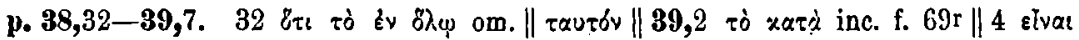

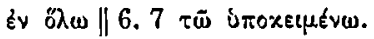

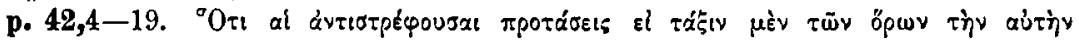

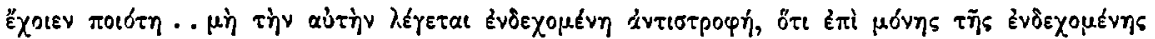

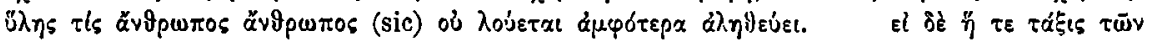

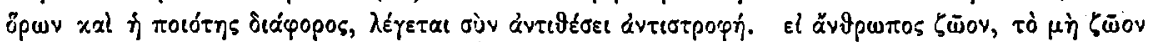

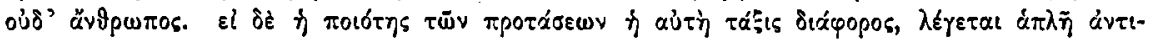

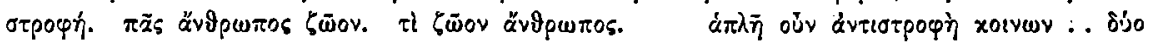

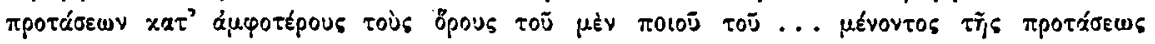

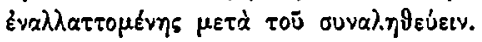

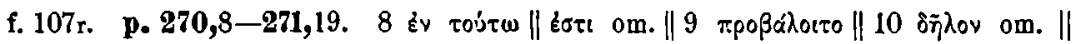

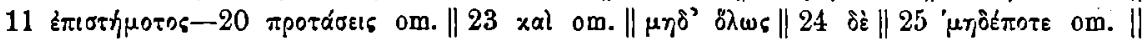

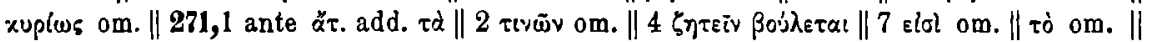

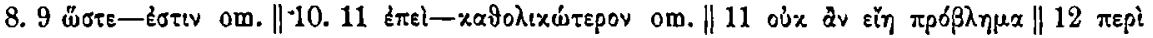

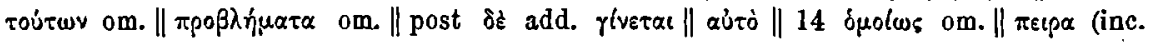

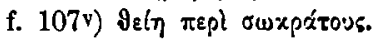

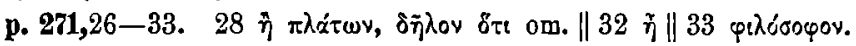

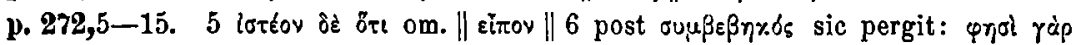

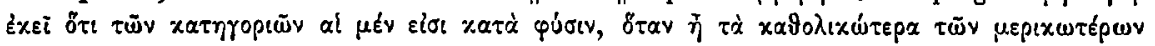

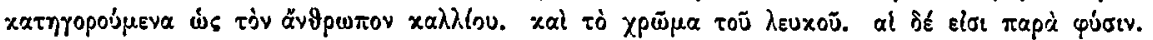

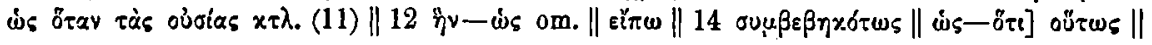

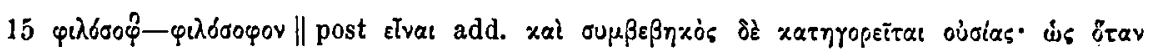

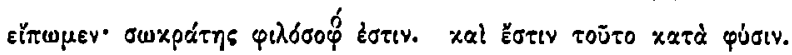




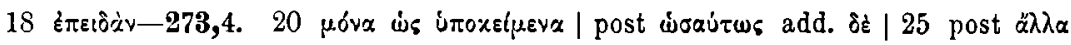

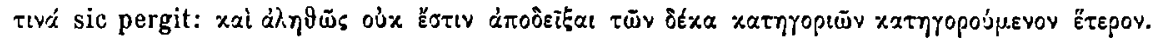

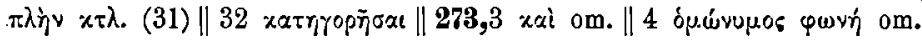

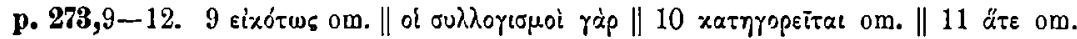

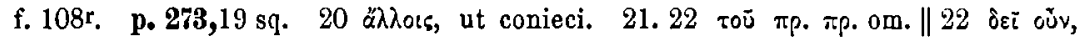

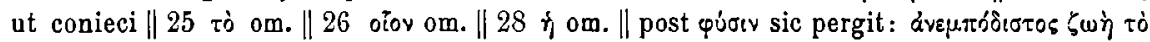

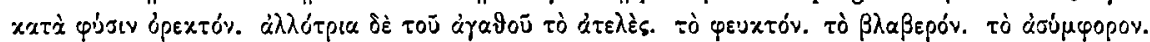

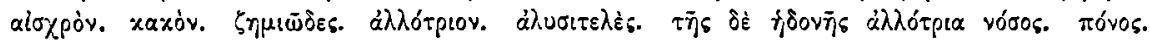

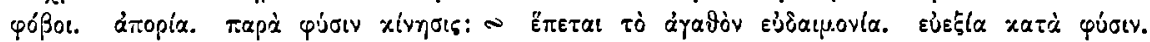

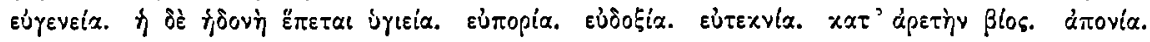

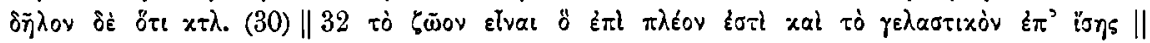

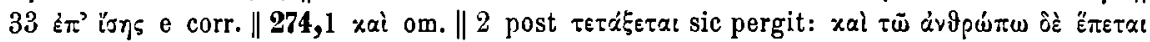

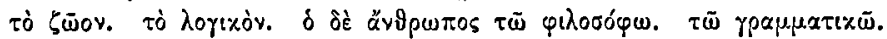

p. 275,30. 31. $31 \varkappa \alpha \ell \tau \dot{\alpha} \not ̈ \mu \sigma เ \alpha$ om.

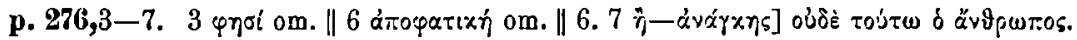

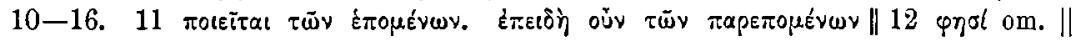

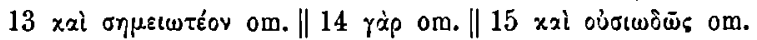

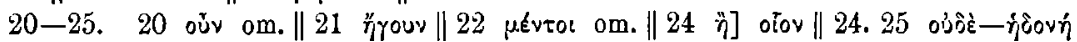

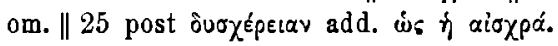

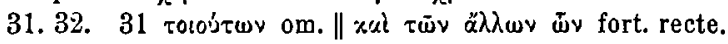

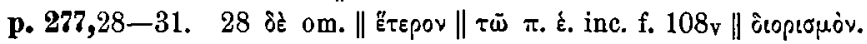

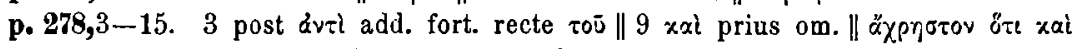

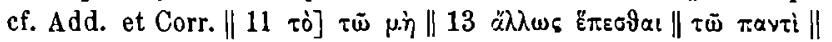

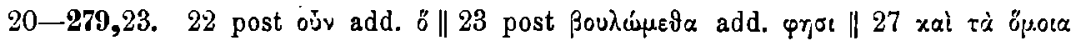

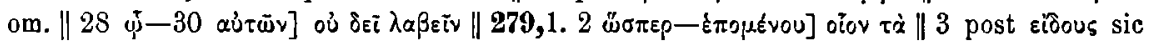

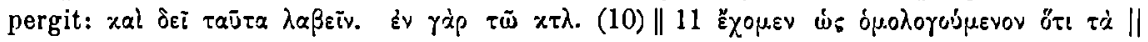

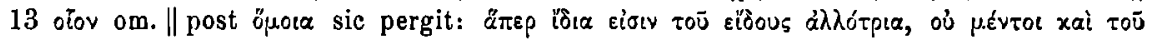

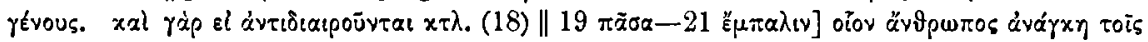

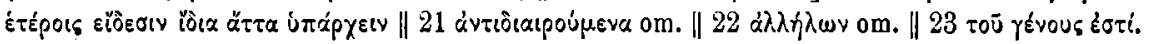

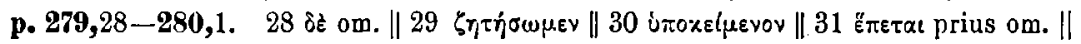

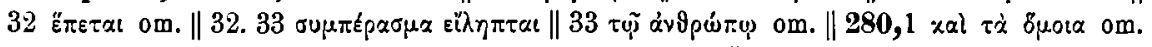

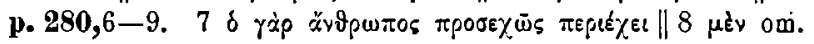

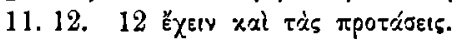

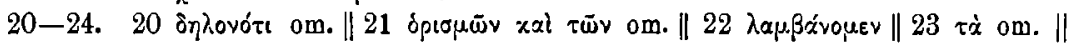
24 хатทүоро' $\mu \varepsilon v \alpha \mathrm{om}$.

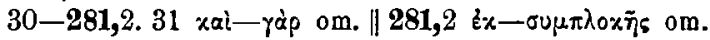

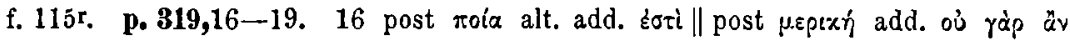

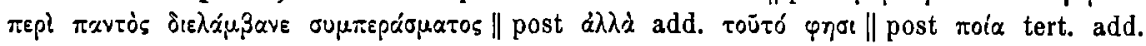

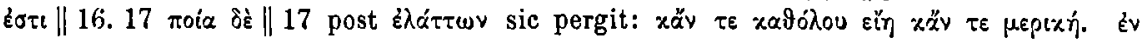

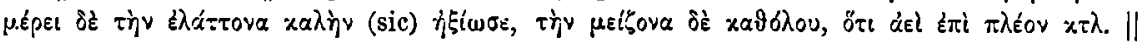

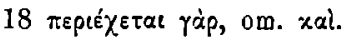

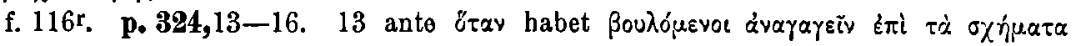

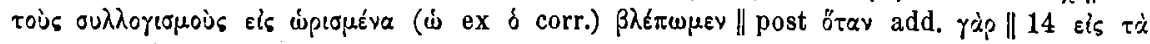

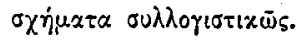

LaURentianus LXXXV 1, qui Oceanus dicitur [Bandini III 237-247] $\mathrm{T}$ bombycinus saec. XIV, forma maxima, perspicue et nitide scriptus, f. $175^{r}$ $-202^{v}$ Philoponi in Analyt. Priora commentarium continet. a Torstrikio

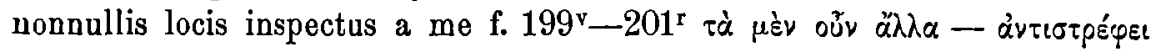
róvov (p. 432,25-454,24) collatus est, quorum varietas p. 433,8-452,31 subnotata est. 


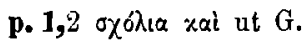

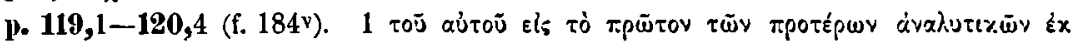

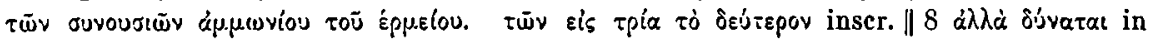

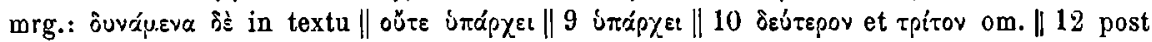

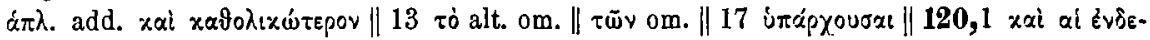

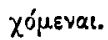

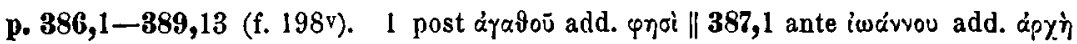

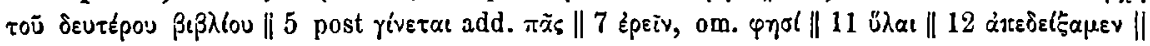

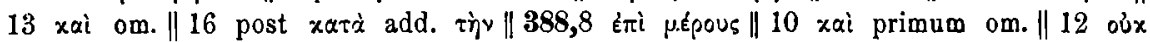

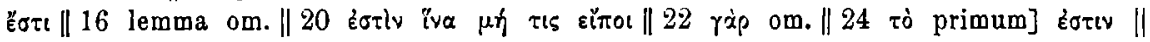

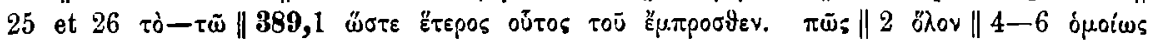

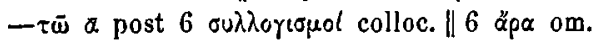
àv in 15 方.

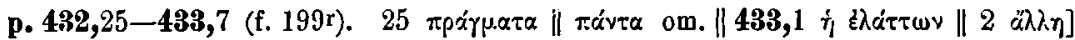

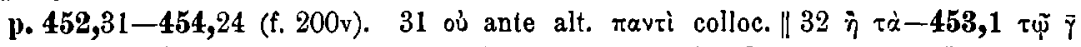

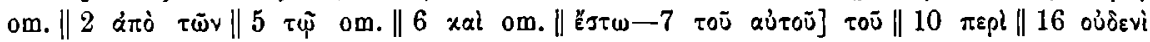

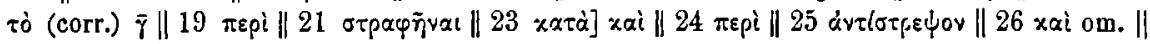

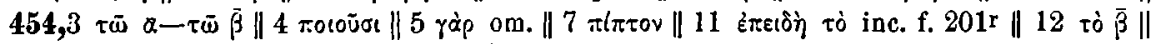

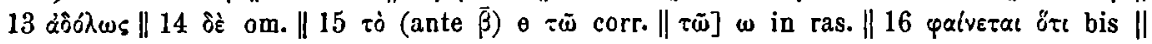

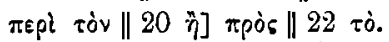

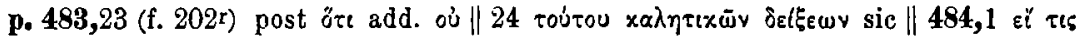

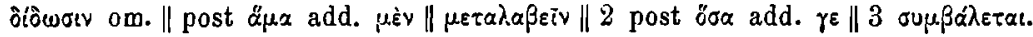

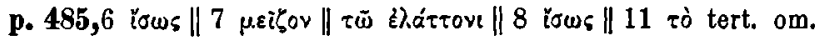

U Marcianus 225 [Zanetti p. 118] olim Bessarionis, chartaceus foliorum 467, saeculo XIV (non XII, ut catalogus vult) exaratus, post Ammonii in $\mathrm{V}$ voc. Porphyrii (cf. vol. IV 3 p. XIII) et Simplicii in Categ. commentaria

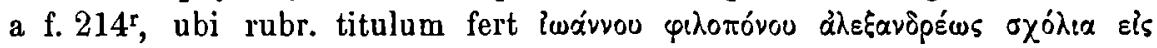

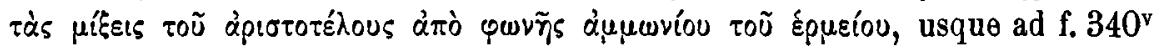
Philoponi commentarium inde a p. $29^{\mathrm{b}} 29$ (p. 119,1) continet, quare in catalogo initio mutilus dicitur. f. $240^{\mathrm{r}}-286^{\mathrm{r}}$ (p. 186,26-314,24) et f. 311 $\mathrm{r}-340^{\mathrm{r}}$ (p. 387,1-485,14) a me Venetiis collata sunt.

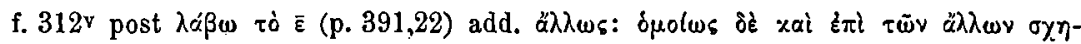

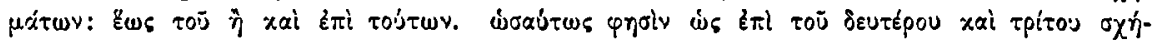

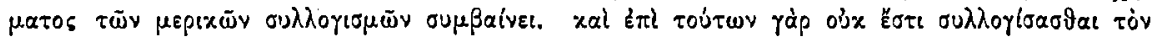

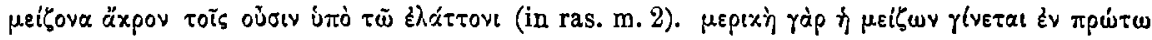

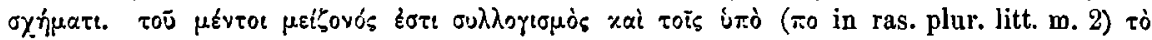

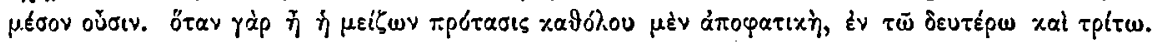

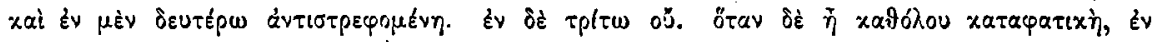

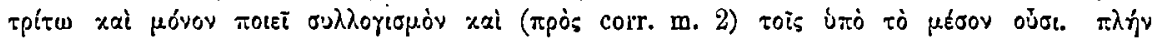

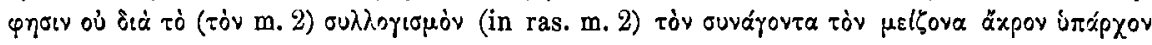

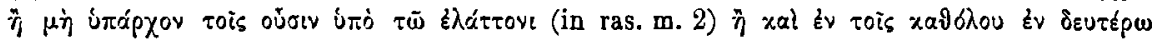

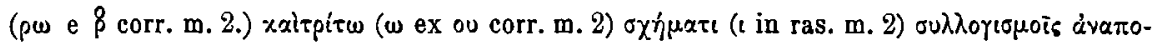

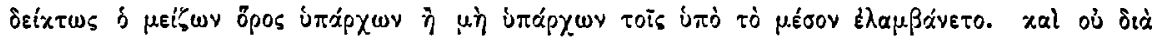

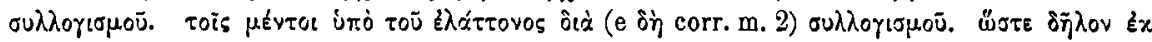

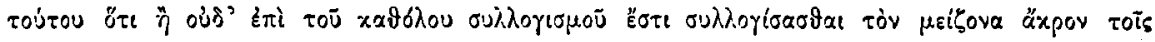

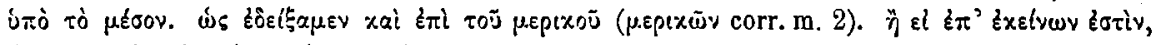

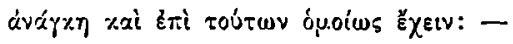

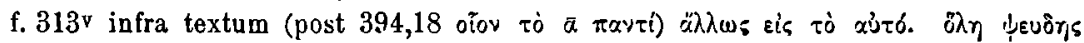

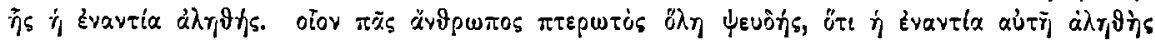




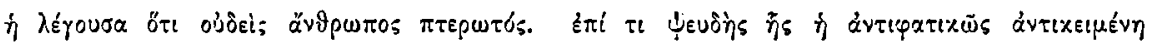

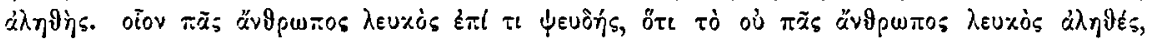

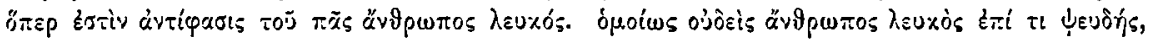

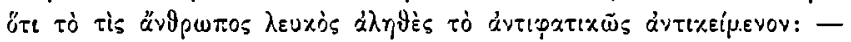

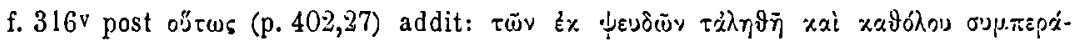

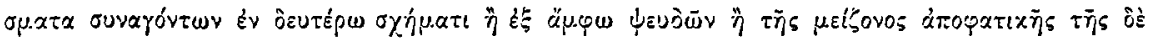

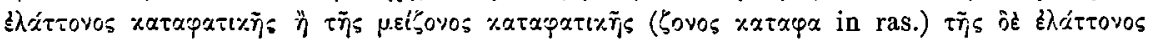

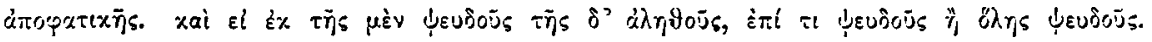

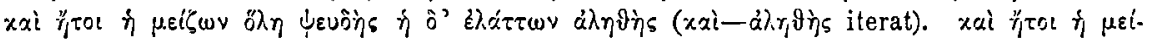

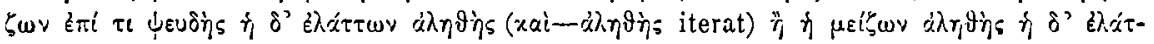

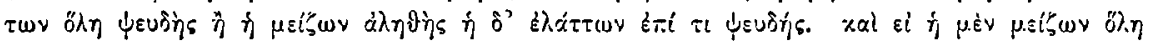

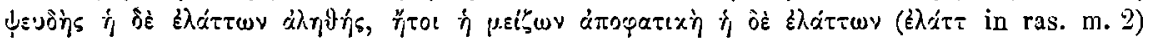

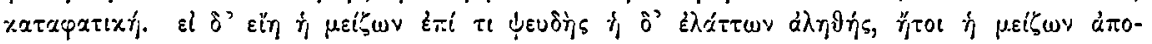

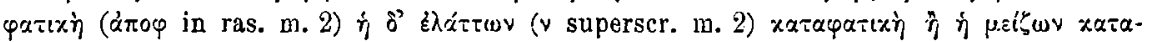

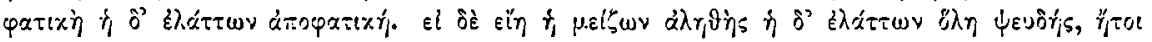

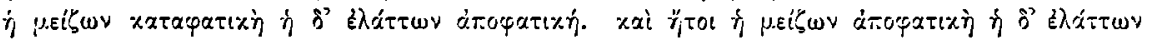

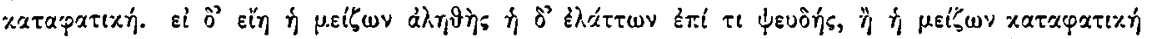

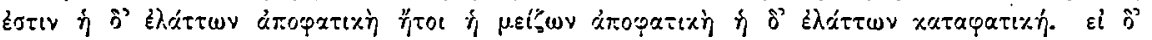

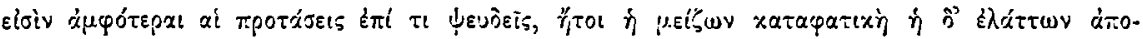
$\varphi \propto \tau เ x \dot{n}$.

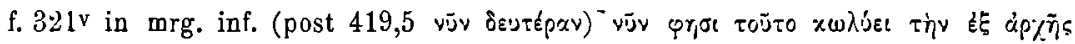

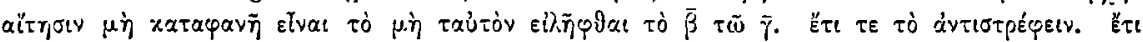

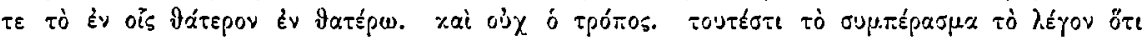

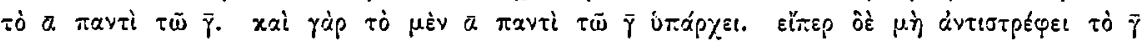

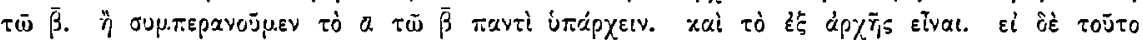

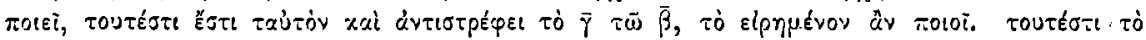

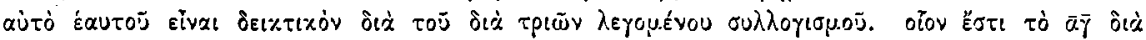

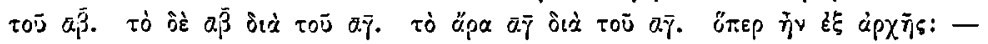

Marcianus 231 [Zanetti p. 119] olim Bessarionis, chartaceus, socundum catalogum saeculo XI, Alfredi Gercke iudicio, qui scribam litteras multo antiquiores imitatum esse perspexit, saeculo $\mathrm{XV}$ exaratus, folia nunc continet 234 , ea quoque turpiter lacerata. titulo caret; nam f. $1^{\mathrm{r}}$ incipit a

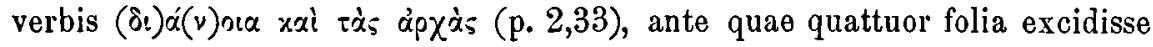
$\lambda \lambda^{\prime}$

inde apparet, quod in fine commentarii f. $216^{\mathrm{v}}$ numerantur $\varphi v \sigma x^{\prime}$. f. $57^{\mathrm{r}}$

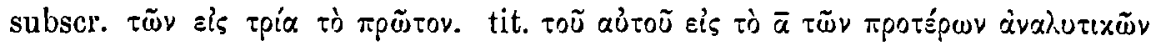

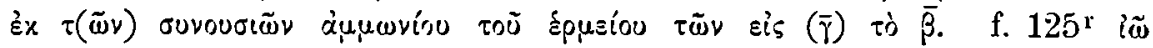

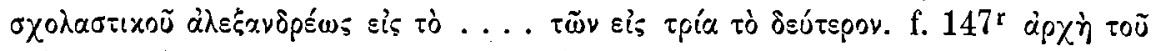

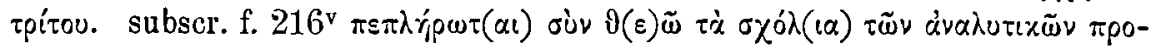

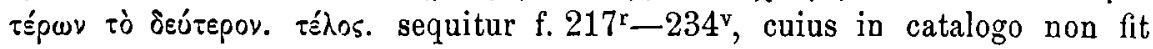

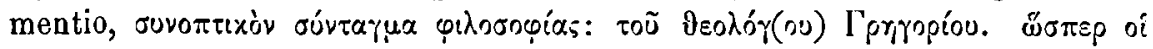

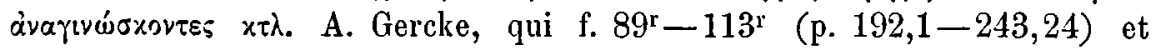
f. $125^{\mathrm{r}}-130^{\mathrm{r}}$ (p. $\left.270,1-279,23\right)$ contulit, atramenti colore tres manus distinxit. qui antea codicem inspexit, A. Torstrik eum libro altero et ineunte (velut p. 388,6 трórous exhibet) et exeunte ita cum $t$ concinere testatur, ut Trincavellum hoc codice usum esse suspicari liceat. varietatem subnotare recte nos supersedisse ut cognoscatur, hoc specimen propono, unde quantum codex hic quoque cum $\mathrm{t}$ consentiat appareat. 


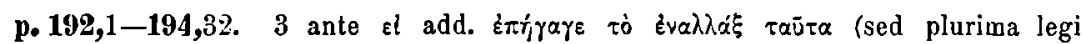

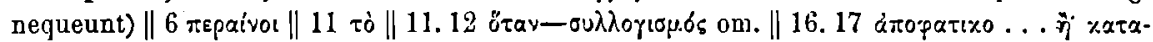

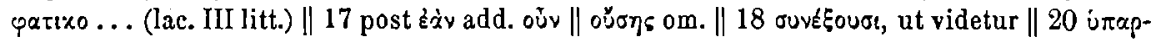

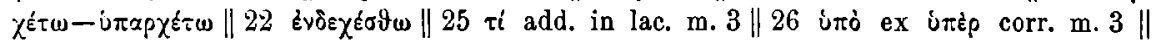

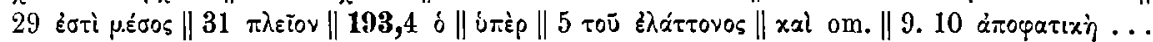

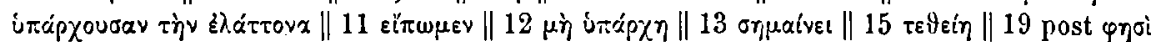

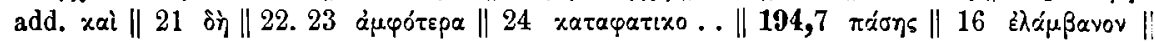

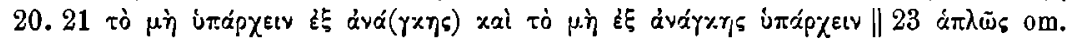

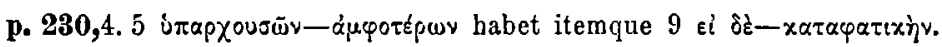

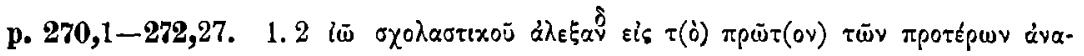

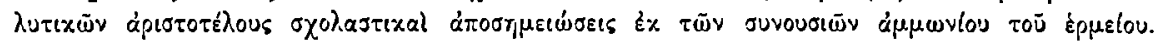

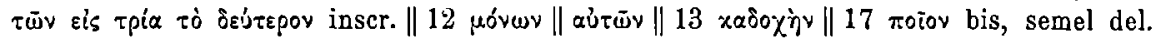

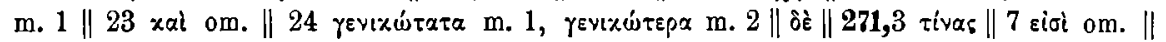

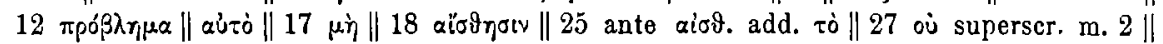

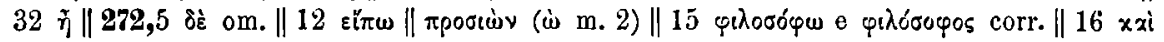

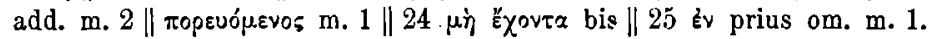

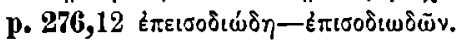

Marcianus 235 [Zanetti p. 119] chartaceus foliorum 267 saec. XV post Davidis (sive Eliae) in Categor. et Ammonii in libr. De interpret. commentaria [cf. vol. IV 5 p. XII] f. $148^{r}-263^{r}$ totum hoc Philoponi com-

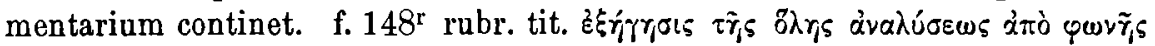

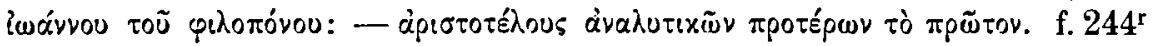

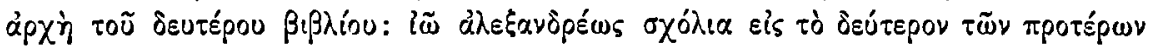

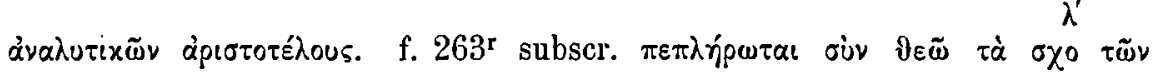

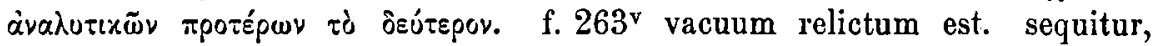
quod in catalogo non commemoratur, commentarium Categoriarum et initio et fine mutilum. ipse Venetiis codicem inspexi.

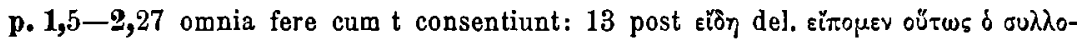

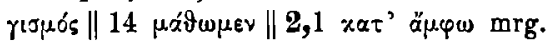

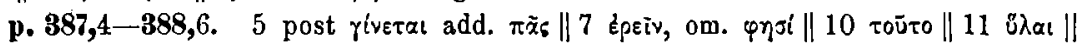

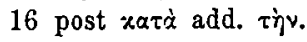

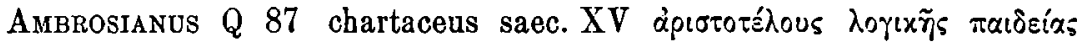
öpyavov continet cum variis excerptis, inter quae etiam Philoponea ex Analyt. Prior. commentario esse A. Torstrik testatur, sed nihil exscripsit.

Escurialensis $\Phi-\mathrm{III}-10$ [Miller p. 171] bombycinus, Milleri iudicio saec. XIII, Torstrikii potius XIV, nitide scriptus, sed in priore parte madore misere corruptus [cf. vol. IV 3 p. XIII] Analytica Priora inde a

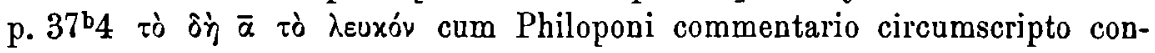

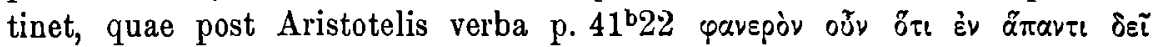
folio 87 inserto interrumpuntur, quod est $\pi \varepsilon p i$ ónjuaros. f. $88^{\mathrm{r}}$ post Philoponi

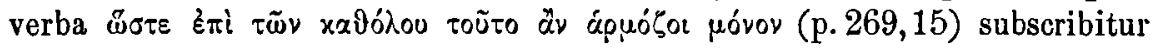

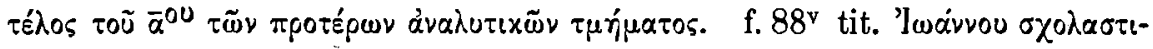

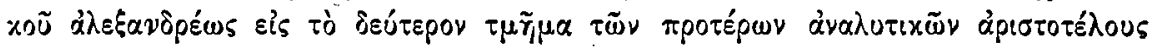

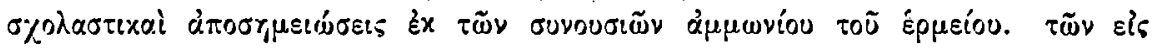

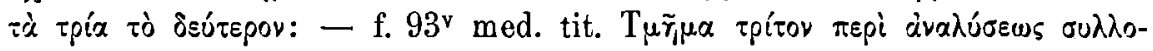




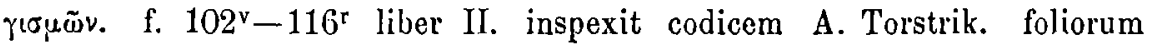
$88^{\mathrm{v}}-102^{\mathrm{r}}$ photogrammata mihi praesto erant, in quibus tamen verba interioribus marginibus proxima non semper satis dilucide erant expressa.

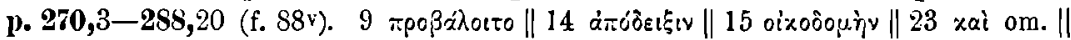

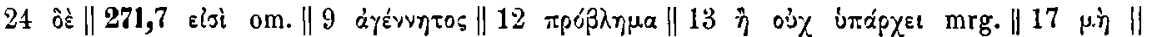

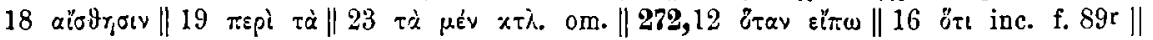

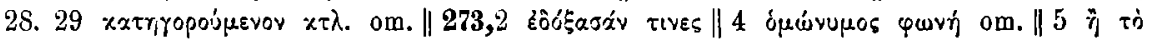

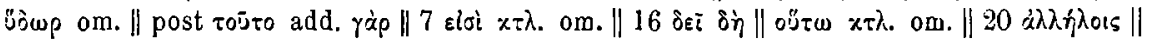

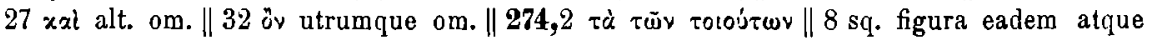

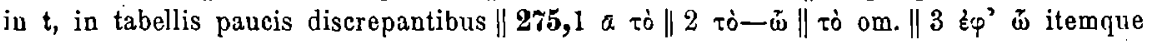

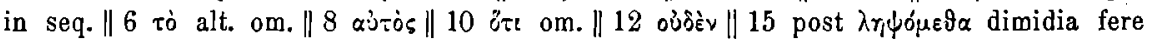

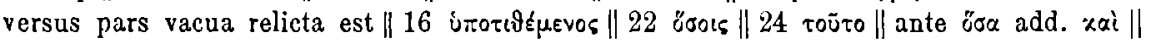

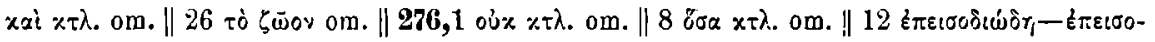
ò

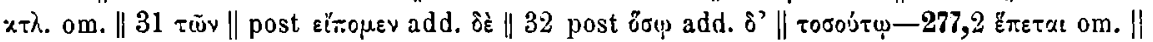

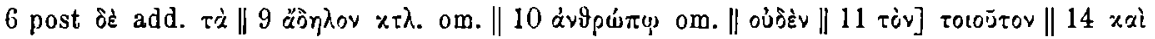

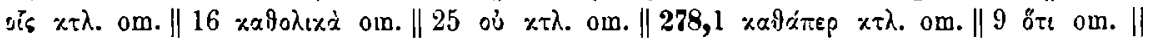

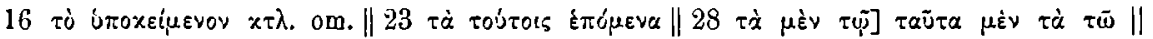
279,2 ởò

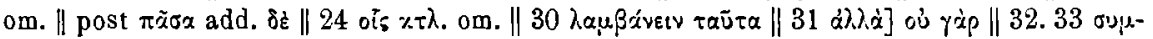

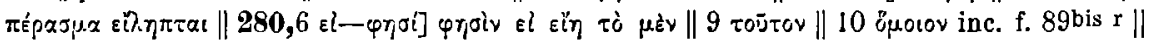

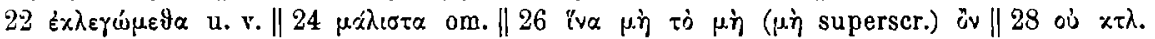

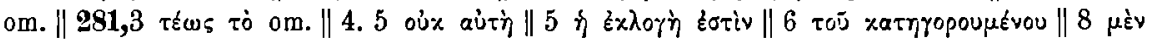
om. || 19. $20 \pi \dot{\lambda} \lambda$ เv-

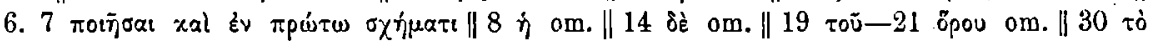

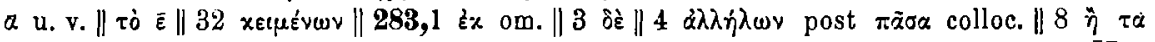

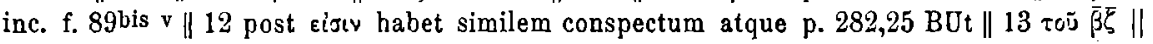

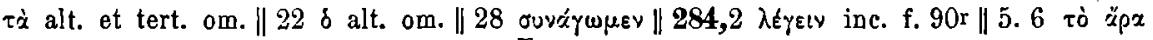

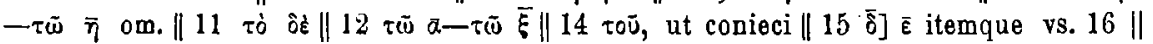

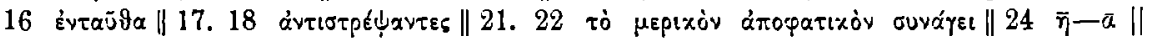

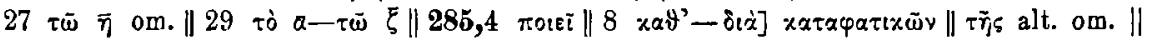

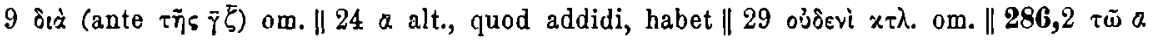

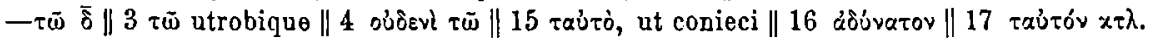

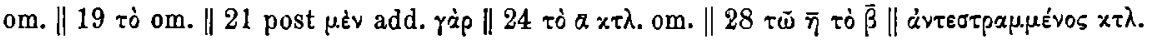

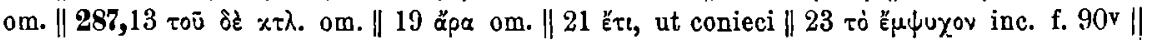

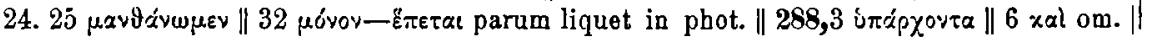

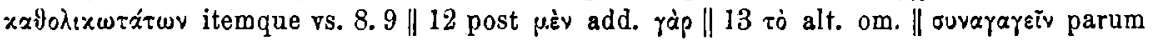

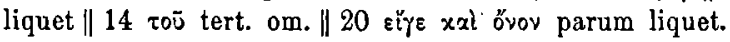

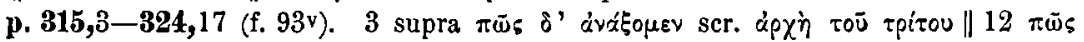

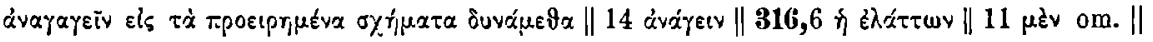

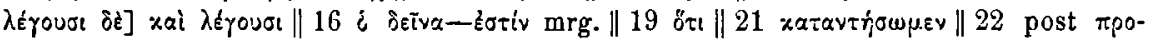

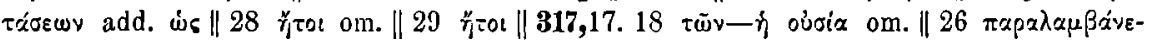

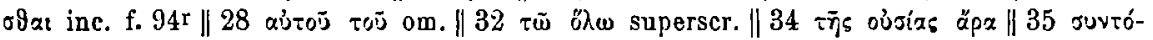

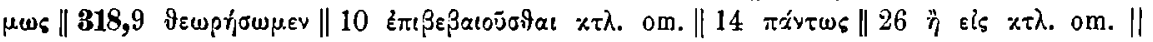

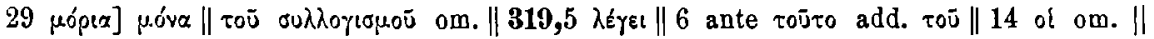

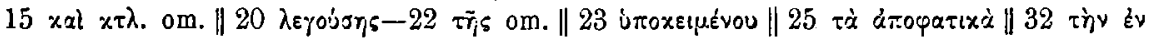

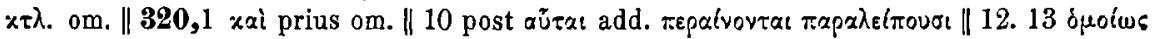

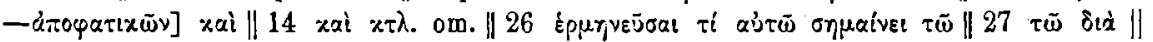

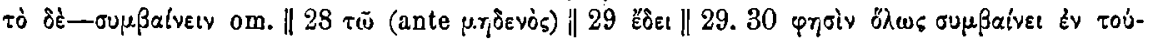

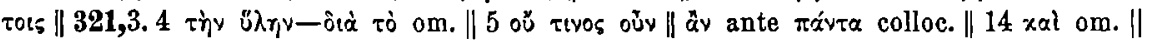

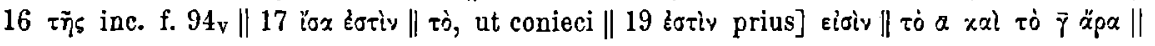




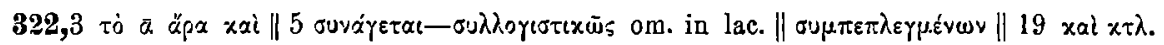

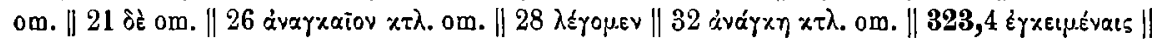

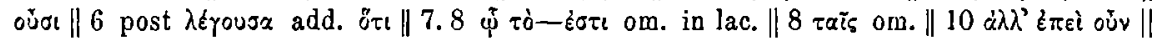

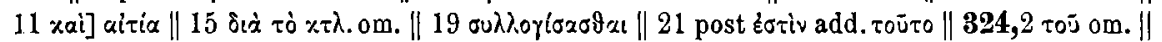

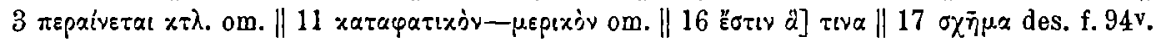

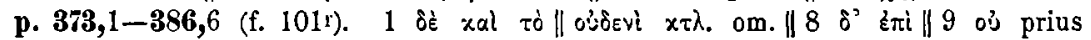

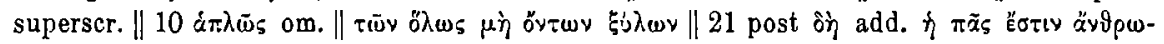

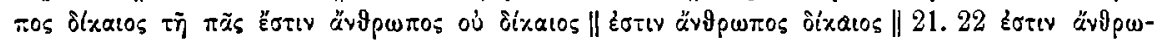

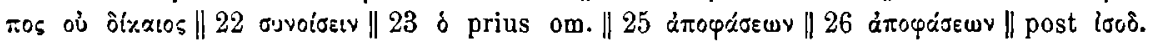

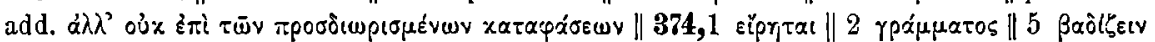

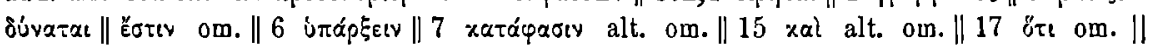

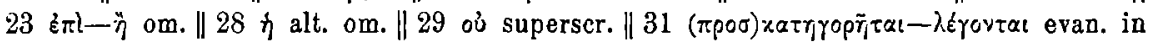

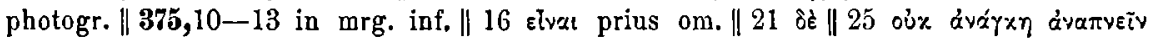

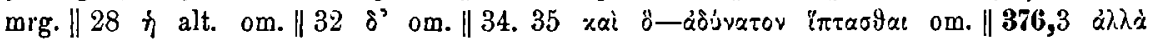

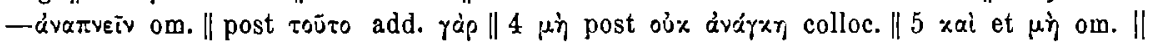

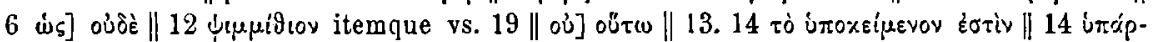

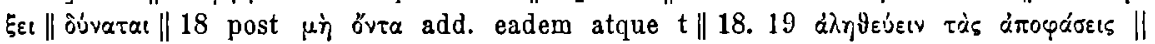

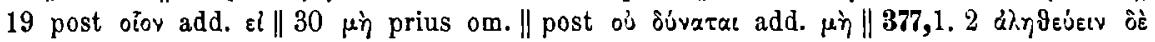

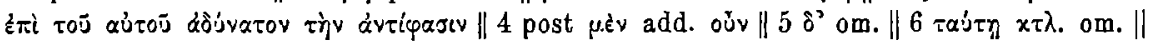

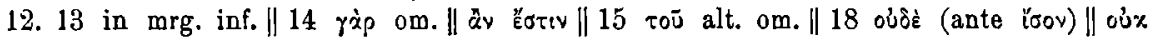
habet \| 22 iे ö $\lambda \omega \varsigma \| 24 \mu \varepsilon \delta \sigma o v$ inc. f. 101v || 25 fig. in mrg. inf. f. 101r, sed oblique scripta

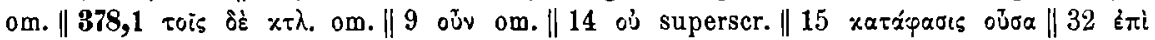

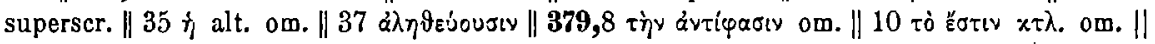

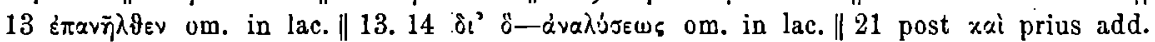

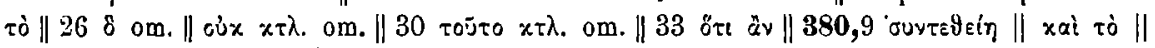

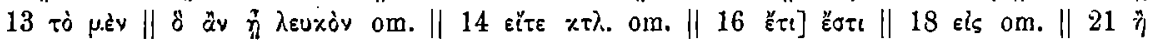

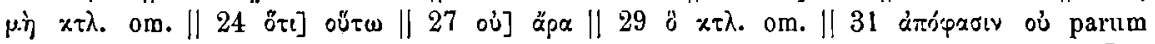

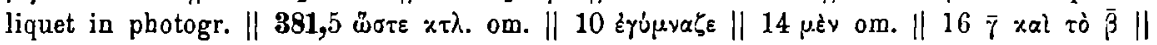

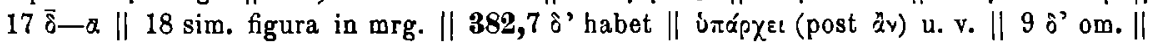

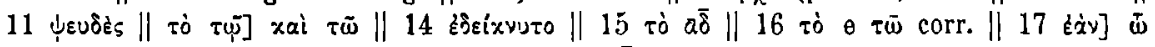

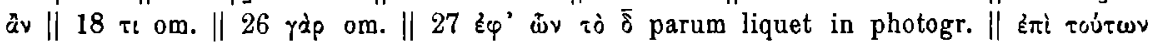

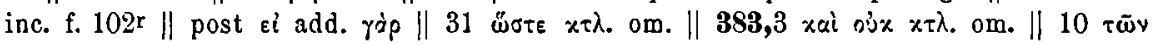

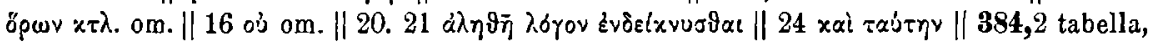

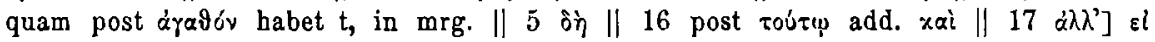

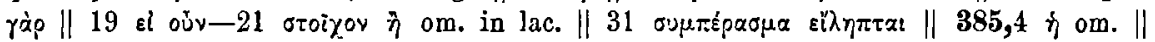

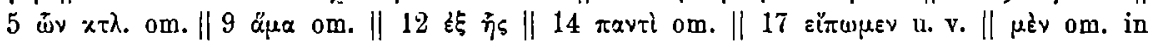

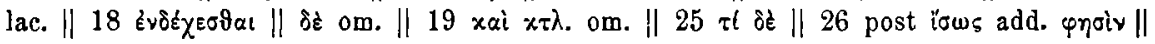

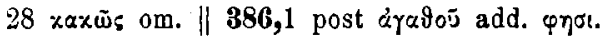

Escurtalensis $\Omega-I-4$ [Miller p. 456] chartaceus auno MDXVII in Creta exaratus, qui Philoponi in Analyt. Prior. libr. I commentarium continet, Torstrikio nullius pretii esse visus est.

Parisinus 1846 [H. Omont II 152] chartaceus saec. XIV secundum catalogum Analytica cum Ioannis Philoponi commentario continet. sed Philopono aliorum scholia admista sunt (cf. V. Rose Herm. II p. 208), eadem quae in cod. $Y$ inveniuntur (cf. vol. IV 6 p. XII). cui codicem simillimum esse et A. Torstrik e prooemio collato collegit et comprobatur iis quae H. Lebègue notavit, qui maiorem partem codicis examinavit. etiam numeri scholiorum iidem sunt atque in $\mathrm{Y}^{1}$ ).

1) Parisinus 1843 [H. Omont II 151] bombycinus saec. XIII f. 120-205 Analytica 
Parisinus 1911 [H. Omont II 162] chartaceus saec. XVI Philoponi in Analyt. Prior. commentarium continens et

Parisinus 1912 [H. Omont II 162] chartaceus saec. XV-XVI, cuius f. $1-48^{v}$ eiusdem in Anal. Prior. libr. II commentarium continent, Torstrikio nullius pretii esse visi sunt.

Parisinus 1917 [H. Omont II 162], olim Mediceus, bombycinus forma B

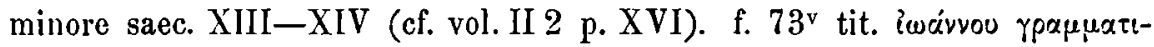

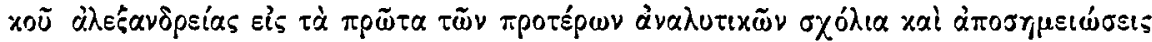

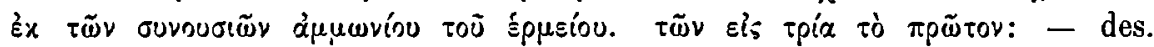
f. $182^{\text {r }}$. initium contulit H. Diels, inde a f. $98^{\mathrm{v}}$ (p. 119) omnia H. Lebègue.

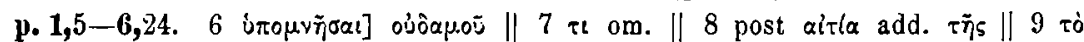

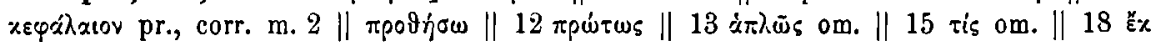

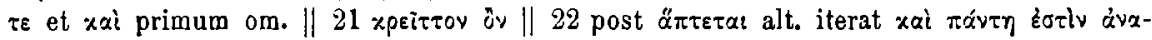

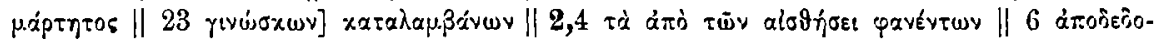

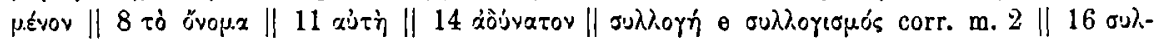

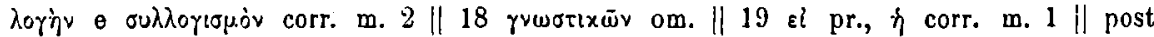

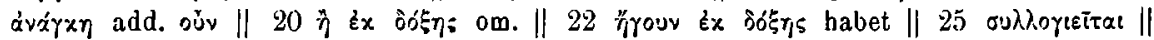

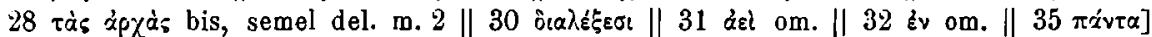

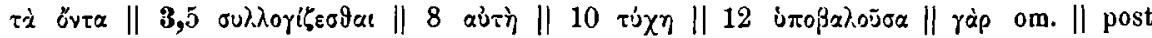

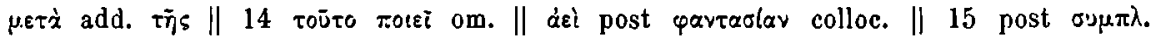

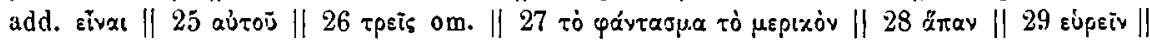

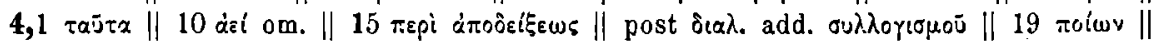

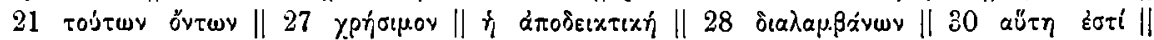

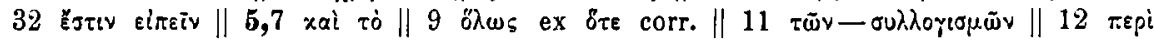

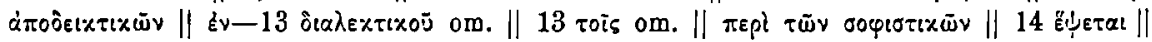

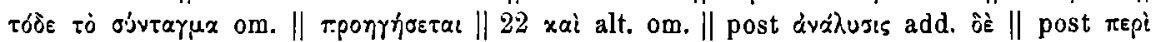

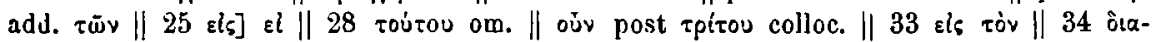

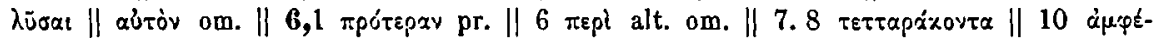

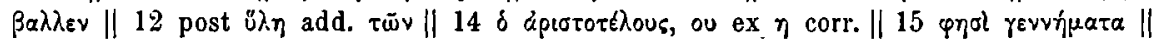

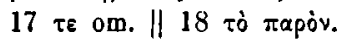

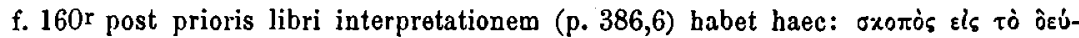

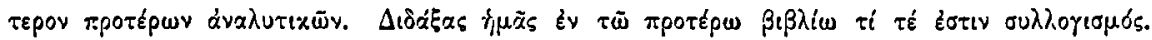

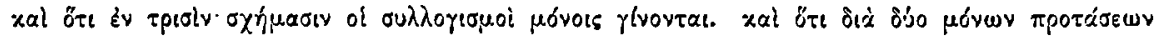

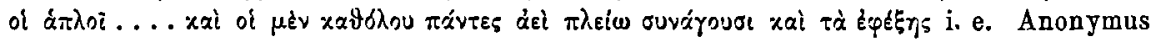
Brandisii Schol. p. 187a16-34.

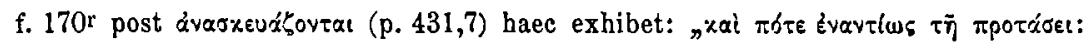

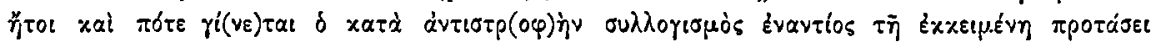

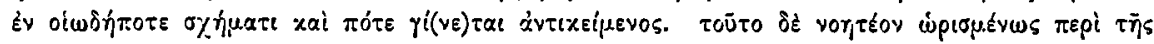

et Priora et Posteriora continet cum variis scholiis [cf. II 1 p. XI], inter quae etiam

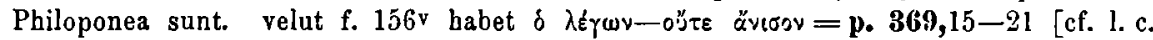

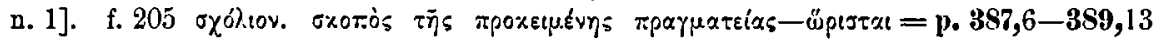

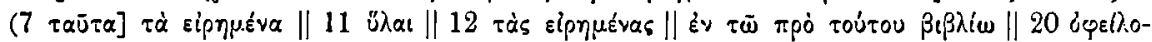

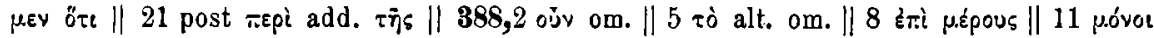

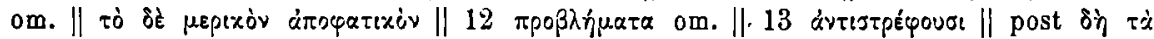

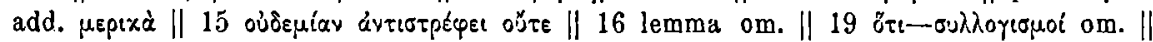

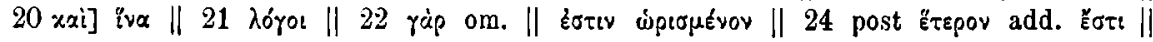

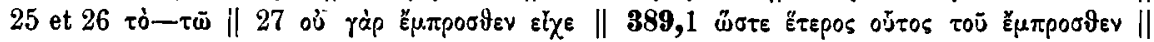

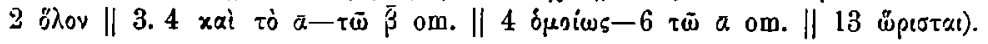




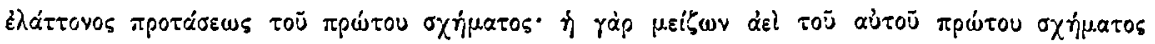

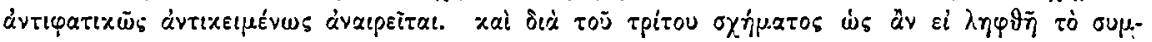

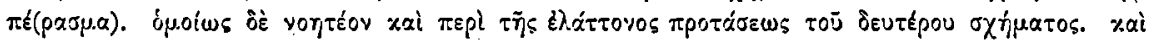

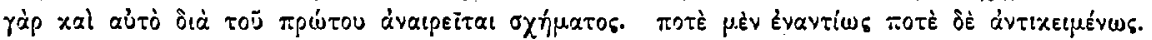

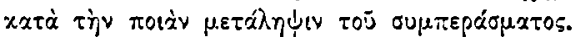

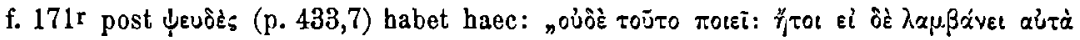

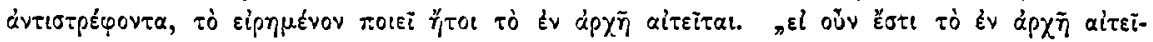

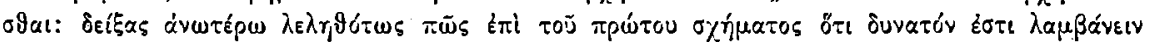

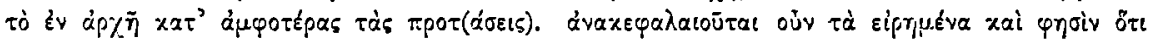

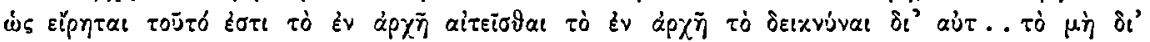

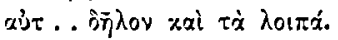

videntur haec e scholiis invasisse, quae multa, saepius à $\lambda . \lambda \omega \varsigma$ addito, adscripta sunt,

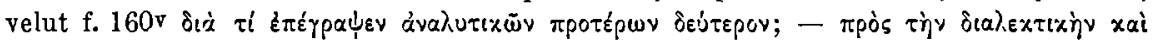

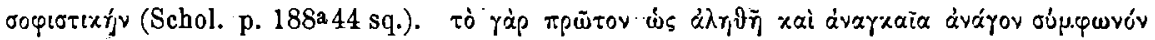

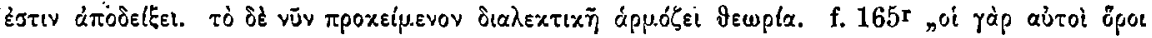

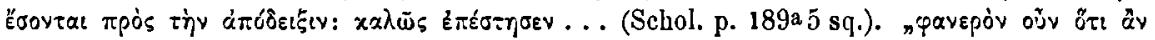

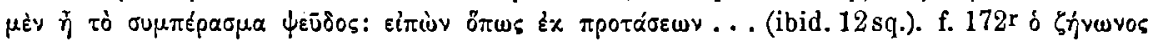

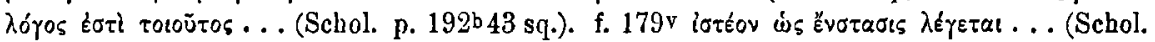
p. 195 a 9 cf. b 18 sq.).

Parisinus 1918 [H. Omont II 163] bombycinus saec. XIV foliorum 197. f. 112 secundum catalogum inc. Ioann. Philop. scholia in Aristotelis Prior. Analyt. librum II. f. $195^{\mathrm{v}}$ eiusdem scholia in hypotheticos syllogismos.

Parisitios 1972 [H. Omont II 173 cf. etiam vol. II 1 p. XIII, II 2 p. XL], olim Mediceus, bombycinus saec. XIII-XIV et qui ita cum eo E congruit, ut inde descriptus esse videatur, Corsurinianus 157 [H. Omont III 145] membraneus saec. XIV, ille f. $210^{r}-470^{r}$, hic f. $180^{r}-362^{r}$ Analyt. et Priora et Posteriora cum variis scholiis continent, quorum primuin f. $210^{r}$

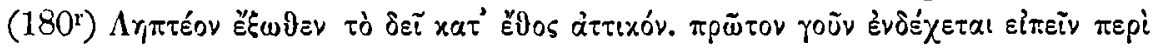

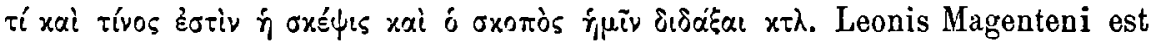

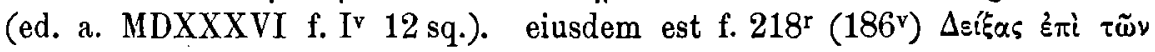

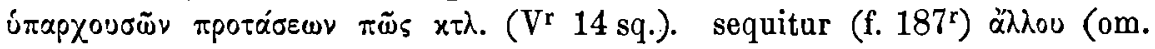

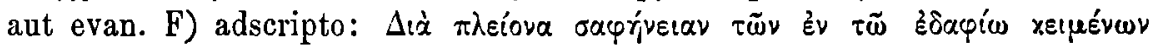

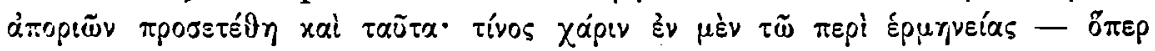

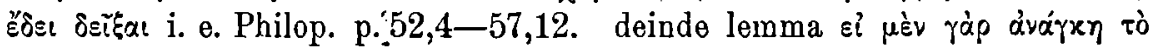
$\tau \lambda^{\prime}$

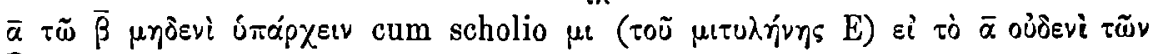

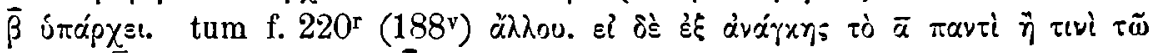

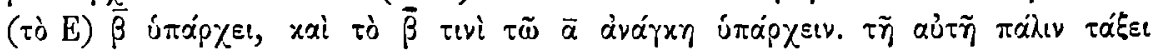

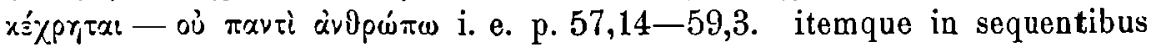
usque ad f. $223^{r}\left(191^{v}\right)$ Magenteni et Philoponi scholia (p. 59,4-64,7) alternant. reliquam Analyticorum Priorum partem Philoponi scholiis carere neque usquam notam ă $\lambda \lambda$ ou deprehendi testatur H. Diels, qui Philoponea contulit. ${ }^{2}$ )

1) de Parisino 1974 saec. XV [Q. Omont II 173], qui f. 138r-145r initium commen-

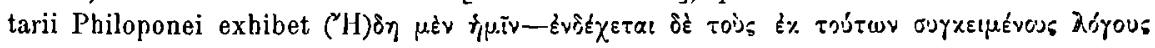
Toذ: p..̀े (p. 14,21), cf. vol. IV 6 p. V. 
Parisinus 2054 [H. Omont II 185] bombycinus saec. XIV-XV folio- S

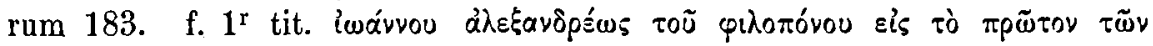

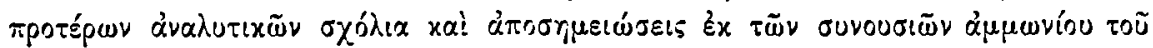

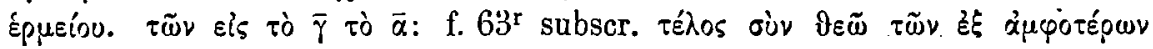

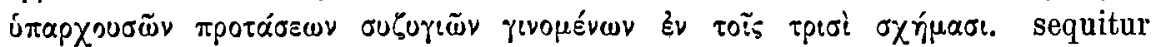

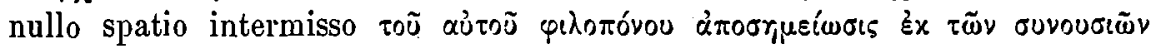

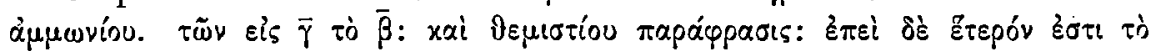

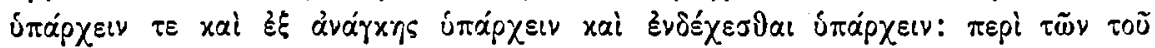

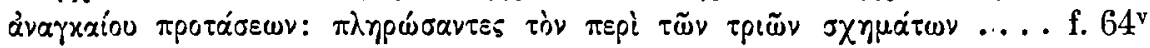

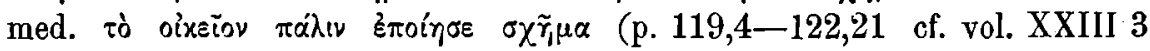

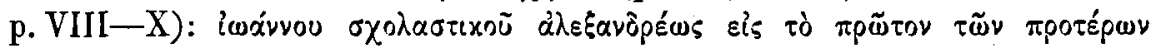

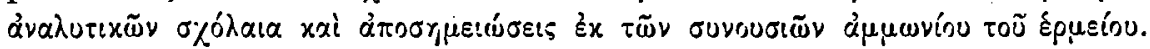

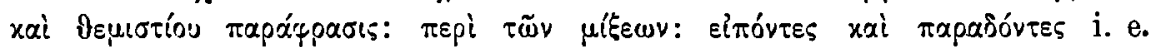
[Themistii] paraphrasis ex Alexandri et Philoponi in Analyt. Prior. I commentariis conflata, quam ex hoc codice (P) ab Ernesto Maass descriptam edidi vol. XXIII 3. cf. Valentini Rose commentationem Über eine angebliche Paraphrase des Themistius (Herm. II 191-213).

Parisinus 2062 [H. Omont II 186] chartaceus saec. XIV f. 58 $-81^{\mathrm{r}}$, quorum f. $58^{\mathrm{r}}-62^{\mathrm{v}}$ xai ă $\lambda \lambda \omega \varsigma$ oủx Ěv (p. 418,32) alia manu minus eleganter scripta esse Torstrikius notavit, Philoponi in Analyt. Priorum II commentarium continet. inferiores omnium foliorum partes humore confectae sunt. anonymi vero "scholia in varia Analyticorum Priorum loca" (f. 143), inter quae, si quidem ex 'initio colligere licet ab H. Omont notato, Philoponea quoque sunt, omnino vix legi possunt. specimen praebuit $H$. Lebègue:

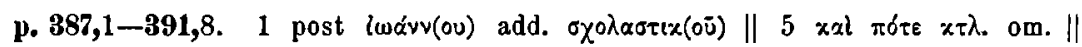

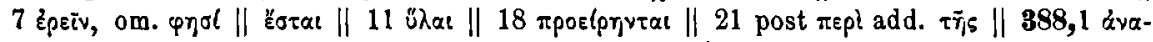

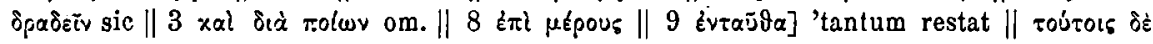

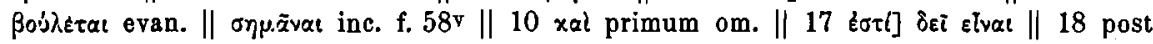

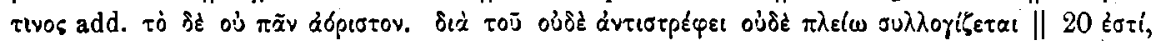

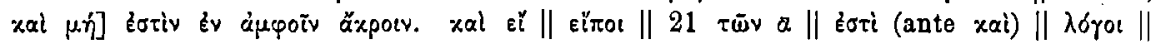

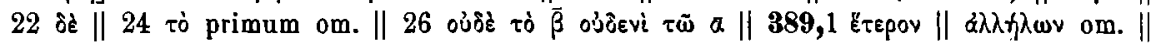

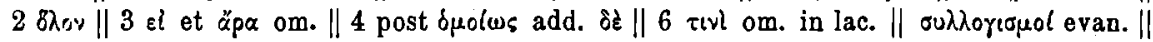

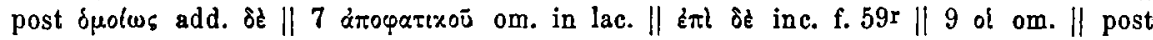

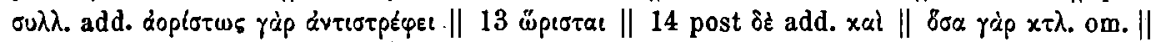

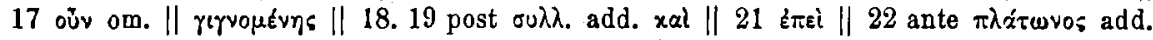

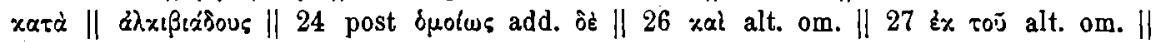

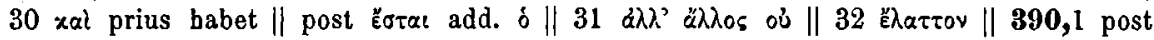

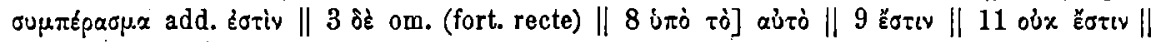

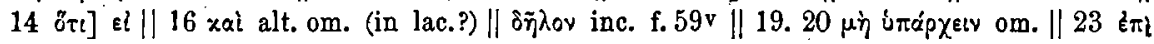

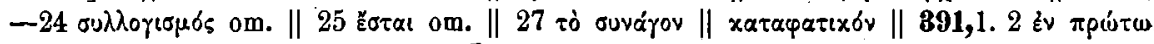

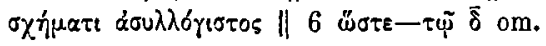

Parisinus 2064 [H. Omont II 186] membranaceus forma minore saec. $\mathrm{P}$ $\mathrm{X}-\mathrm{XI}$ post Ammonii in Anal. Prior. I commentarium (cf. vol. IV 6 Praef.)

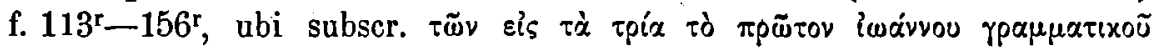

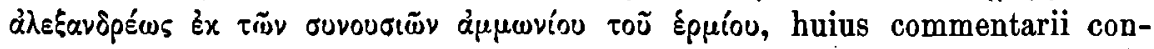

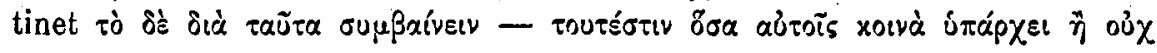




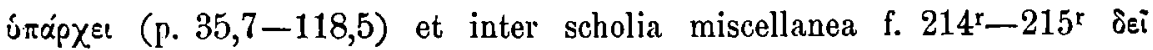

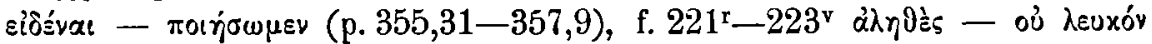

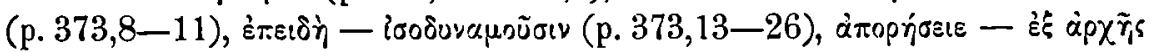
(p. 374,3-377,4). transscripserunt codicem anno 1884 E. Richter et P. Hirt, quorum exemplaria denuo contulit de Boor. ef. quae de hoc codice notata sunt vol. IV 5 p. XXIII n. 2, IV 6 p. XII, XVIII 3 p. VII.

A Coislinianus 160 [H. Omont III 146] bombycinus forma media saec.

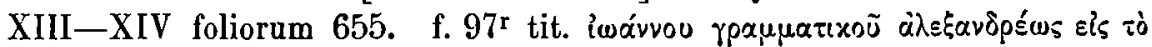

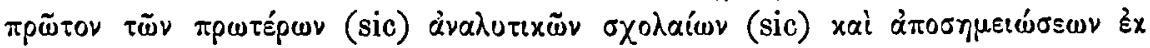

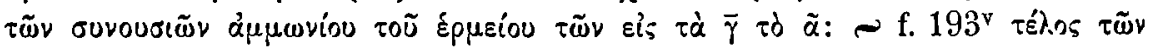

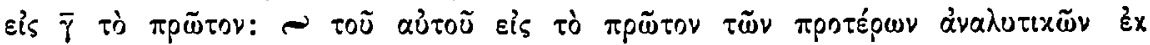

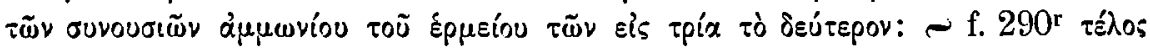

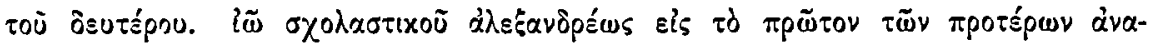

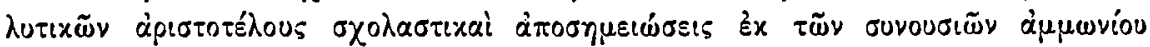

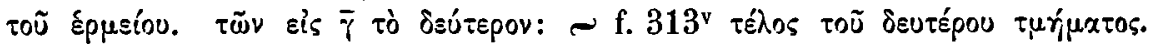

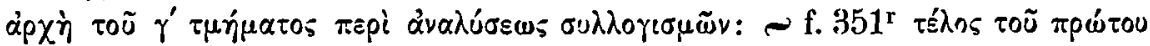

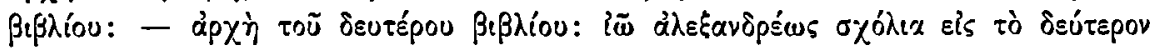

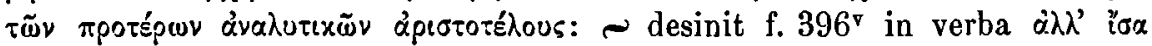

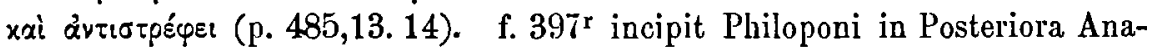
lytica commentarium. initium contulit $H$. Diels, reliqua ipse contuli :

p. 1,5-6,24 (quae iuxta margines legi non possunt, uncis inclusimus). 7 ( $\varepsilon$ ) $\|$

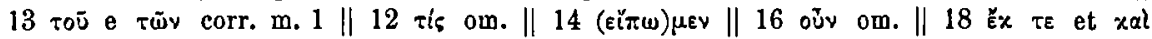

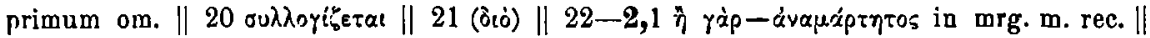

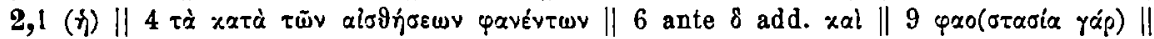

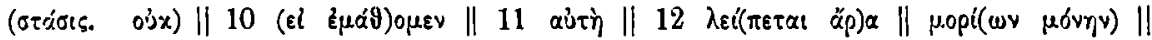

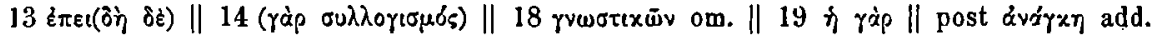

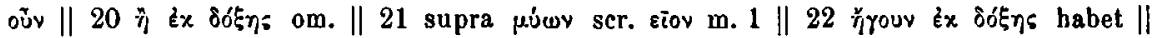

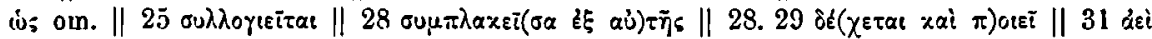

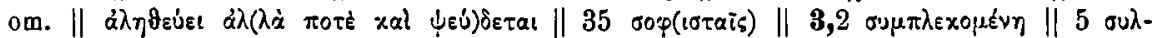

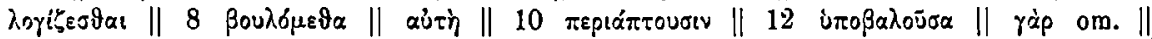

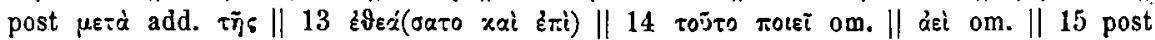

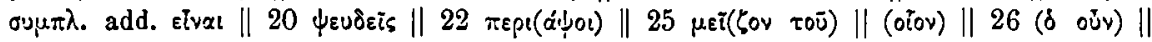

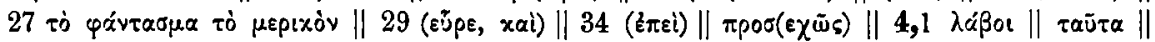

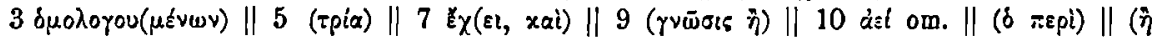
ȧkl

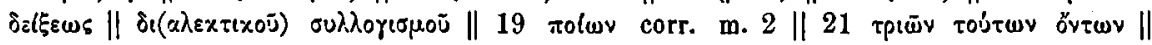

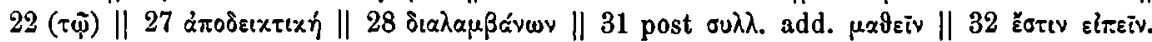

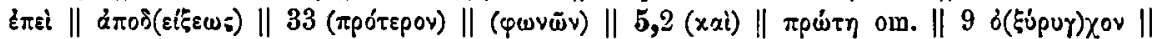

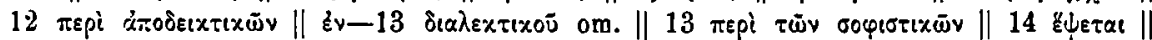

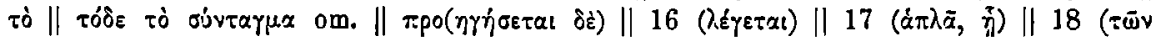

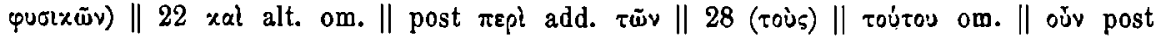

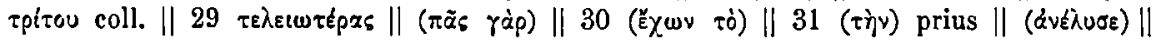

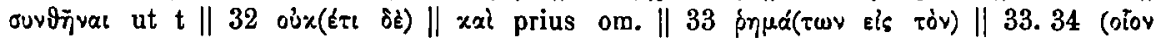

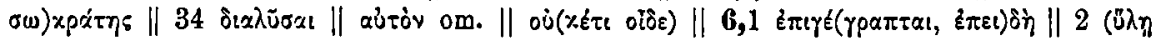

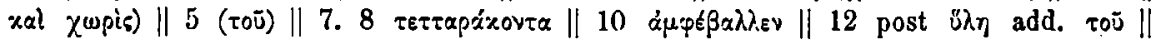

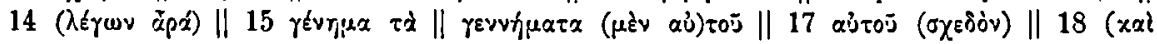

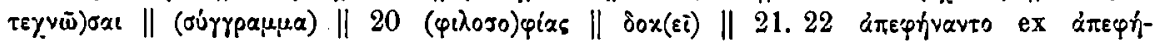
vovto corr. || 


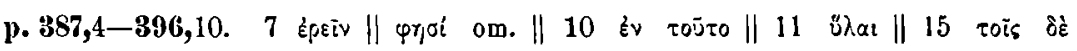

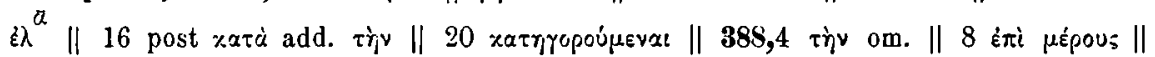

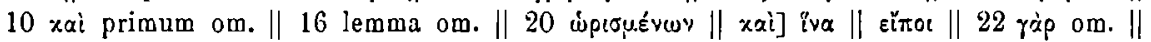

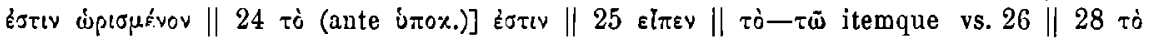

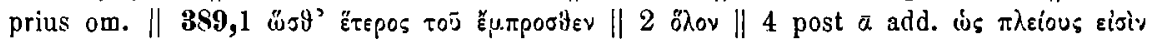

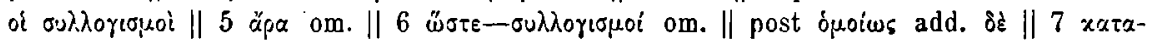

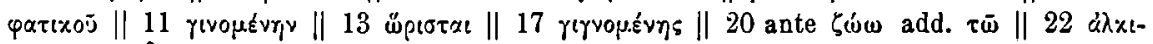

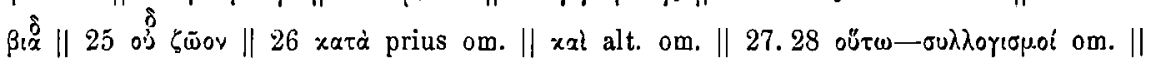

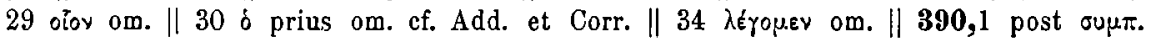

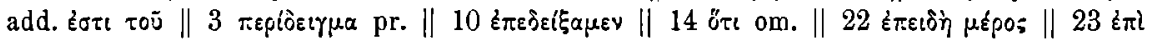

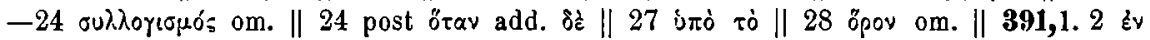

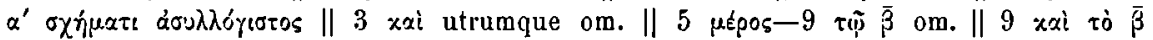

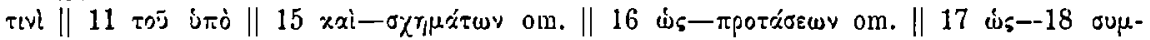

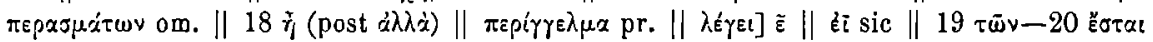

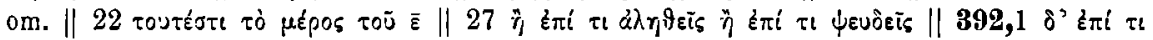

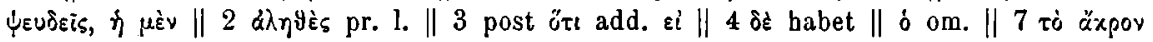

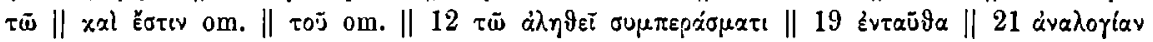

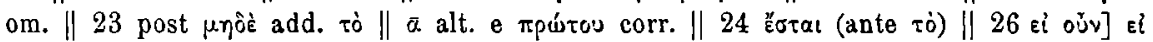

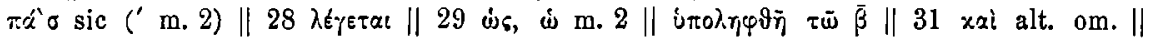

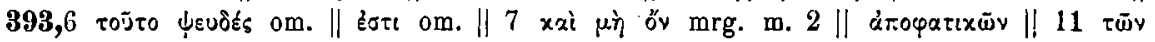

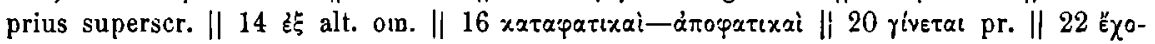

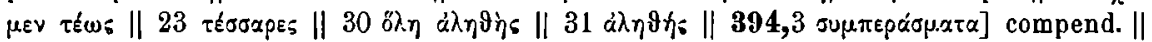

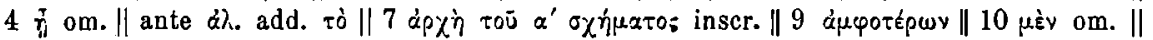

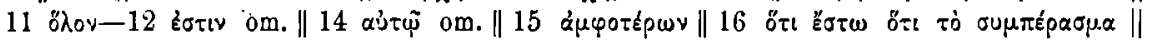

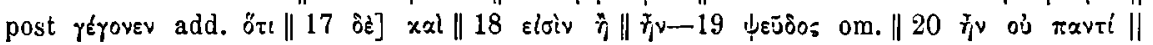

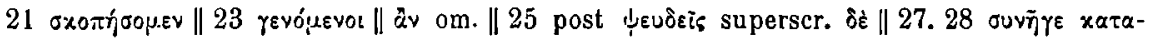

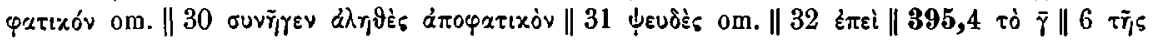

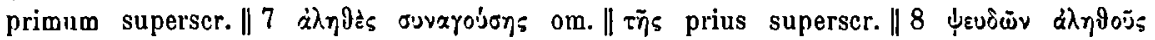

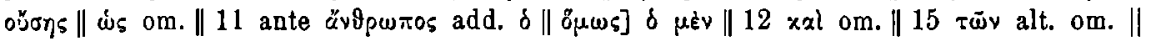

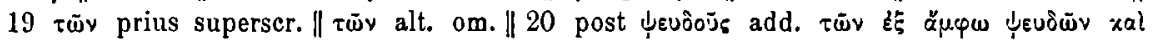

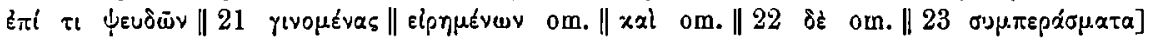

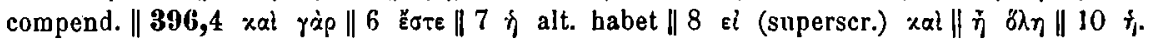

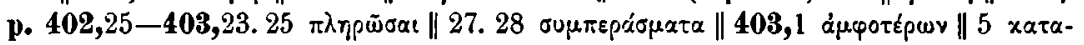

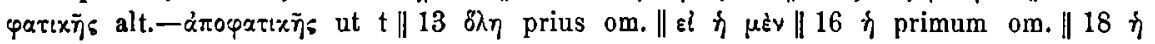

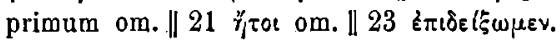

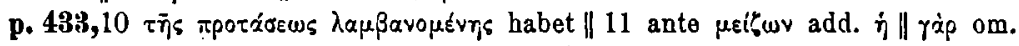

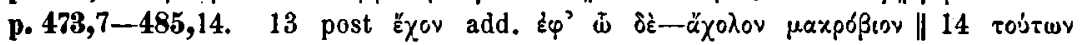

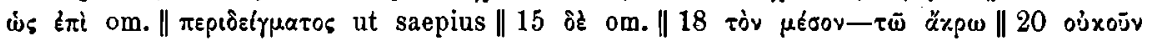

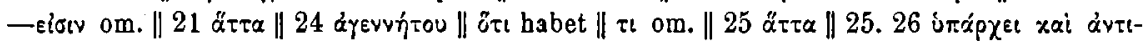

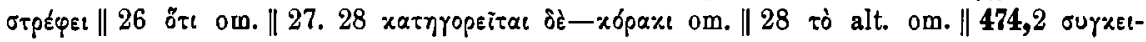

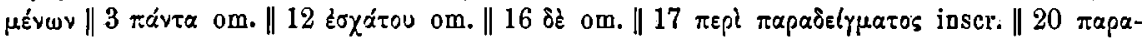

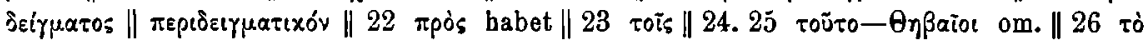

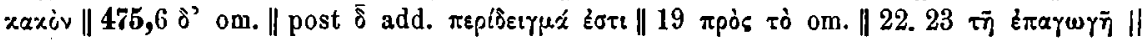

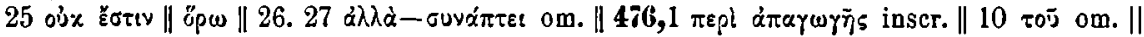

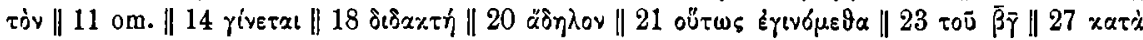

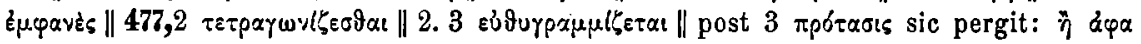

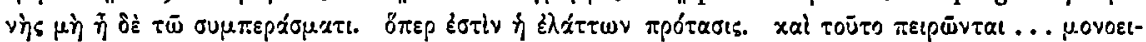

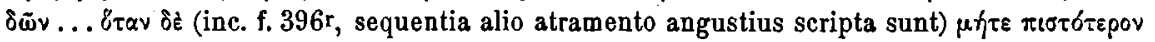

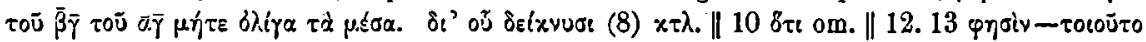

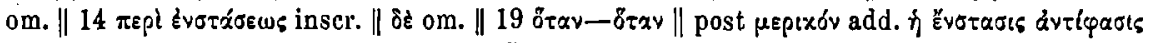

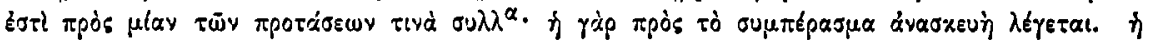




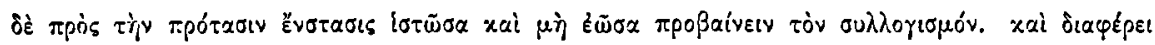

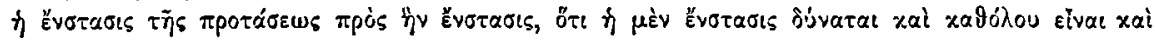

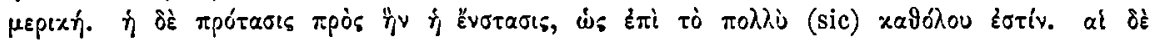

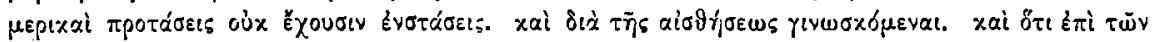

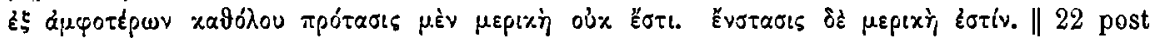

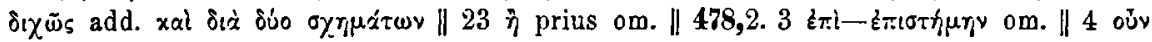

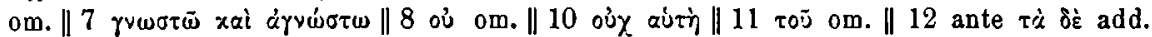

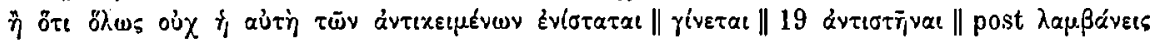

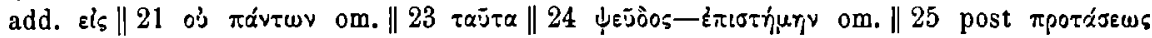

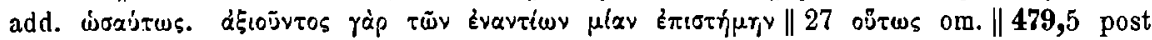

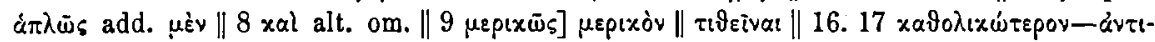

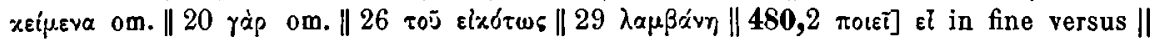

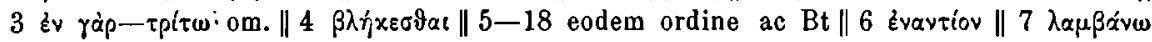

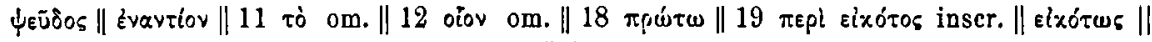

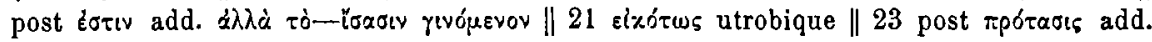

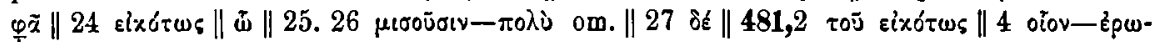

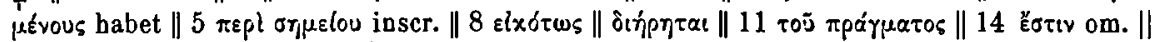

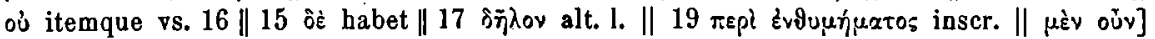

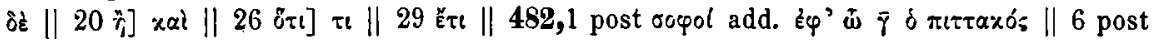

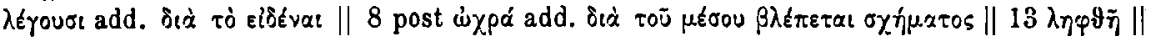

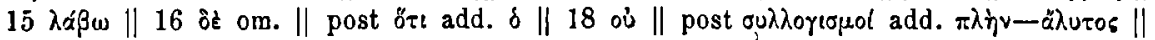

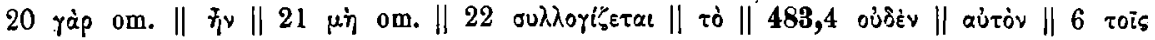

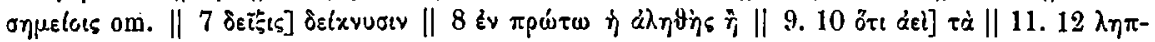

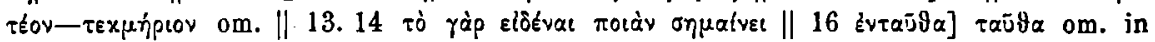

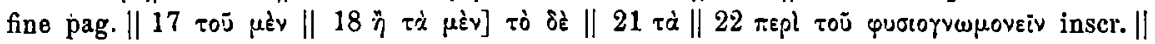

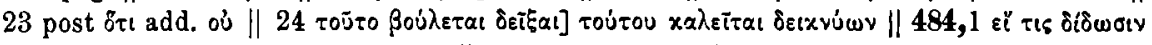

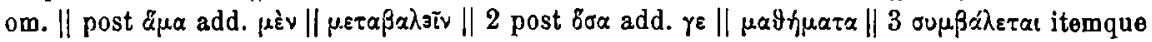

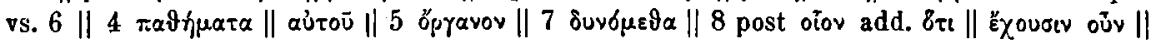

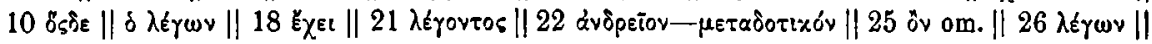

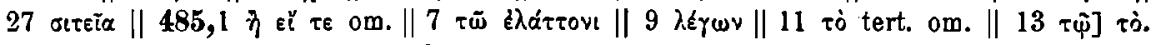

Parisinus Suppl. gr. 687 [H. Omont III 299]. saec. XII f. 3-6, 8-9 membranea, quae secundum catalogum fragmentum commentarii in logicam Aristotelis continent, ad Philoponum pertinere vidit K. Kalbfleisch [Herm. XXX 632]. foliorum ordo turbatus est. nam f. 3 inc. ... $\omega \nu \pi \rho \circ \beta \lambda \eta \mu(\alpha ́ \tau \omega \nu)$

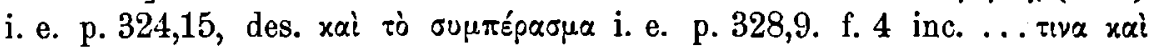

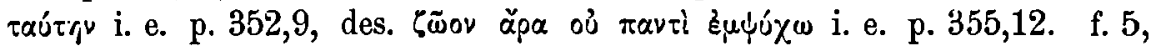

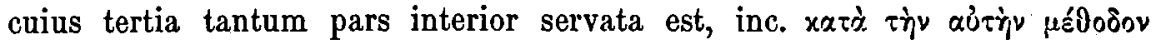

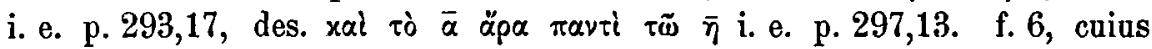
e f. r. initia, e f. v. extrema tantum versuum verba servata sunt, inc.

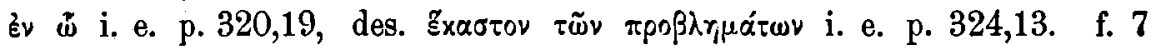
papyraceum a bibliopega insertum vacuum est. f. 8 , cuius summus versus

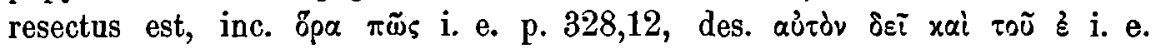

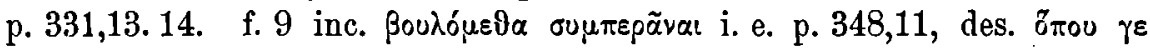

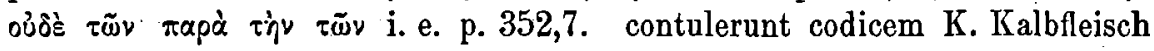
et C. E. Ruelle, qui etiam scholiorum specimen dedit:

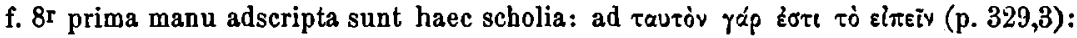

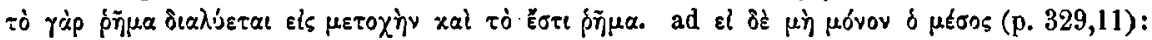

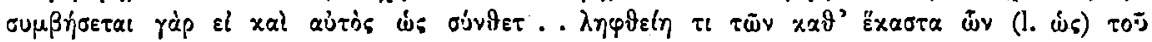

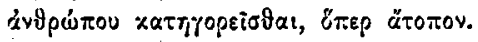




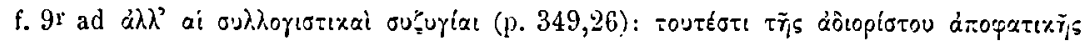

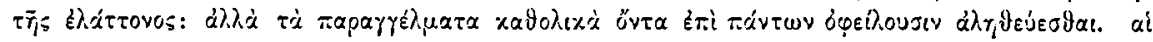

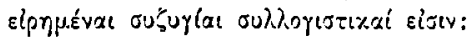

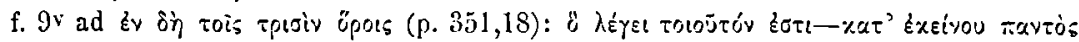

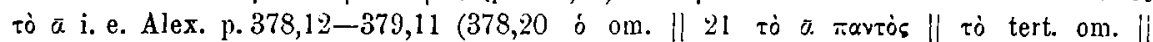

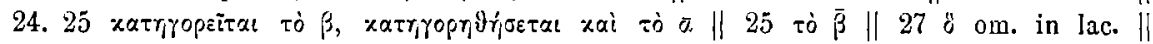

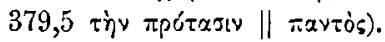

f. $4^{\mathrm{r} .} \mathrm{v}$ textui eadem manu insertas figuras habet similes atque $t \mathrm{f}$. LXXXVIr et I.XXXVIIr.

Parisinus Suppl. gr. 1156 [H. Omont III Add. 400] membr. saec. XII MI

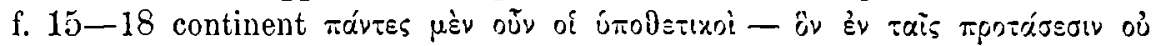

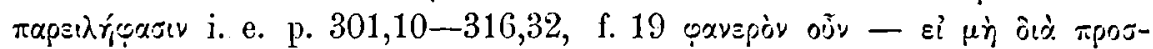

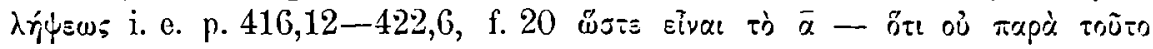

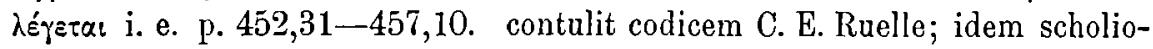
rum specimen praebuit:

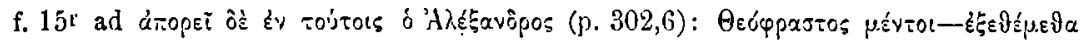

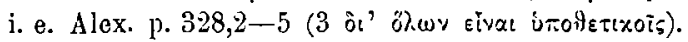

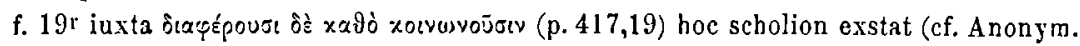

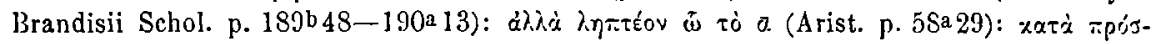

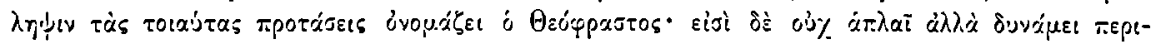

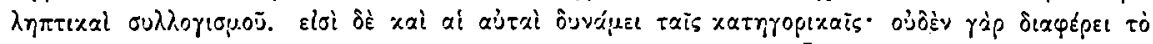

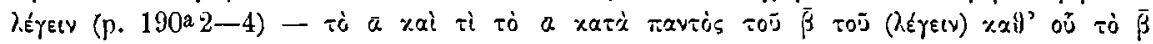

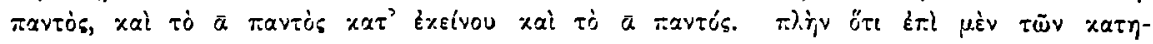

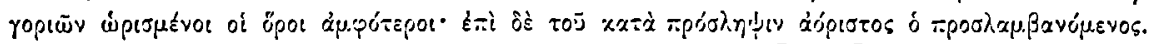

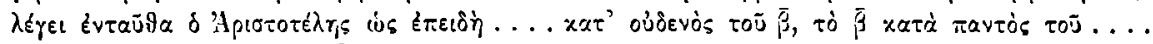

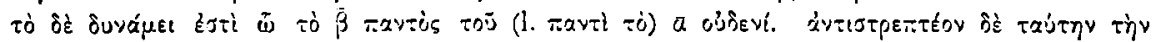

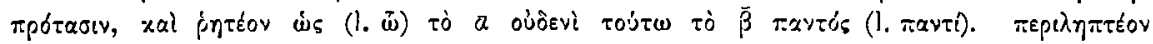

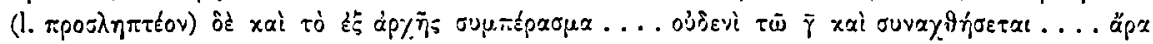

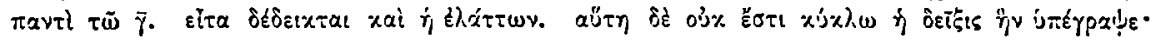

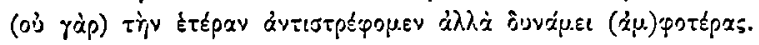

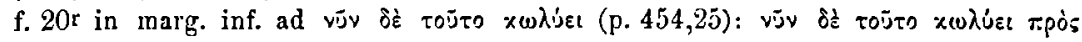

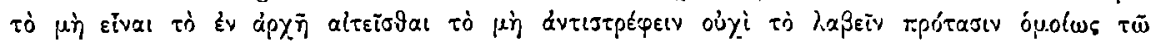

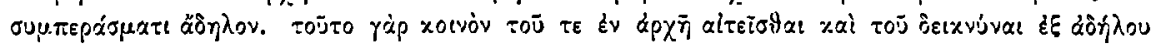

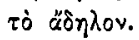

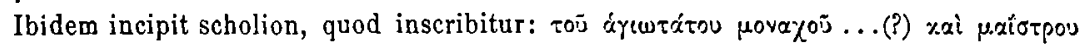

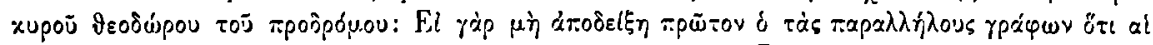

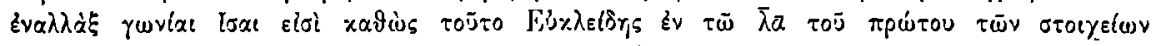

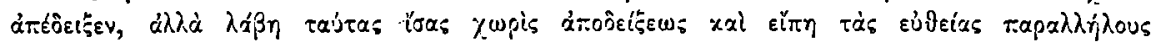

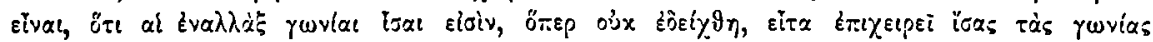

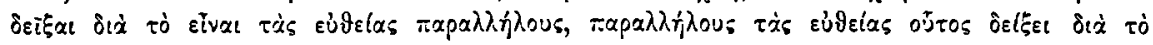

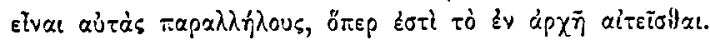

f. $20^{\mathrm{v}}$ omnes margines occupat scholion (saec. XIII-XIV) partim evanidum, cuius

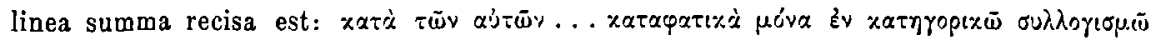

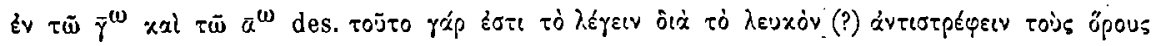

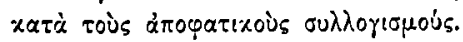

f. 15r (man. 2?), 18v (man. 2?), 20r (man. 1) in mrg. figurae syllogisticae appictae sunt.

Baroccianus 155 [Coxe I 265] chartaceus saec. XV foliorum 416, qui

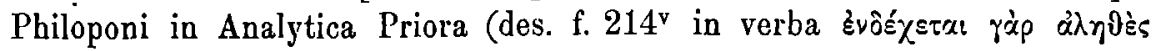

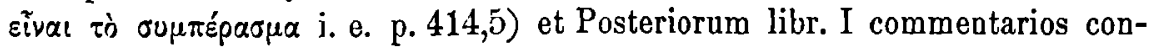


tinet, a Torstrikio nullius pretii indicatus est; nam commentarium in Anal. Pr. I mendosissime scriptum et lacunosum esse, in libr. II (inc. f. 202r) cod. U

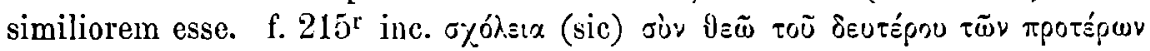

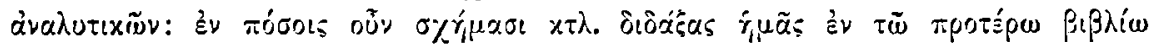
i. e. Anonymus Brandisii Schol. 1. $187^{a} 16 \mathrm{sq}$.

Oxoniensis Collegii Novi 236 [Coxe I 86] chartaceus saec. XVI foliorum 394 Philoponi in Analytica Priora et librum I Posteriorum commentaria continet. in extremo libro I Analyt. Prior. nonnulla ex alio exemplo, quod Év

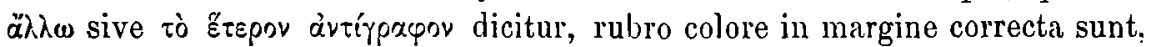

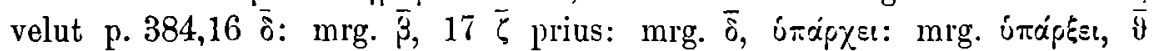

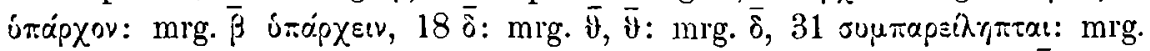

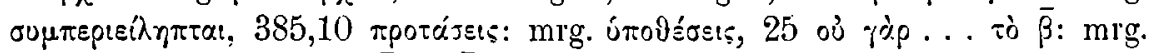

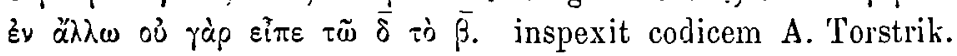

Vindobonensis phil. gr. 41 [Nessel p. 28. 29] chartaceus saec. XV. f. 23r

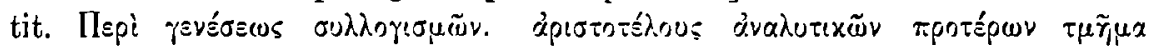

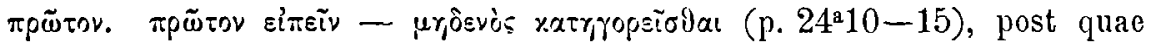

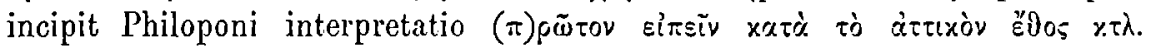

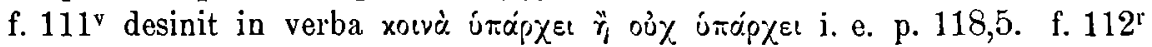

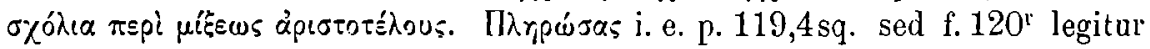

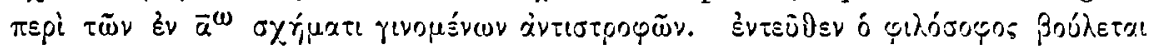

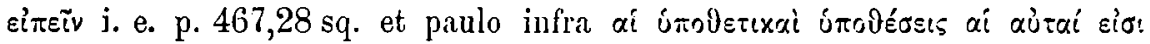

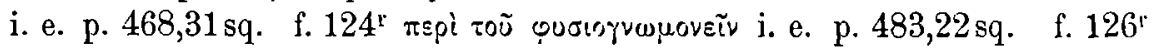

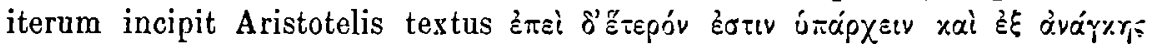
úxápxstv i. e. c. 8 p. $29^{\mathrm{b}} 29 \mathrm{sq}$. cum notis interlinearibus et marginalibus

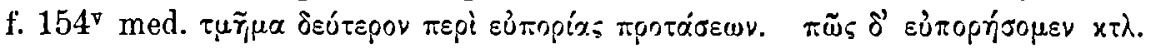

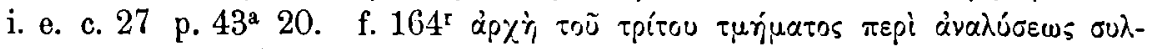

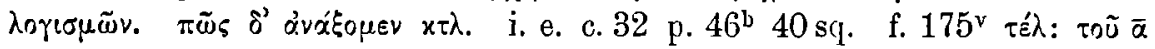

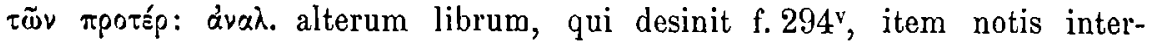
linearibus et marginalibus ornatum esse A. Torstrik testatur. ex is quae excerpsi hoc specimen propono:

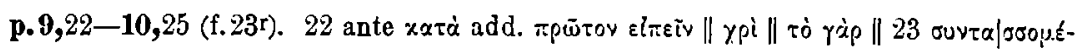

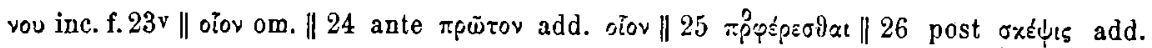

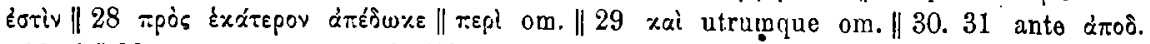

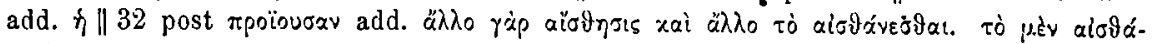

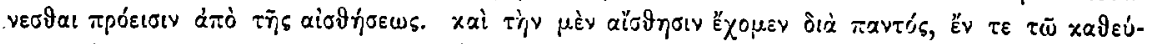

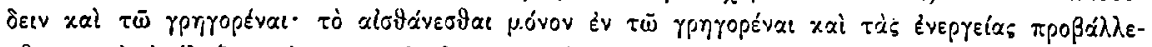

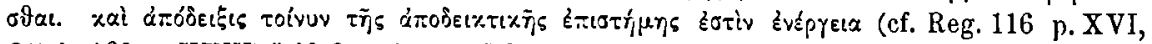

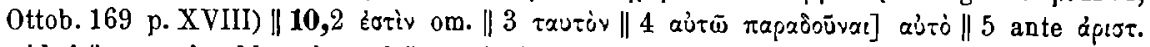

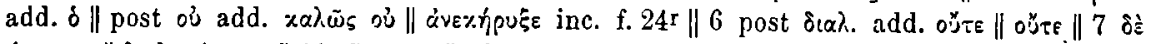

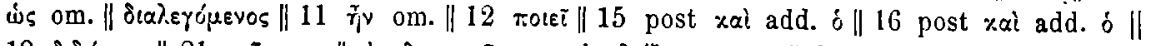

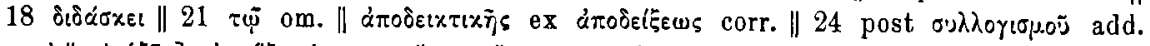

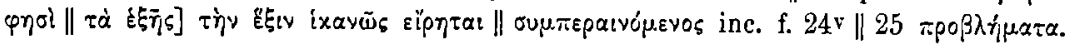

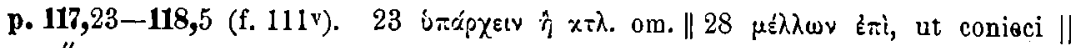

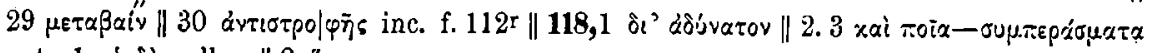
ante 1 of $\delta$ celloc. $\| 2$ Ëxastos. 
Vindononensis phil. gr. 139 [Nessel p. 79. 80] chartaceus saec. XIV post Alexandri in Anal. Prior. commentarii prooemium f. $150^{\mathrm{v}}-151^{\mathrm{v}}$

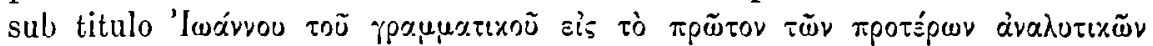

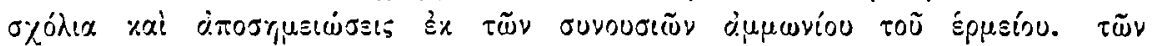

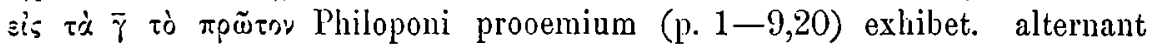

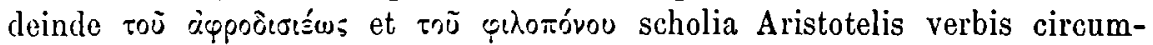

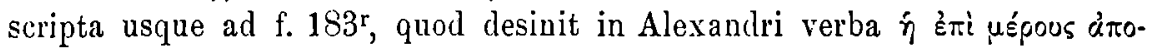

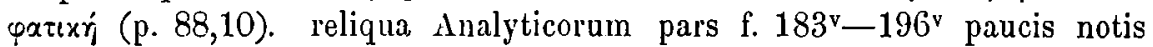
marginalibus exceptis scholiis caret (cf. vol. II 1 p. XIII). initium prooemii ipse contuli, initium interpretationis contulit II. Diels:

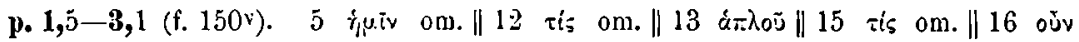
oin. \| rvíos

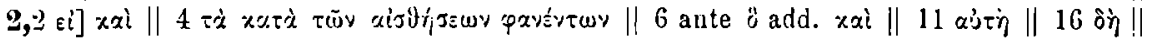

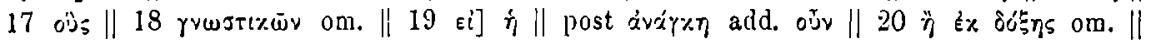

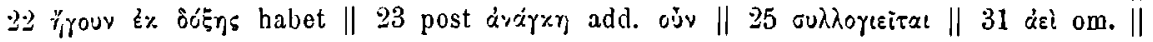

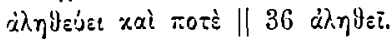

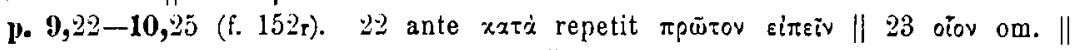

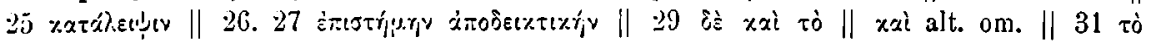

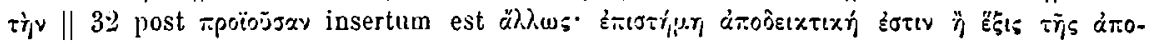

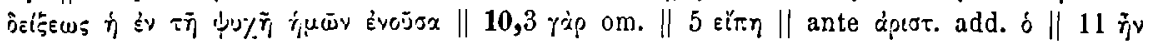

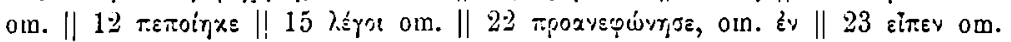

Monacensis August. 406 [Hardt IV 253] chartaceus saec. XVI folio-

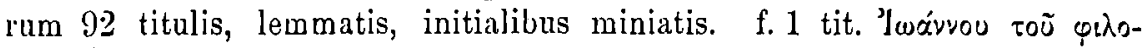

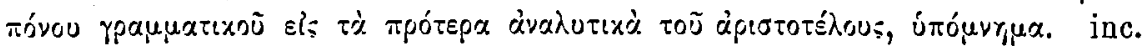

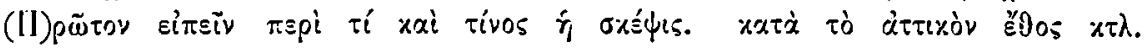
(p. 9,21 sq.). initium contulit H. Diels, reliqua ipse notavi.

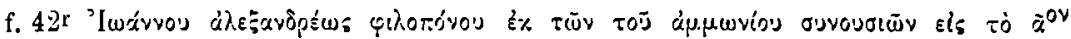

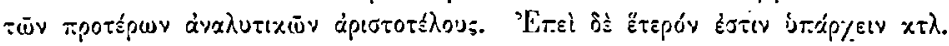

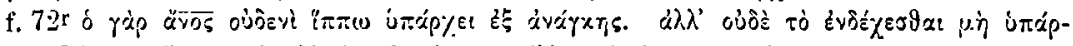

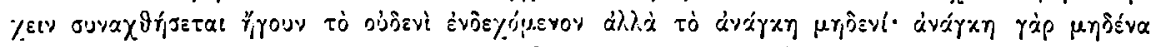

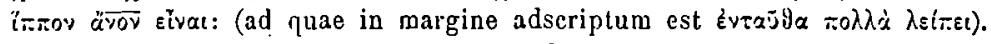

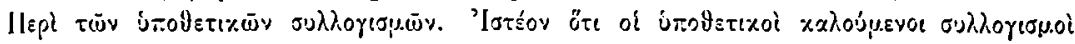

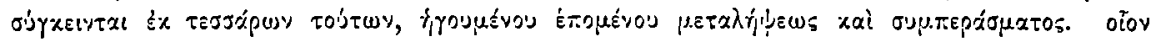

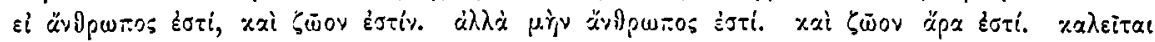

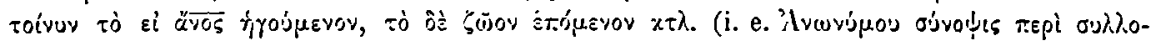
үเ

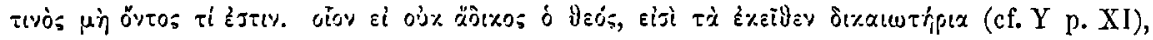

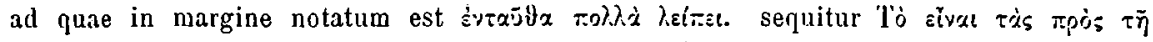

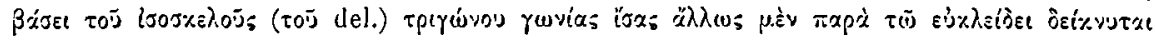

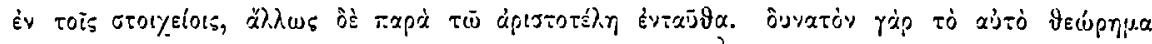
Stapóp

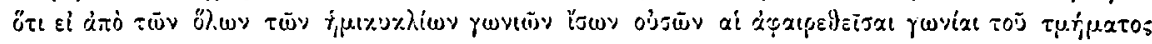

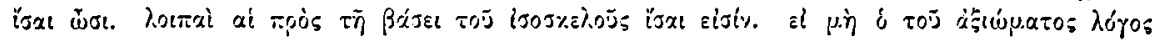

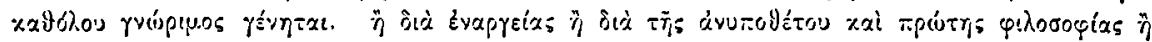

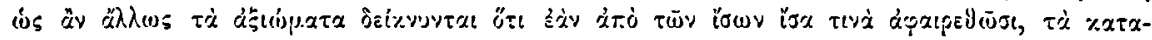

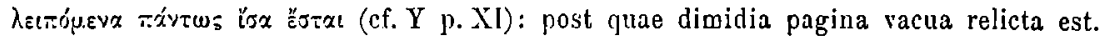

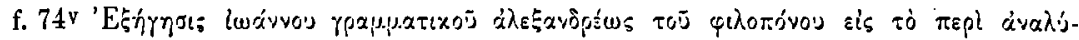

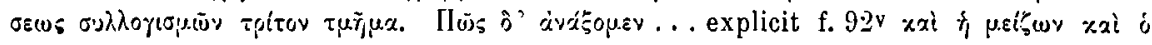

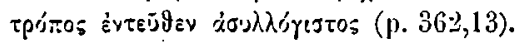


p. 9,21-10,25, 315,3-316,17, 361,14-362,13 paene omnia cum Y concinunt, a quo haec tantum discrepant: 9,30 ante dirśses

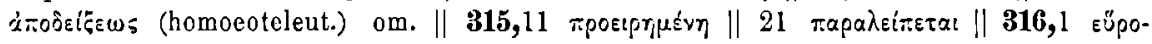

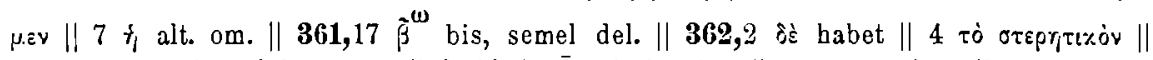

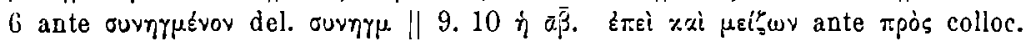

Phillipsianus 1512 [= 199 Meerman. $=256$ Clarom. $=101$ Pelic. $]$ chartaceus saec. XVI foliorum 52, olim Claudii Nauloti, nunc in bibl. reg. Berolinensi [Verz. der von d. kgl. Bibl. z. Berl. eruorb. Meerman-Hss. des Sir Thom. Phillips p. 45 n. 108], f. 1-46 Philoponi in Analyticorum Priorum librum II commentarium continet. ipse codicem inspexi.

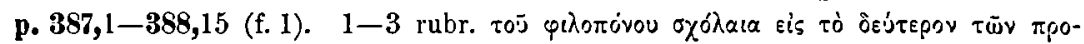

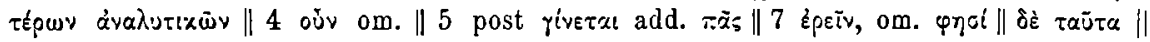

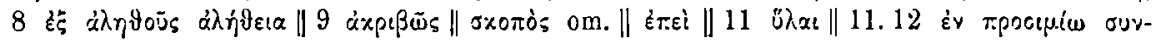

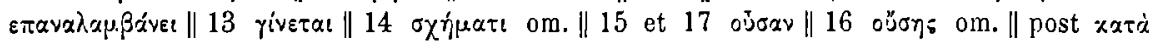

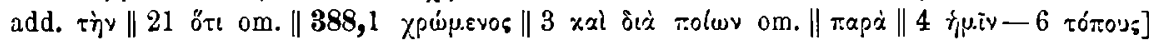

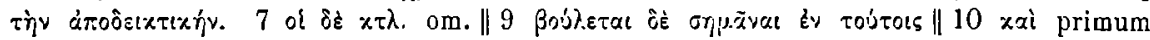

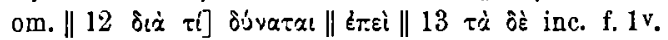

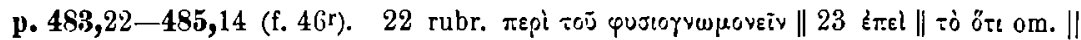

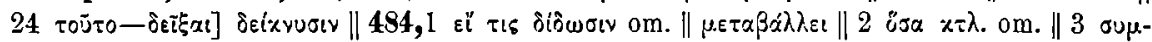

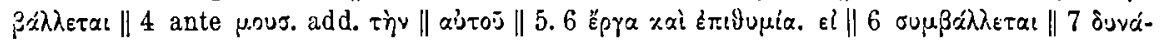

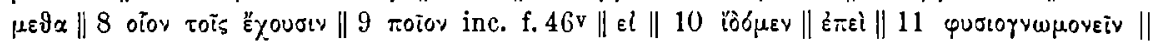

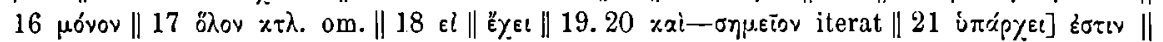

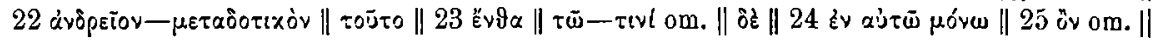

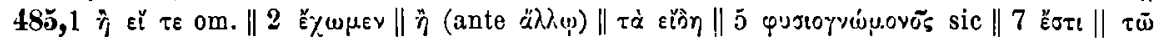

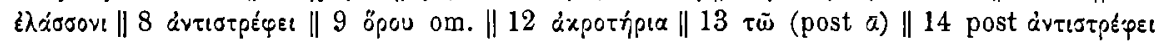

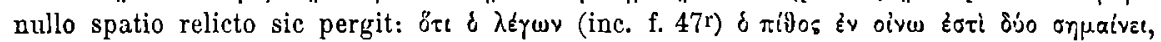

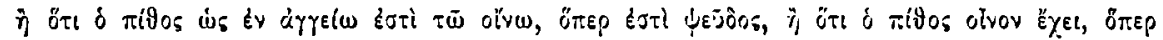

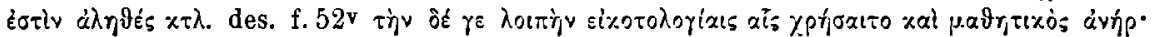

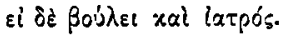

$\mathrm{t}$ EDITIo PRINCEPS, quae prodiit Venetiis in aedibus Bartholomaei Zanetti Casterzagensis, aere vero, et diligentia Ioannis Francisci Trincaveli. Anno a partu virginis. MDXXXVI. Mense Aprili, inscribitur ISANNOI ГPAM-

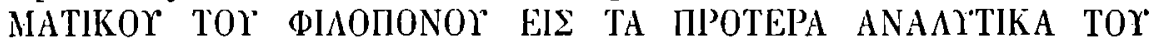

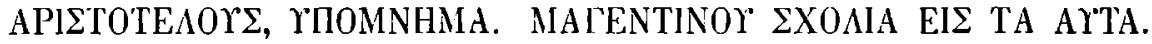

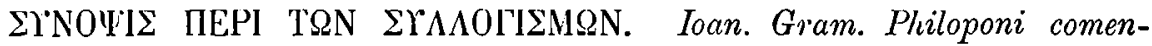
taria in Priora Analytica Aristotelis. Magentini comentaria in eadem. Libellus De syllogismis. f. II ${ }^{\mathrm{r}}$ epistula est: Herculi Gonzagae Cardinali maximo Victor Trincavellus. $F$. ex qua hace notentur:

Itaque cum his diebus Philoponi et Mayentini comentaria in priores analyticos Arist. libros a situ et squalore blactisque eruta, quibus iandiu obvoluta erant, opera nostra vindicata in lucem proditura essent, statui quicquid studii diligentiae et operae illis poliendis in. pendissem, tibi quam libentissime offerre...... Habes igitur Cardinalis amplissime horum praestantissimorum authorum uno veluti manipulo comprachensa comentaria, quibus illi, diversa tamen comentationis formula, aureum il et perelegans Aristotelis opus explicant. alter enim fusus est et in questionibus digressionibusque frequens, alter vero praessus et brevis, et veluti $\pi \propto \rho \propto \varphi \rho \alpha \sigma i \eta \dot{s . ~ q u i b u s ~ e t i a m ~ t e r t i o ~ l o c o ~ u t ~ u n u s q u i s q u e, ~ q u i ~ h a c ~ d i s c i p l i n a ~ d e l e c t u t u r, ~ s e m p e r ~}$ pro temporis et otii oportunitate habeat quo frui possit, libellum quendam incerti sed docti authoris de syllogismis, quo ille universam syllogismovum materiam in breve quoddam compen- 
dium et quandam reluli summam redigit, addidinus. quae omnia si in eam integrilatem et perfectionem, quam desideraban, reducere non potui, culpa exemplarium id evenit, quae lacera et vetustate, corrosa, vitioque temporum depravala habui, el quandogae unica. nam nulli (deum testor) industrie ac labori peperci, ut quond eius fieri possel meliora rederentur.

Tabellarum et schematum syllogisticorum, quae unulta editioni principi inserta esse supri (p. VII n. 2) dixi, haec exempla proponantur:

f. XIIv
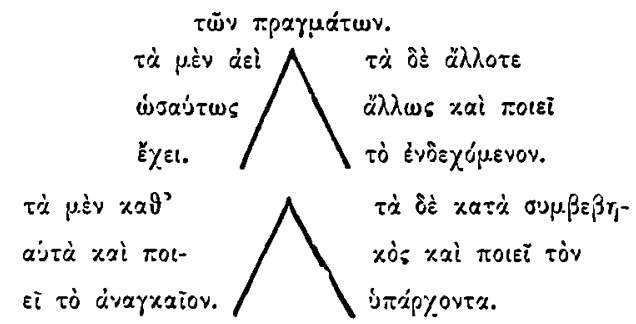

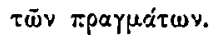
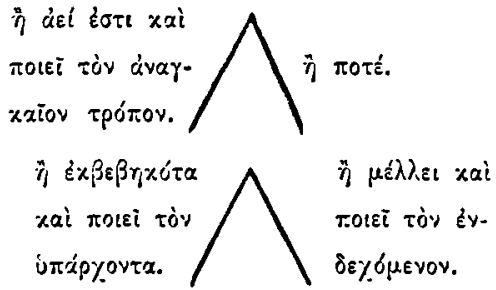

f. $X I r$

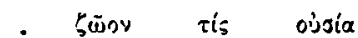
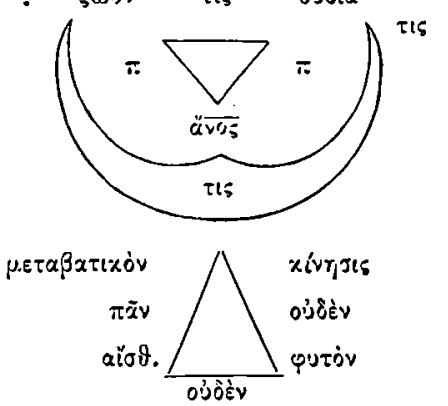

Hinc Chr. Brandis a. 1836 in volumine Scholiorum p. 141-195 multa b excerpta "ad cod. Coislin. 160 et Reg. Paris. 1917 passim collata", sed plerumque immutata edidit. quae correxit littera b signavi.

Versiones Latinae mihi innotuerunt hae:

Guil. Dorothei (Ven. a. MDXLI), quam ipse non inspexi.

In libros priorum resoluticorum Aristotelis commentarie annotationes... iterum greco ... in latinum versae. Lucillo Philalthaeo interprete. Ven. a. MDXLIV.

Commentaria in priora analytica ... lat. Lucillo Philalthaio interprete. Ven. a. MDLX.

In duos priores Analyticos Aristotelis libros commentarii . . ab Alexandro Iustiniano Chio medico in linguam lat. . . conversi . . Ven. a. MDLX. 



\section{IOANNIS PHILOPONI}

\section{IN ARISTOTELIS ANALYTICA PRIORA}

COMMENTARIA 
